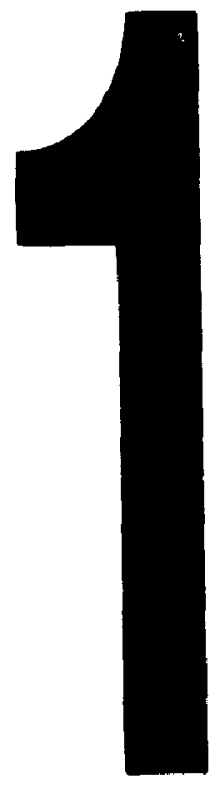

PM-1 3\%" $\times 4 "$ PHOTOGRAPHIC MICROCOPY TARGET NBS 1010a ANSI/ISO \#2 EOUIVALENT

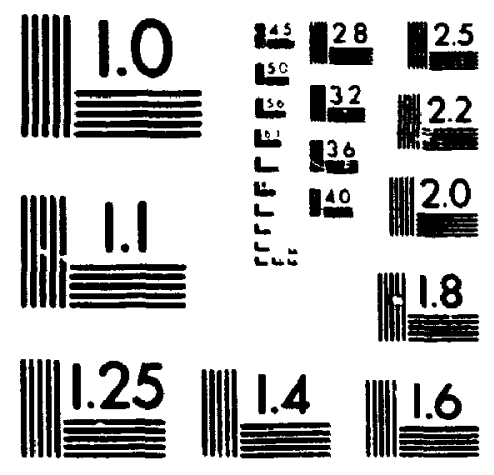

PRECISIONSM RESOLUTION TARGETS 
National Library

of Canada

Acquisitions and

Bibliographic Services Branch

395 Weltington Street

Ottawa. Ontario

K1A ON4
Bibliothèque natıonale

du Canada

Direction des acquisitions et

des services bibliographiques

395. rue Wellington

Ottawa (Ontarto)
The quality of this microform is heavily dependent upon the quality of the original thesis submitted for microfilming. Every effort has been made to ensure the highest quality of reproduction possible.

If pages are missing, contact the university which granted the degree.

Some pages may have indistinct print especially if the original pages were typed with a poor typewriter ribbon or if the university sent us an inferior photocopy.
La qualité de cette microforme dépend grandement de la qualité de la thèse soumise au microfilmage. Nous avons tout fait pour assurer une qualité supérieure de reproduction.

S'il manque des pages, veuillez communiquer avec l'université qui a conféré le grade.

La qualité d'impression de certaines pages peut laisser à désirer, surtout si les pages originales ont été dactylographiées à l'aide d'un ruban usé ou si l'université nous a fait parvenir une photocopie de qualité inférieure.

La reproduction, même partielle, de cette microforme est soumise à la Loi canadienne sur le droit d'auteur, SRC 1970,. C-30, et ses amendements subséquents. 


\title{
AFTER THE RESIDENCE:
}

Predictors of future placements and behaviour

by

GORDON MCCLURE B.A., M.A.

\author{
A thesis submitted to \\ the Faculty of Graduate Studies and Research \\ in partial fulfilment of \\ the requirements for the degree of
}

Doctor of Philosophy

Department of Psychology

Carleton University

Ottawa, Ontario, Canada

1 October 1993

- copyright

1993, Gordon McClure 
National Library

of Canada

Acquisitions and

Bibliographic Services Branch

395 Wellinglon Street

Ottawa. Onlario

K1A ON4
Bibliothéque nationale

du Canada

Direction des acquisitions et des services bibliographiques

395. rue Wellington

Ottawa (Ontario)

roul ine votre reterence

Our ine Notreserference

The author has granted an irrevocable non-exclusive licence allowing the National Library of Canada to reproduce, loan, distribute or sell copies of his/her thesis by any means and in any form or format, making this thesis available to interested persons.
L'auteur a accordé une licence irrévocable et non exclusive permettant à la Bibliothèque nationale du Canada de reproduire, prêter, distribuer ou vendre des copies de sa thèse de quelque manière et sous quelque forme que ce soit pour mettre des exemplaires de cette thèse à la disposition des personnes intéressées.
The author retains ownership of the copyright in his/her thesis. Neither the thesis nor substantial extracts from it may be printed or otherwise reproduced without his/her permission.
L'auteur conserve la propriété du droit d'auteur qui protège sa thèse. Ni la thèse ni des extraits substantiels de celle-ci ne doivent être imprimés ou autrement reproduits sans son autorisation.

ISBN $\quad 0-315-92943-X$ 
Name

Cordon Meclure

Dissertertion Abstracts International is arranged by broad, general subject calegories. Please select the one subject which most nearly describes the content of your dissertation. Enter the corresponding four-digit code in the spaces provided.

Psichology
$152,5 \mathrm{U} \cdot \mathrm{M} \cdot \mathrm{I}$

SUBSECT CODE

\section{Subject Cotegories}

\section{THE HUMANIIIS AND social seinanens}

\section{COMmUNCATONS ANO THE ARTS}

Architecture

Art History.

Cinemo

Fine Ant:

Information Science

boumalism

library Science

Mass Communications

Music

Speech Communicotion

Theorter

\section{EDUCATION}

Administration

Adult and Contınuing

Agricultural

Bilingual and Multicultura

Business

Community College

Curriculum and Instruction

Eoty Childhood

Elementory

Guidonce and Counseling

Heolith

History of

Home Economics

Industrial

Language and Literature

Mothematics

Music

Philosophy of

0377

0900

0357

0723

0391

0398

0708

0413

0459

0515

0514

0516

0517

0273

0282

0688

0275

0727

0518

0524

0277

0680

0745

0520
0278

0278
0521

0279

0280

0522

0998
0523
Psychology

Reoding

Religrous

Secondery

Sociol Sciences

Sociology of
Special

Teocher Training

Technology

Tests and Measurements

Vocational

\section{LANGUAGE, LITERATURE AND}

\section{LNGUistics}

Languoge

Ancient

inguistics

Literature

General
Classical

Comparative

Medieval

Modern

American

Asian

Canodian (English)

Conodion (French)

English

monic

Latın American

Middle Eastern

Romance

Slavic and East Europeon

\section{5}

0535

0714

0533

0534

0340

0529

0510

0288

0747

0679

0289

0291

0401

0294

0295

0298

0298

0316

0305

0352

0355

0593

0311

0312

0315

0313

0314
PHIOSOPHY, RELGION AND

THEOLOOY

Philosophy

Religion

General

Biblical Studies

Clergy

Philosophy of

Theology

SOCAL SGENCE

Americon Studies

Anthropology

Archoeology

Cuthural

Business Administration

General

Accounting

Banking

Manogement

Marketing

Conodion Studies

Economics

Agriculfuro

Agricultural

Finance

History

Labor

Theory

Geography

Gerantology

Histary

General
0422

0318

0321

0319

0320

0322
0469

0323

0324

0324
0326

0327

0310

0272

0770

0454

0338
0385

0501

0503

0505

0508

0509
0510

0511

0358

0366

0351

0578

\section{THE SCIENCES AND ENOINEERINO}

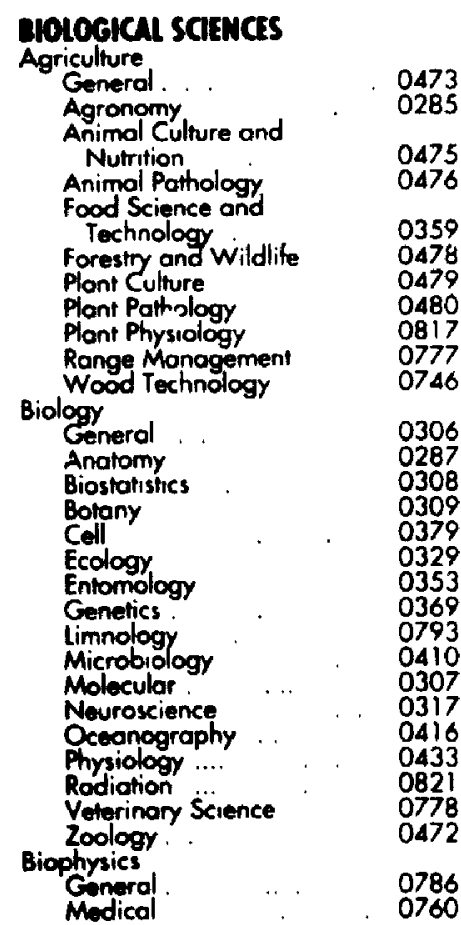

GARTH SCEENES

Biogechemistry.

Geochemisiny

$\begin{array}{ll}\text { Geodesy } & 0370 \\ \text { Geology } & 0372 \\ \text { Geophysics } & 0373 \\ \text { Hydrology } & 0388 \\ \text { Aunerology } & 0411 \\ \text { Paleobotony } & 0345 \\ \text { Paleoecology } & 0426 \\ \text { Paleontology } & 0418 \\ \text { Paleozoology } & 0985 \\ \text { Palynology } & 0427 \\ \text { Physical Geogrophy } & 0368 \\ \text { Physical Oceonography } & 0415\end{array}$

HEALTH AND ENVIRONMENTAL

\section{SCIENCES}

Environmentol Sciences

Health Sciences

$$
\begin{aligned}
& \text { General } \\
& \text { Audiology } \\
& \text { Chemolherapy }
\end{aligned}
$$

Dentistry

Hospital Managemen

Human Development

Immunology

Medicine and Surgery

Mental Healih

Nursing

Obstetrics and Gynecology

Occupational Healih and

Therapy

Ophtholmology

Pathology

Pharmocology

Phormogy

Physical therapy

Public Heol

Rodiology

Recreotion

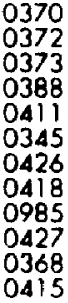

0381

0571

0419

0382
0573

0573

O575

\footnotetext{
Speech Pathology

$$
\text { Toxicology }
$$

Home Economics
}

\section{PHYSICAL SCIENCES}

Pure Sciences

Chemistiy

$$
\text { General }
$$

Analytical

Biochemistry

Inorganic

Nuclear

Organic

Pharmaceutica

Physical

Polymer

Rodiation.

Mothematics

Physics

General

Astronomy and

Astrophysics

Atmospheric Science

Atomic

Electronics and Electricit

Elementary Particles and

High Energy

Fluid and Plasma

Moleculor

Nucleor

Optics

Rodialion

Statislics

Applind Sciences

Applied Mechanics 
The undersigned hereby recommend to the Faculty of Graduate Studies and Research acceptance of the thesis,

"AFTER THE RESIDIENCE: Predictors of future placements and behaviour" submitted by

GORDON MCCLURE, B.A., M.A.

in partial fulfiment of the requirements
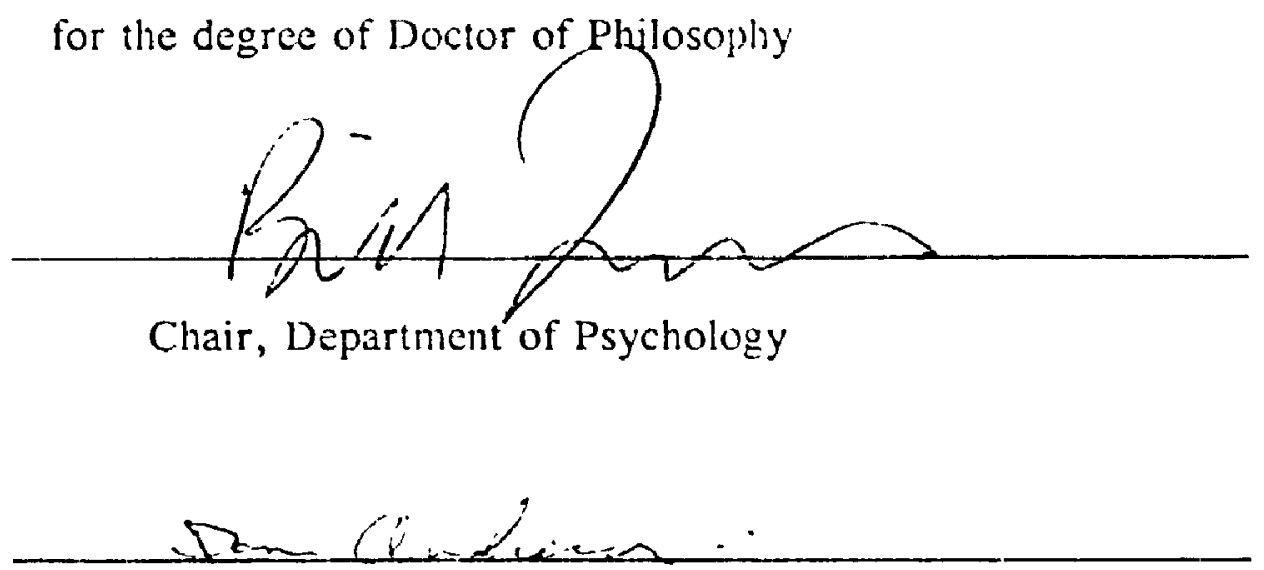

Thesis Supervisor

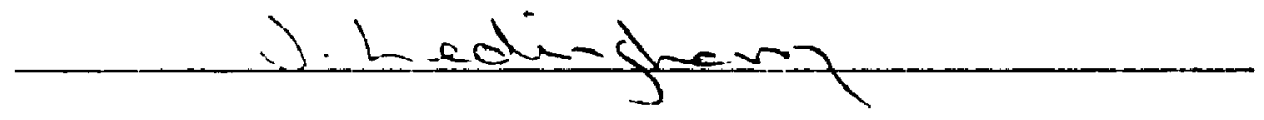

External Examiner

Carleton University

November 1993 
Abstract

Fifty-nine residential welfare and behavioral programmes serving 411 children and adolescents from one regional municipality during the first six months of 1991 were surveyed to find predictors of where clients lived during a two-year follow-up from July 1991 to June 1993 and of client behaviour after two years. Front-line staff completed client risk factor and behaviour checklists and programme questionnaires. Risk scores were higher for youths than for children, iowest for Inpatient Psychiatry and highest for Maternity and Custody homes. There were higher mean scores for externalizing disorders for males and for internalizing disorders for females. Across programmes, Inpatient Psychiatry and Maternity homes had the lowest, and Custody and Treatment Agencies the highest mean scores for externalizing disorder. Psychiatry and Treatment Agencies had the highest mean scores for internalizing disorder. Front-line workers' education and programme environment and evaluation measures varied significantly across programme types. Follow-up placement data was available only for Children's Aid Society clients $(n=230)$. Placement outcome was the percentage of successful placement days in a two-year period or until the earlier discharge of each client from Children's Aid care. Successful placement days were the days that clients were not psychiatric inpatients, in a treatment centre, in custody or absent without leave. The highest mean percentage of successful days was after group homes $(91.4 \%)$ and the lowest percentage after custody programmes $(29.8 \%)$. Successful placement was correlated with clients being younger, having fewer presenting problems, risk factors, needs and criminal acts, 
and lower externalizing disorder scores. A hierarchical multiple regression of eight variables on placement accounted for $41 \%$, and another similar regression of five variables on placement for $29 \%$ of the variance. Results suggested that clients from programmes with more Child and Youth Counsellors with diplomas and with a practical orientation, good client involvement and a relapse prevention programme had more successful residential placements independently of client risk and externalizing disorder scores. Only $35.2 \%$ of clients returned follow-up behaviour checklists. Follow-up externalizing disorder was predicted by Phase One risk and externalizing scores. Followup internalizing disorder was predicted by Phase One internalizing disorder scores only. Implications for residential programmes and research were suggested. 
Acknowledgements

The author gratefully acknowledges the help of residence child and youth coursellors, supervisors and directors who took time to complete the surveys and to be interviewed. Carol Tillman was a valued research assistant throughout the study. Phase One also had the help of Liz Armstrong, Elizabeth Cloutier and Pierrette Desjardins. A Steering Committee met regularly to guide the researcher. Administrative support was provided by the Ottawa Area Residential Placement Advisory Committee. Phase One was financed by the Ottawa Regional Office of the Ontario Ministry of Community and Social Services. Phase Two was supported by the research committee of the Chief Executive Officers of Treatment Centres led by Mike Balla. David Offord and colleagues of the Chedoke-McMaster Child Epidemiology Unit generously provided free use of their checklists and prepublication data. The Ontario Association of Children's Mental Health Centres provided free use of the computerized singing of the Children's Behaviour Checklist (Offord \& Boyle, 1990) from their Standardized Client Information System. 
Table of Contents

PREVIOUS STUDIES $\ldots \ldots \ldots \ldots \ldots \ldots \ldots \ldots \ldots \ldots \ldots \ldots$

Treatment Evaluation Model $\ldots \ldots \ldots \ldots \ldots \ldots$

Factors of the Model $\ldots \ldots \ldots \ldots \ldots \ldots \ldots \ldots$

Setting Factors $\ldots \ldots \ldots \ldots \ldots \ldots \ldots \ldots \ldots$

Client Factors $\ldots \ldots \ldots \ldots \ldots \ldots \ldots \ldots \ldots$

Age, sex, \& intelligence. $\ldots \ldots \ldots \ldots \ldots \ldots$

Client Disorders . . . . . . . . . . . . . 10

Risk factors $\ldots \ldots \ldots \ldots \ldots \ldots \ldots \ldots$

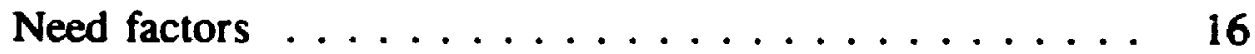

Worker Factors $\ldots \ldots \ldots \ldots \ldots \ldots \ldots \ldots \ldots \ldots$

Programme Factors $\ldots \ldots \ldots \ldots \ldots \ldots$

Process Factors $\ldots \ldots \ldots \ldots \ldots \ldots \ldots \ldots \ldots \ldots$

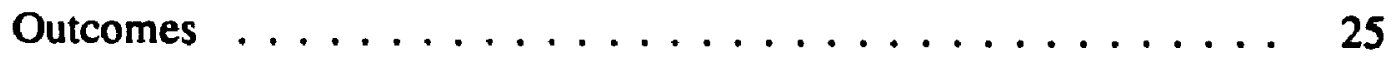

Programme $/$ Client Matches . . . . . . . . . . . . . . . . 29

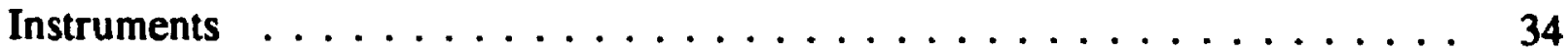

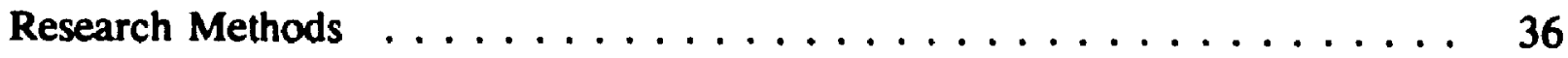

Summary of Literature Review $\ldots \ldots \ldots \ldots \ldots \ldots$

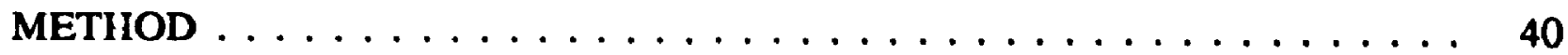

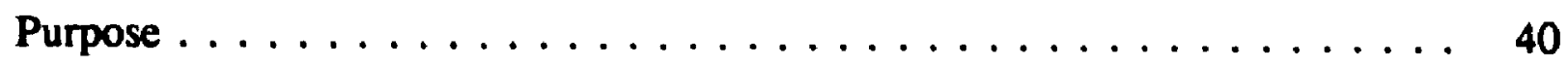

Phase One: Descriptions $\ldots \ldots \ldots \ldots \ldots \ldots \ldots \ldots \ldots \ldots$ 
Phase One Sample $\ldots \ldots \ldots \ldots \ldots \ldots \ldots \ldots \ldots \ldots \ldots$

Instruments $\ldots \ldots \ldots \ldots \ldots \ldots \ldots \ldots \ldots \ldots \ldots \ldots$

Residences $\ldots \ldots \ldots \ldots \ldots \ldots \ldots \ldots \ldots \ldots \ldots$

Clients $\ldots \ldots \ldots \ldots \ldots \ldots \ldots \ldots \ldots \ldots \ldots$

Data Collection $\ldots \ldots \ldots \ldots \ldots \ldots \ldots \ldots \ldots \ldots$

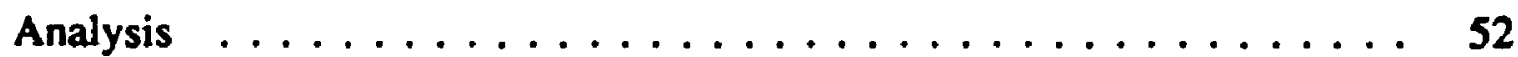

Phase Two: Predictors of Outcomes $\ldots \ldots \ldots \ldots \ldots \ldots$

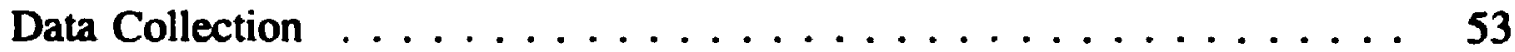

Placement Sample $\ldots \ldots \ldots \ldots \ldots \ldots \ldots \ldots$

Behaviour Sample $\ldots \ldots \ldots \ldots \ldots \ldots \ldots \ldots$

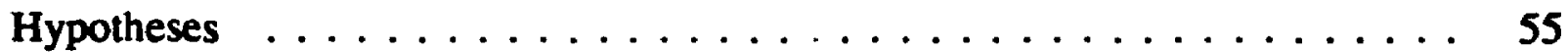

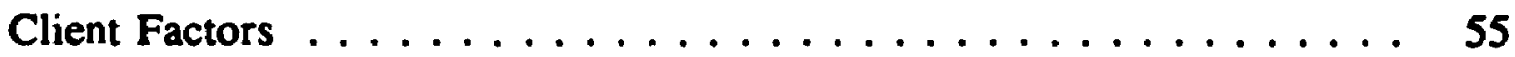

Worker \& Programme Factors $\ldots \ldots \ldots \ldots \ldots \ldots \ldots$

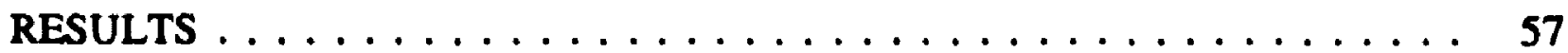

Phase One: Descriptions $\ldots \ldots \ldots \ldots \ldots \ldots \ldots \ldots$

Sample $\ldots \ldots \ldots \ldots \ldots \ldots \ldots \ldots \ldots \ldots \ldots \ldots$

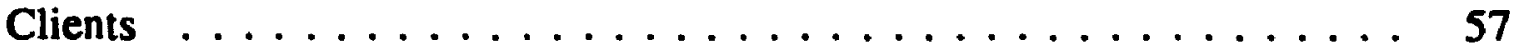

Risks and Needs $\ldots \ldots \ldots \ldots \ldots \ldots \ldots \ldots$

Behaviour Disorders . . . . . . . . . . . . . . 64

Residences $\ldots \ldots \ldots \ldots \ldots \ldots \ldots$. . . . . . . . . . . . 69

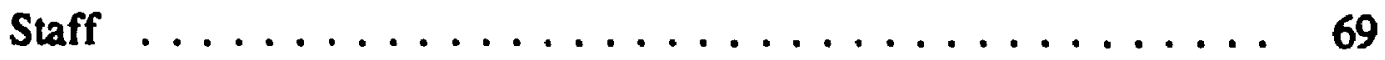


Programme ...................... 69

Programme/Client Matches $\ldots \ldots \ldots \ldots \ldots \ldots \ldots \ldots$

Phase Two: Predictors of Outcomes $\ldots \ldots \ldots \ldots \ldots$

Placement Outcomes $\ldots \ldots \ldots \ldots \ldots \ldots \ldots \ldots \ldots$

Correlates of Placement $\ldots \ldots \ldots \ldots \ldots \ldots \ldots$

Behaviour Outcomes $\ldots \ldots \ldots \ldots \ldots \ldots \ldots \ldots$

Sample Bias $\ldots \ldots \ldots \ldots \ldots \ldots \ldots \ldots \ldots$

Correlates of Disorders $\ldots \ldots \ldots \ldots \ldots \ldots$

Combined Predictors of Outcomes . . . . . . . . . . . . . 87

Predictors of Placement . . . . . . . . . . . . 87

Predictors of Phase Two Behaviour Disorders . . . . . . 92

Hypotheses . . . . . . . . . . . . . . . . . . 99

Placement Outcomes . . . . . . . . . . . . . . . 99

Behavioral Outcomes $\ldots \ldots \ldots \ldots \ldots \ldots \ldots$

Combined Predictors . . . . . . . . . . . . . . . . . 101

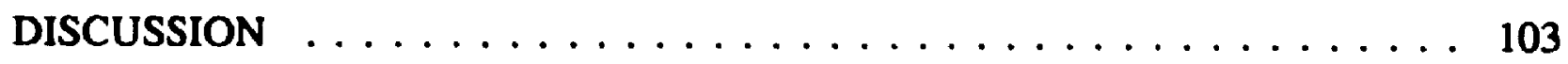

Limitations of the Study $\ldots \ldots \ldots \ldots \ldots$

Phase One: Descriptions $\ldots \ldots \ldots \ldots$. . . . . . . . . . . . 104

Phase Two: Predictors of Outcomes . . . . . . . . . . . . . . 109

Client Factors $\ldots \ldots \ldots \ldots \ldots \ldots \ldots \ldots \ldots \ldots \ldots \ldots$

Worker Factors $\ldots \ldots \ldots \ldots \ldots \ldots \ldots \ldots \ldots \ldots \ldots \ldots$ 
Programme Factors . . . . . . . . . . . . . . . . 112

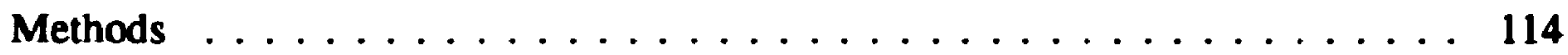

IMPLICATIONS FOR TREATMENT PROGRAMMES $\ldots \ldots \ldots \ldots \ldots \ldots$

REFERENCES . . . . . . . . . . . . . . . . . . . . . . . . 119

\section{APPENDICES}

Appendix 1: YLSI Youth Level of Service Inventory . . . . . . . . . . . . . 129

Appendix 2: ARQ Agency \& Residence Questionnaire $\ldots \ldots \ldots \ldots 131$

Appendix 3: PEI Programme Evaluation Inventory $\ldots \ldots \ldots \ldots \ldots$

Appendix 4: COPES ..................... 136

Appendix 5: COPES Subscales Definitions . . . . . . . . . . . . 140

Appendix 6: CRF Risk \& Need Factors $\ldots \ldots \ldots \ldots \ldots \ldots \ldots$

Appendix 7: RFRL Referrals $\ldots \ldots \ldots \ldots \ldots \ldots \ldots \ldots \ldots \ldots$

Appendix 7: Client Needs \& Available Services $\ldots \ldots \ldots \ldots \ldots$

Appendix 8: Service/Needs Matching Criteria . . . . . . . . . 152

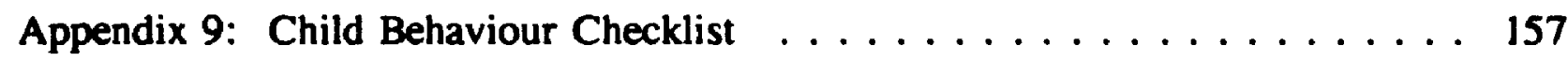

Appendix 10: CBC Criteria . . . . . . . . . . . . . . . 163

Appendix 11: Child Behaviour Checklist - Revised . . . . . . . . 165

Appendix 12: CBC-R Criteria $\ldots \ldots \ldots \ldots \ldots \ldots \ldots$ 
LIST OF TABLES

Table 1: Risk and Need Factors $\ldots \ldots \ldots \ldots \ldots \ldots$

Table 2: Programmes $\ldots \ldots \ldots \ldots \ldots \ldots \ldots \ldots \ldots \ldots$

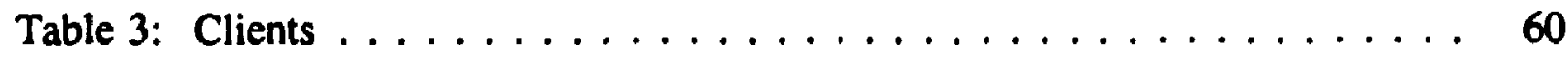

Table 4: Mean Risk Factors By Sex \& Age . . . . . . . . . . . . 62

Table 5: Mean Risk Factors By Programmes . . . . . . . . . . . . 63

Table 6: Behaviour Disorders By Sex \& Age . . . . . . . . . . . 66

Table 7: Eehaviour Disorders By Programmes . . . . . . . . . . . 67

Table 8: Behaviour Disorders By Sex, CAS Clients \& Programmes . . . . . 68

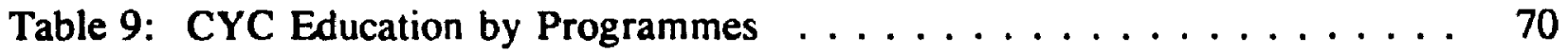

Table 10: PEI Programme Evaluation Scores By Programmes . . . . . . . . . 72

Table 12: Percentages of Matches in Service \& Presenting Problems . . . . . . 74

Table 13: Mean Percentage of Successful Placements Days by Client Variables 76

Table 14: Mean Percentage of Successful Placement Days by Programme

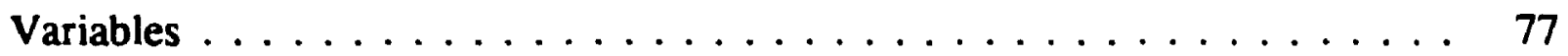

Table 15: Correlations of Client Age, Sex \& Risk Factors With Outcomes . . 79

Table 16: Correlations of Client Disorders with Outcomes . . . . . . . 80

Table 17: Correlations of Residence Variables With Outcomes $\ldots \ldots \ldots$. . 81

Table 18: PEI Correlations With Outcomes \& Programme Type $\ldots \ldots \ldots$

Table 19: COPES Correlations With Outcomes . . . . . . . . . . . . 84 
Table 20: Hierarchical Regression of Client, Worker \& COPES Programme Variables

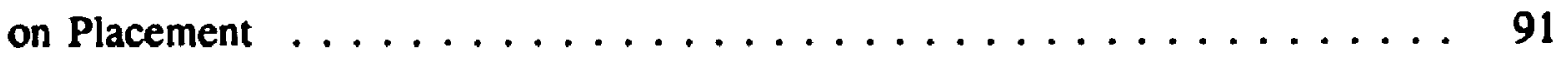

Table 21: Hierarchical Regression of Client, Worker \& PEI Programme Variables on

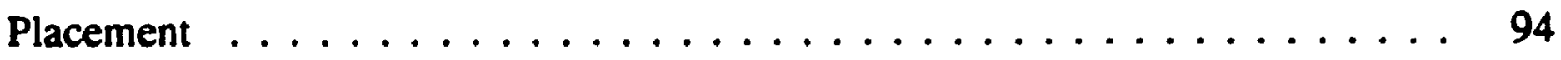

Table 22: Hierarchical Regression of Client \& Worker Variables un Phase Two Externalizing Behaviour $\ldots \ldots \ldots \ldots$. . . . . . . . . . . 96

Table 23: Hierarchical Regression of Client \& Worker Variables on Phase Two Internalizing Behaviolir $\ldots \ldots \ldots \ldots \ldots \ldots$

\section{LIST OF FIGURES}

Figure 1: Factors in Evaluation: $\ldots \ldots \ldots \ldots \ldots \ldots \ldots$ 
There has been concern about residential services for children for a long time. This concern has not been reduced by the replacement of large institutions with small group homes and treatment centres. Instead, the complexity of the system has raised more questions.

Unfortunately, we do not know very much about these homes and centres. Because they seldom have been studied systematically, we know very little about the programmes or the clients. Also, we do not know how the characteristics of programmes, or of clients, are related to events after residential placement. Therefore, we have insufficient information with which to decide if our present residences are any more effective than the institutions they replaced. The long term purpose of the present study was to provide preliminary information as a base for future studies of the effectiveness of residential care. Its immediate purpose was to identify the characteristics of programmes and clients from which outcomes of residential placements might be predicted.

There have been few studies of residential services in the past and most of them have had serious conceptual and methodological problems. A common concept $11^{-1}$ problem, according to Hoge and Andrews (1986) and Quay (1986), was that studies were based on simplistic models of intervention. The models used had related interventions to outcomes without considering other crucial factors, such as the needs of the clients. A common methodological problem was the use of inadequate measures of prediction and criterion variables. The following review of previous studies illustrates these limitations of concept and method. It also provides the rationale for the approaches used in the present study. 


\section{PREVIOUS STUDIES}

Early descriptions of residential programmes in the 1960 's did not include client characteristics. These descriptions were surveys, within geographic areas of goals, mandates, number wients, and public or private operation only. The purposes of these studies were to exaraine changes in services over time or to compare services in different areas.

Repeated surveys showed how the residential welfare and treatment system had grown over time in complexity, in the number of centres and in the types of children served. Two US national surveys showed that over sixteen years the number of facilities nearly doubled. Their total capacity, however, remained about the same (Star \& Kuby, 1967; Dore, Young \& Pappenfort, 1984).

There also were changes in the use of different types of residences. Fewer clients were in maternity residences, despite increases in the number of births for adolescents. The proportion of residences used for child welfare only declined from approximately one-half to one-third. The number of juvenile justice residences increased by one and one-half times and the number of mental health residences increased by almost four times. Residences were started for the treatment of substance abuse. During the period a higher proportion of residences became privately operated.

There were similar changes in Ontario residential services. The first Ontario survey of all publicly funded programmes compared mandates and clients in 92 residential treatment centres, training schools, group homes and in inpatient psychiatry (Randall and McClure, 1972; Randall, McClure \& Sone, 1974). They used home and school 
checklists to compare the behaviour of all child and youth residents. Their checklists were made up of factors from previously standardized instruments. Factors were (a) disruptive behaviour, (b) social withdrawal, (c) social maturity, (d) psychotic behaviour, (e) school learning and (f) coordination difficulties. Significant differences were found among particular centres in type and degree of disturbance but differences were not found among the social systems of children's mental health centres, training schools and community group homes.

The Randall \& McClure 1972 survey was compared with services sixteen years later (Ontario MCSS, 1988). As in the US, the number of residential treatment centres had nearly doubled but the capacity had only increased by 10 per cent. Large institutions had reduced their children's residential services. Most training schools and large treatment centres for youth were replaced by small group homes.

There have been studies of residences in three Ontario regions. The first region included Peterborough, Durham, Northumberland and Kawartha/Haliburton counties (Nutter \& Sullivan, 1989; Hudson, et al., 1988; Difrancesco, 1987; Sunday \& Moore, 1986) The second region was around Kingston (Sutherland \& Docherty, 1986). The Kingston study was limited to private, for profit, residences. The third region studied was Ottawa-Carleton (VCSCC, 1985; YM/YWCA, 1990). All studies provided brief descriptions of each residence. Of these studies, only two used standardized client behaviour measures (Nutter \& Sullivan, 1989; Sunday \& Moore, 1986).

One Peterborough area study found sex differences in behaviour (Sunday \& Moore, 1986). They used the Child Behaviour Check List (CBCL, Achenbach \& Edelbrock, 
1983). They found that boys in group homes were as disturbed as boys in mental health centres but that girls in group homes were less disturbed than girls in mental health centres. Another Peterborough area study used a modified version of the CBCL (Nutter \& Sullivan, 1989). It found that the two main problems of clients were unhappiness and nonfunctional relationships with adults. School-related problems, aggressive behaviour, lying, cheating and offensive language also were common.

The Ottawa-Carleton (OC) study followed a large increase is the number of small group homes for the treatment of youth and young offenders. Agencies responded to the increase by setting up a regional Voluntary Children's Services Coordinating Committee (VCSCC). This committee sponsored studies of area programmes to find gaps in services.

Such studies required better descriptions of programmes than had been done previously. When children were placed in large institutions, studies could be done within one or two cenires that had clearly stated goals and programmes. As programmes were transferred to small centres, adequate studies could only be done across many centres. Also, the increased number of centres required questionnaires and other types of measures that could be used by staff with different levels of training.

In 1985, the VCSCC sponsored the first survey and description of all mental health treatment services within the OC region (VCSCC, 1985). Social indicators of community needs and estimated prevalence of disorders were compared with available services. They found that most of the needs of the population of OC were better served than the needs 
of those in other Ontario regions. Later, a directory of services for youth in conflict with the law was published (YM/YWCA, 1990).

The next major study was Ontario-wide. It examined the behaviour of a random sample of 210 clients in 66 residential programmes (Fulton \& Braseliten, 1991). The authors used Magura scales (Magura \& Moses, 1986) to measure the degree of social impairment in clients. They found that clients were more impaired in residential than in non-residential services. Within residential services CAS wards and young offenders were more impaired than others. Also males were more socially impaired than females, achieved less in school and had more police interventions after admission to residences. The level of behavioral problems, however, was similar for males and females.

These surveys served their declared purposes of comparing Ontario residences over time and among regions and described some characteristics of their clients. The authors did not however, provide sufficiently detailed descriptions of programmes or clients to serve as a basis for studies of the effectiveness of programmes.

Scholars have identified several requirements to improve such studies. These are, better descriptions of programmes and of programme implementation, better classification of client disorders, better outcome measures and a model that relates them to each other in a rational way (Casey and Berman, 1985; Hoge and Andrews, 1986; Quay, 1986). Treatment Evaluation Model

One such model is that of Hoge and Andrews (1986). It represents treatment outcomes as a product of five factors: setting, client, worker, programme and process that have an effect upon outcomes, separately and in combination (Fig. 1). They note that there are 
problems of analysis in using their model in research studies. To analyze many variables and their interactions in a multifactor model requires the use of large samples of clients and of treatments. This suggests that surveys may be the only method economical enough to use in studies based on complex models. Hoge and Andrews (1986) also suggest testing for main effects of factors first, and then the elimination of some variables, before testing for interactions between factors.

Despite analytical problems, multifactor, multilevel models have been better predictors of outcomes than simple models. Studies have shown, for example, that models using combinations of individual and setting measures were two or three times better predictors of behaviour than models using individual or setting measures alone. This was shown among normal adults (Endler, 1980) and among boys in residential treatment (Raush, Dittman \& Taylor, 1959).

The use of a complex model is also supported by Quay (1977) using the concept of programme integrity. Integrity was defined by Quay to mean the extent to which the stated programme was put into effect. He suggests four measures of programme integrity. These are (a) the treatment characteristics, (b) the delivery of the service, (c) the personnel and (d) the match of personnel, clients and treatment. The first three measures of programme integrity in Quay's model are similar to the programme, process and worker factors of Hoge and Andrews model (1986). The fourth measure, client/treatment matches, is similar to matches between client needs and treatments in the Andrews et al. (1990) theory described below. 
Quay (1977) says that integrity is as important as research design and the use of clearly defined, specific outcomes in programme evaluation. He gives as an example a study with an exemplary design and clear outcomes (Kassebaum, Ward \& Wilner, 1971). Despite good study design according to Quay, these researchers were unable to confirm that the treatment was effective because of lack of programme integrity. Quay says that this study was also exemplary because it provided sufficient information to evaluate programme integrity.

There is general agreement that a multi-factor, multi-level model is required for the evaluation of residential placements. Relationships have been shown between many factors and residential outcomes. Yet statistical analysis limits the number of factors that can be used. Therefore, factors must be selected that fit an appropriate model, can be reliably measured and are the most useful predictors of outcomes. Factors were selected for the present study on this basis.

\section{Factors of the Model}

The model of Hoge and Andrews (1986) that was used as the basis for the present study is shown in Figure 1. Hoge and Andrews define each factor in their model and report results of studies that related factors to outcomes. Other studies relating factors to outcomes have added to their work. These studies also will be reported in this section of the review.

\section{Setting Factors}

Setting factors were defined as the political, economic, social and other variables of the client's community that affect the development of problems and the outcomes of 
treatment (Hoge and Andrews, 1986). For example, differences in rates of disorder have been found between rural and urban areas and between countries (Offord et al., 1987; Rutter, Cox, Tupling, Berger, \& Yule, 1975; Rutter, Tizard, Yule, Graham, \& Whitmore, 1976; Trites, Dugas, Lynch, \& Ferguson, 1979).

\section{Client Factors}

Client factors are the particular characteristics of clients and their families that have been related to the outcomes of treatment (Hoge and Andrews, 1986). These factors may affect outcomes directly or indirectly in combination with other factors.

Age, sex. \& intelligence. Client factors of age, sex, and intelligence have been shown to affect outcomes and treatment effects in some studies and not in others. Weisz et al. (1987) studied children and adolescents aged 4 to 18 and found that treatment was more effective for children than for adolescents. Casey and Berman (1985) found no difference in effect sizes based on age. They, however, had reviewed studies of children under age 13 only. Younger age of onset and admission was associated with poorer outcomes (Blotcky, Dimperio and Gosset; 1984). Treatment effects were found to be smaller for studies with more boys than girls by Casey and Berman (1985) but not by Weisz et al. (1987). The long term outcomes for boys were reported to be better than those for girls by Blotcky, Dimperio and Gosset (1984). There is agreement on the effects of intelligence on outcome. Two reviews found that higher intelligence was related to better outcomes in most studies (Fineberg, Sowards \& Kettlewell, 1980; Blotcky, Dimperio and Gosset, 1984). 
Fimure 1: Factors in Evaluation:

An outline of the multiple sources of variation in the outcome of direct intervention (Adapted from Andrews \& Kiessling, 1980 and Hoge \& Andrews, 1986)*

\title{
BROAD SETTING FACTORS: COMMUNITY CONDITIONS
}

\section{CLIENT FACTORS}

*Presenting Problems (behaviour disorders)

* Basic Bio-Demographics

Administrative Information

-Risk Levels

*Need Areas and Levels

Responsivity Considerations

Other...
WORKER FACTORS

Practice Preferences

Basic Bio-Demographics

Administrative Information

-Training/Experience

Relationship Skills

Structuring Skills

Other...

Programme FACTORS

Agency Philosophy

*Agency Resources

Political-Economic structure

Social Structure: role, status and membership composition

Monitoring of Programme Implementation/Service Delivery

Linkages, intra and inter-agency

Other...

\author{
SERVICE PLANS \\ Level of Service \\ *Targets of Service \\ Style/Mode of Service \\ Other...
}

PROCESS AND CONTENT OF SERVICE DELIVERY

Number of Interviews/Sessions

Type of Interviews/Sessions

*Clinical Process: Relationship and Structuring Conditions

Other...

INTERMEDIATE OUTCOMES

*Changes in Presenting Problems (Behaviour Disorders)

Changes in Need

Client Satisfaction

Other...

\author{
ULTIMATE OUTCOMES \\ *Changes in Behaviour \\ *Changes in Residential Placement \\ Recidivism \\ Cost-Efficiency \\ Consumer Satisfaction \\ Other...
}

\footnotetext{
- Note: Factors examined in the present study.
} 
Client Disorders. There is some disagreement on the direct effects of the type of disorder on treatment outcomes. Most studies and reviews found that overcontrolled (neurotic) clients had better outcomes than undercontrolled (personality disorder) clients. Both types also did better than psychotic clients (Blotcky, Dimperio and Gosset, 1984; Fineberg, Sowards \& Kettlewell, 1980; Gosset et al., 1973; Tramontana, 1980). Casey and Berman (1985) found that treatment effects were smaller for social adjustment problems than for hyperactivity, phobias or somatic problems. Only Weisz et al. (1987) found no difference in sizes of effect between disorders for 'overcontrolled' versus 'undercontrolled' clients or for clients with specific types of disorders such as delinquency and phobias. Further studies of whether client age, sex and behaviour disorders predict outcomes are required.

Risk factors Client risk factors have predicted outcomes directly and indirectly in combination with other factors. Risk factors are client and family characteristics that have been found to be associated with an increased probability of negative outcomes in previous studies.

An early approach was to select risk factors from those that have been shown repeatedly to be correlates of disorders (Table 1). It has been assumed that those correlates that precede the onset of disorders increase the risk of the development of disorders. It also has been assumed that they were related to the effectiveness of treatments. Both assumptions have been supported by studies reported below. 
Table 1: Risk and Need Factors "

Houschotd

- Low income

- Unamoloyed

- Walfare

- Subridized housing

- Crowded living

Reridentin intubility

Urben ve nural residence

Neighbounhood crime rale

Pareatel

- Trented for "nerves"

Psychistric Disorder

- Criminal history

- Chronic health problems.

- Low maternal education

Low verbal intelliance

- Substance abuse

Framily

Family dysfunction (cohesion a communication)

Suppon in parenting

Parentineskill deficits

Mother-step-father home

Powar-aucrtive punishment

- Violence

Lex, inconsigtent rules:

Child neslect

- physical abuse

- exual abuse

Child Fhysical \& Temperament

- Chronic health problems

Mesomorphy

Early developmental problems

Hyperactivity

Low birth weight

Adventurous temperament

- Physical dienbility

Ego-centrism

Fira born or only child

Risk-Laking

Eacily frustrated

Conscientiousness

Brain disorder, epilepay

Moral immaturity

Language disorder/delay

- Factors examined in the present study.

- YSLI items or similar items are underlined. 
Chid Competence

- Low verbel intelligence

Laming dimbilities

- School echievement.

- School frilures a remedinl help

- Skills in sports, music, hobbies

Perticipation

-In adult-led activities (eports hobbies clubs)

- In school sctivities

In informal activities

Relationahipe

- Gettine alone with ochen

- Few friende cocial isolate

- Confidant

- Gane memberahio

- Delimuent friends

- Older friends

- Relationships - peers

$$
+ \text { family }
$$$$
\text { - teachers }
$$

\section{Child Problems}

- Diegnosed disorders

- Chronic nunnine away

- Convicted of an offence

- Home conduct problems

- School conduci problems

Truncy

- Substance abuse

- Sexually abuses others

- Eating disorders

- Suicidal behaviour

- Hiph level of erenession

- Speech problems

- School atlendance

- School suspencion

- Out-of-school ( $<16$ years of age)

- Home teaching

Other

Number of uressful life events

- Sex \& age interact with risk \& type of disorder
Poor coping skille

History of delinquency

Allitudes, values, beliefs supportive of crime

High psychopathy scores 
Factors listed in Table 1 were selected based on three criteria. They were all found in general population studies, preceded the onset of disorders and made an independent contribution to the prediction of disorders in multivariate studies. Evidence for factors fitting these criteria was found in a review by Links (1983) of 12 studies and in 10 later studies (Byles, Byrne, Boyle \& Offord, 1986; Cohen \& Brook, 1987; Cohen, Brool', Cohen, Velez \& Garcia, 1990; Epstein \& Cullinan, 1983; McGee, Silva \& Williams, 1984; Offord, Boyle \& Jones, 1987; Offord \& Boyle, 1989; Offord, Boyle, Racine, Szatmari \& Fleming, 1990; Ontario MCSS, 1990; Rae-Grant et al., 1989).

A later approach to selecting risk factors was to study which correlates predicted the outcomes of treatment. Such risk factors have been studied in both delinquency and mental health samples. In delinquency, studies of risk factors were reviewed by Loeber and Dishion (1983) and Leschied, Austin, \& Jaffee (1989). The authors selected ilsk factors for which there was strong evidence. From these faciors, the Level of Supervision Inventory (LSI) was developed and tested by Andrews and colleagues (Andrews, Robinson, \& Balla, 1986). A Youth Level of Service Inventory (YLSI) has now been developed using 112 similar factors (Andrews, Robinson \& Hoge, 1985). Forty-four risk and need factors that are in the YLSI or are similar to YSLI items are underlined in Table 1.

In mental healtr. samples, some family problems have been found to be risk factors. The Ontario Child Health Study (OCHS, Offord. et al., 1987) combined risk and protective factors from previous studies to develop a Family and Household Form. The Form was standardized on a large sample of the general Ontario population (Rae-Grant, 
et al., 1989). The authors found that single parents, welfare, subsidized housing and the functioning of clients' families were risk factors. Family functioning was defined as the extent to which family members related and communicated with each other. In the OCHS it was measured by the short form of the McMaster Family Assessment Device (Byles, Byrne, Boyle \& Offord, 1988). Family factors were highly correlated with child disorders, perceived need of professional help and poor school performance. The OCHS did not include subjects similar to those in the present study because all children in residences and institutions were excluded. Results of the OCHS are still useful in the present study to compare family problems of children in residences to the general population of their age and sex. Such a comparison of risk factors was done for residents of 43 Ontario institutions in a recent study (Fulton \& Braseiten, 1991).

There is evidence that family risk factors are associated with outcomes of treatment. Negative outcomes have been associated with the family variables of antisocial parents, parental psychopathology and poor family functioning (Blotcky, Dimperio \& Gosset, 1984; Rae-Grant et al., 1988).

OCHS risk factors and other indicators of social problems have been applied to the general population of the Ottawa-Carleton (OC) region (VCSCC, 1985). Results suggested that the OC population were at lower risk for disorders than other major urban centres in Ontario and at lower risk than the provincial average. Yet there were more child and youth residences in the OC region per capita than elsewhere in the province.

Risk factors listed in Table 1 include client problems, strengths and coping skills. Client strengths and skills were called protective factors by Rae-Grant et al. (1988). 
Protective factors included good relationships with others, being a good student, participation and competence. Similar factors were included in the Hoge and Andrews (1986) evaluation model. The auth , included strengths and skills in their model partly in response to critics who advocate prevention instead of treatment. Hoge and Andrews (1986) believed that the enhancement of coping skills should be one part of any appropriate correctional treatment.

Risk factors derived from correlates of disorders also predicted outcomes of treatment among young offenders. They were particularly effective predictors when they were combined with each other. One review (Andrews, Bonta \& Hoge, 1990) noted that as early as 1950 Glueck and Glueck found seven variables that in combination predicted outcomes. They also listed six recent studies, using four instruments, in whici the total number of risk factors predicted treatment outcomes.

The Youth Level of Service Inventory (YLSI; Andrews, Robinson \& Hoge, 1985) used combined risk factors to study delinquents. The YSLI was a list of 104 risk factors for delinquency (Appendix 1). It was designed to help workers place offenders in the most effective treatment setting according to their risk level. Settings available for delinquents differ in intensity of service. They range from probation through group homes to treatment and detention centres. YSLI scores have been shown to predict outcomes of young offender and welfare services in several recent studies (Scott, 1985; Andrews \& Robinson, 1984; Andrews, Robinson \& Balla, 1986).

The YSLI items have been included in Table 1. Only some YSLI factors can be investigated using survey methods (Column 1). Other YSLI items require personal 
interviews and clinical judgment, because they ask for detailed delinquent history, sibling problems and 24 additional personality and attitude items (Column 2). Only survey factors were used in the present study.

Risk factors related to outcomes in previous studies included family socio-economic status and dysfunction, parental problems and client problems and strengths. Client strengths included getting along with others, school achievement, friendships, competence and participation. They are listed in Table 1. Measures of type and level of behavioral disorders are also risk factors. All risk factors are possible predictors of residential outcomes and therefore important factors to study.

The Hoge and Andrews (1986) model suggested that risk factors act independently and in combination with treatment factors to affect outcomes. Two recent meta-analyses (Andrews et al., 1990; Lipsey, 1990) provided strong support for this part of their model. There was an interaction between levels of risk and intensity of treatment. Intense treatment was effective for high risk clients but ineffective for low risk clients. Less intensive treatment was effective for low risk clients but ineffective for high risk clients.

Need factors. Need factors have been reported to predict outcomes indirectly in combination with other factors. The needs of children and youth in residences have been defined in two ways. First, needs were defined as perceived need for professional help (presenting problems) and second as a subset of risks. Both types of needs are listed in Table 1. They include client problems and strengths and family and parental problems. Needs used in the present study are marked with an asterisk in Table 1. A checklist of risks and needs was developed for the present study using these items (Appendix 6, Part 
C). Table 1 also includes other needs that may be related to delinquency and other conduct disorders and to emotional disorders.

Perceived needs were the reasons why parents or others (or the clients themselves) referred clients to treatment centres. Someone believed that the clients needed help with specific 'presenting problems' (Difrancesco, 1987; Nutter \& Sullivan, 1989). In child welfare residences, clients may have been referred for other reasons, such as protection or support. Presenting problems in child welfare residences were those that the staff believed were the most immediate and important needs of the clients when they first arrived. Children in group homes from small urban and rural areas had more presenting problems than children from Metro Toronto (Difrancesco, 1984). In another study, presenting problems were not well related to the reasons for placement (Nutter \& Sullivan, 1989). The authors said that many clients with emotional problems were placed in programmes designed primarily for behaviour management.

A second approach defined nteds as a subset of risk factors (YLSI; Andrews, et al., 1989; YM/YWCA, 1990). For these authors, needs were identified as those risk factors that could be changed by treatment and, when they were changed, were associated with subsequent variation in the chances of behaviour disorders. These needs, therefore, were appropriate treatment targets. Andrews et al. (1989) suggested that treatment focused on these needs should lead to better outcomes.

The authors were concerned especially with crimogenic needs. Crimogenic needs were characteristics of clients that have been associated with the chances of subsequent criminal conduct. Andrews et al. (1989) suggested eight crimogenic needs that should be 
intermediate targets in the treatment of clients in correctional services. These targets were, (1) to reduce antisocial attitudes and feelings, (2) to reduce delinquent peer associations, (3) to increase familial affection, (4) to improve parental supervision, (5) to promote identification with anticriminal role models, (6) to improve self control and self management skills, (7) to teach prosocial skills, and (8) to reduce chemical dependencies. These targets or programme needs were derived from risks listed in Table 1.

\section{Worker Factors}

Worker factors in the Hoge and Andrews (1986) model were characteristics of workers that directly and indirectly affect outcomes. Andrews and Kiessling (1980) suggested that much of the variability within treatments was due to worker characteristics. Quay (1977) said that worker factors were one aspect of programme integrity. He suggested including in studies the three worker factors of (a) the degree of expertise, (b) the amount of training provided by the institution, and (c) the degree of worker supervision.

It is not clear that worker training is related to outcomes. Weisz et al. (1987) found no main effect for therapist training. Yet, there were interactions between worker training and client age and worker training and type of disorder. Workers with professional iraining were equally effective in the treatment of children and adolescents. Workers without professional training were more effective with children than with adolescents. They also found that professional training improved the effectiveness of treatment for clients with emotional problems. It did not help clients with conduct problems. Casey and Berman (1985) found no effect for the training, experience or sex 
of workers. Persons (1966) found that outcome was not a function of differences in the experience of the five therapists in the study.

There have been many studies that have related other worker characteristics such as their therapeutic skills to outcomes. These studies were not reviewed here because the present study was based entirely on surveys. Therefore direct measures of worker skills were not available.

\section{Programme Factors}

It is essential to include a good description of the programme in any evaluation of residential programmes. It seems reasonable to believe that a good description would include the agency philosophy, prescribed programme and resources available to support the programme. There is insufficient agreement among researchers about which are the most important programme variables to use in predicting outcomes. Also, Hoge and Andrews (1986) noted that these variables are difficult to select. There is little agreement upon appropriate measures of programme variables.

Quay (1977) described programme factors as one of four aspects of programme integrity. He suggested studying the programme factors of specificity, empirical basis and proven utility in other settings. Quay (1986) found that changes during the programme period were shown by most programmes with explicit treatment procedures, goals and staff training.

Other programme factors also have been found to predict effect sizes of outcomes. One factor, the level of treatment, was measured in two ways in one meta-analysis (Lipsey, 1990). The first measure included duration, frequency and amsunt of treatment; 
the second measure was residential versus nonresidential treatment. These two measures interacted so that longer duration of treatment and more contact was associated with higher effect sizes except the continuous contact provided by residential treatment.

Two other factors associated with larger effect sizes were (a) services provided outside formal correctional settings and institutions, and (b) services under the influence of the evaluator. Lipsey ascribed the latter effect to better implementation of programme rather than to researcher bias.

Behavioral treatments were found more effective than other styles of treatment by most researchers. Andrews et al. (1990) and Lipsey (1990) found that behavioral-oriented, skill-oriented, and multi-modal treatment of delinquents was associated with larger effect sizes than less structured and focused treatments such as counselling. Weisz et al. (1987) found that behavioral treatments were more effective than nonbehavioral ones despite client age, therapist experience or type of problem. Yet Casey and Berman (1985) did not find a difference in effect size between behavioral and other types of programmes. This difference may be because Casey and Berman (1985), unlike Weisz et al. (1987) eliminated all behavioral programmes where the outcome measure was similar to a measure used in training. Quay (1986) found that nonverbal behavioral approaches were most successful for conduct disorders, especially during the programmes. Casey and Berman (1985) also compared behavioral treatment with cognitive-behavioral, cliericentred and psychodynamic treatments. Only psychodynamic treatment showed no difference between treated and other groups. 
Other differences in the effectiveness of types of treatments have been studied. Neither Casey and Berman (1985) nor Weisz et al. (1987) found differences in effect sizes between group and individual therapy. Ro-Trock, Wellisch and Schoolar (1977) found that adolescent psychiatric inpatients who had family therapy had fewer rehospitalizations after three months than those that had individual therapy. Also, they took fewer days to return to school or work.

Within treatment programmes, variables related to good long term outcomes were practical orientation (Moos, 1974a), remedial education (Hobbs, 1966; Shore \& Massino, 1973; Rutter, Quinton \& Hill, 1990) and job placement (Shore \& Massino, 1973). Quay (1986) suggested that the long term effect of the Shore and Massino (1973) study may have been due to their combination of psychotherapy with remedial education and job placement.

In Ontario, studies relating programme variables to outcomes, have seldom been done. Studies have been limited because most Ontario studies of group homes and residential treatment centres have provided only minimal descriptions of programmes. The early surveys described above included only the types of agencies, their methods of funding and their stated missions.

Two recent Ontario studies described residential programmes in more detail. Fulton \& Braseliten (1991) studied 66 residential programmes in 43 institutions across Ontario. Data from the first phase of the present study also included detailed descriptions of all residential programmes serving Ottawa-Carleton clients. In a previous report, programmes were examined to see if they met the needs of each client (McClure et al., 1991). 
Besides these two studies, an especially detailed study of correctional programmes in Ontario is now underway (Andrews et al., in progress).

Fulton \& Braseliten (1991) described Ontario programmes using seven variables (a) primary mission, (b) cost, (c) service volume, (d) staffing, (e) physical plant, (f) client behavioral control, and (g) use of community. The mission of one-third of the programmes was support and the mission of two-thirds was treatment. Treatment included crisis intervention, assessment, custody and other treatment. Costs varied widely across missions and within each category. Service volume was reported for the entire sample only. Staffing levels varied greatly. Most programmes $(72 \%)$ were provided in a community-based home setting. The level of behavioral control was similar in all programmes. One-half of the programmes were fully involved in and dependent on community resources; the others were moderately restrictive with in-house recreation and education available. They also gathered data for a sample of clients. This is reported below.

Descriptions of Ottawa-Carleton residence programmes were included in a previous report (McClure et al., 1991). More detailed programme descriptions are available now. They are reported in the results of the present study.

All of the residence programmes descriptions reported above used ad hoc questionnaires and structured interviews, (VCSCC, 1985; Nutter \& Sullivan, 1989; Sutherland \& Docherty, 1987; Fulton \& Braseliten, 1991). The development of a standardized programme inventory would allow better comparisons between the results 
of various studies. This development depends upon evidence that would lead to agreement as to the most important programme variable to measure.

\section{Process Factors}

Process factors in the Hoge and Andrews (1986) model were measures of the actual transactions between clients and treatments. The process may not be the same as the prescribed programme or global descriptions of it, such as behavioral or client-centred. Quay, (1977) describes process factors as service delivery, one of four aspects of programme integrity. Within service delivery, he included monitoring the programme elements (to know what actually happened), duration of the service, and intensity of the service.

Process variables of programme duration, intensity, structure and personal relationships have been shown to be related to outcomes. Longer programmes have been generally associated with better outcomes (Blotcky, Dimperio \& Gosset, 1984; Fineberg, Sowards \& Kettlewell, 1980, Lipsey, 1990). Casey and Berman (1985), however, found that shorter treatments were more effective than longer treatments.

Intensity of treatment may be measured by frequency of sessions and residential or community agency setting. Lipsey (1990) found that these two measures interacted with duration so that longer duration of treatment and more contact was associated with higher effect sizes except the continuous contact provided by residential treatment.

This result may be related to two findings of Andrews et al. (1990). They found that programmes providing higher levels of treatment improved outcomes for high risk clients but made them worse for low risk clients. They also found that the effects of clinically 
appropriate treatment were attenuated in residential settings. Appropriate residential settings were not as effective as sinilar nonresidential settings and inappropriate residential settings had more negative outcomes than similar nonresidential settings.

Several authors have suggested that higher programme structure was associated with better outcomes (McClure \& Ferguson, 1989; Andrews et al., 1990; Lipsey, 1990). the need for high structure also was implied by the suggestions by Quay (1986) that programmes with explicit goals were most effective. This need for structure was supported by the suggestion of Andrews and Kiessling (1980) that programmes with concrete problem solving, systematic skill training and explicit reinforcement of anticriminal attitudes were most effective.

Good personal relationships have been associated with better treatment outcomes. Andrews and Kiessling (1980) suggested that appropriate service required warm relationships betwun workers and clients. Good client/child care worker relationships have been found more important than good client/therapist relationships for positive outcomes (Blotcky, Dimperio \& Gosset, 1984).

The process by which programmes are implemented can be described by the perceptions of clients and staff. Researchers have shown that clients and staff have different views about how the programmes are implemented and these views differ from the prescribed programmes. This work on perceptions of psychological climate was pioneered by Moos (1974a). He first developed environment scales for use in psychiatric wards (Ward Atmosphere Scales [WAS], Moos, 1974a). Since then, he and his colleagues have developed many similar scales. They have applied thenı to many 
different types of settings including residential treatment programmes (Community Oriented Programmes Environment Scale [COPES] Moos, 1974b). The COPES has been used extensively in research in the USA and Britain.

The perceived environment sampled in the COPES includes three dimensions and ten scales (Appendix 6). Relationships, the first dimension, includes involvement, support and spontaneity. The second dimension, personal development, includes autonomy, practical orientation, personal problem orientation, anger and aggression. The third dimension, system maintenance and change, includes order and organization, programme clarity and staff control. These scale scores were related to resident, staff, programme, policy and outcome variables (Moos, 1974a). Similar factors were related to outcomes of adult psychiatric wards using a parallel form to the COPES, the Ward Atmosphere Scale (Moos, 1974a). Practical orientation, good personal relationships and high structure all were related to the length of time patients remained in the community after discharge. In a study using a parallel school environment scale (CES, Moos \& Trickett, 1974) two scales, relationships, and order and organization, were the best predictors of outcome of therapeutic educational classes (McClure \& Ferguson, 1989).

\section{Outcomes}

There were two types of outcomes in the Hoge and Andrews (1986) model, intermediate and ultimate outcomes. Ultimate outcomes were long term changes in client problems, risk/need factors and client satisfaction and repeated contacts with treatment institutions. Intermediate outcomes were changes that lead to ultimate outcomes. 
There has been little agreement on outcome criteria in past studies of general behaviour disorders. Quay (1986) said that researchers often did not specify criteria or they stated criteria in such global terms t! iat they were essentially unmeasurable. Hoge and Andrews (1986) agreed that confusion in outcome literature came from vague and inconsistent outcome measures. They suggested a variety of data sources, a broad range of specific and measurable outcomes and improvement in the psychometric properties of measures. Many measures that have been used are inadequate in this way.

Both Quay (1986) and Hoge and Andrews (1986) noted another problem with outcomes. Outcome criteria sometimes are measurable but not personally and socially relevant. Some behaviour modification has served to improve control within the residence but not to improve the life of the client after discharge. Hoge and Andrews (1986) suggested that clinical, not statistical, significance, should be the basis of evaluation. They also suggested that evaluation should include the stresses in the situation of the client after discharge. Therefore, treatment should be evaluated not only by the reduction of problems but also by the improvement of personal strengths and competencies. These competencies would enable clients to cope with their realistic life situation. Hoge and Andrews (1986) included a focus on developing personal resources and competencies within their risk/need constructs.

One review showed that the intermediate outcomes of reduced fear and improved cognitive performance showed larger effect sizes than the outcomes of improved self concept and personality measures (Casey and Berman (1985). The latter two outcome effects were not significantly different from no effect. Almost all treatments of fear and 
cognitive performance were behavioral. Social and global adjustment and achievement outcome effects were significant but did not differ from each other.

One type of intermediate outcome may be especially relevant to studies of residential programmes. Placements following discharge from the programmes may be a measure of their success. For example, discharge to the parental home or to independent living may be a better outcome than discharge to a more intensive treatment centre or discharge to court custody.

Intermediate outcomes are less important than ultimate outcomes as the purpose of residential programmes is to have a long term effect on the life of the client. Yet long term evaluations are especially difficult to do. They are very expensive as the clients are often hard to find. The exemplary long term study was that of Robins (1974). She found most clients of a child guidance centre after 30 years. She then related their childhood and family problems to their adult functioning. Unfortunately, the descriptions of the child guidance programmes were inadequate. Therefore she could not study the effects of various types of programmes on long term outcomes.

Since the time of the Robins study, better descriptions of programmes and client measures have maje studies of long term outcomes possible. For residential programmes, however, results of studies of ultimate outcomes have disagreed. Weisz et al. (1987) found that effect size was as large for intermediate outcomes as it was for followups after an average of 168 days. Reviews of psychiatric inpatient programmes concluded that most programmes were effective at the immediate followup period. Yet long term gains were generally disappointing for the well executed residential studies 
reviewed by Quay (1977). The interval between discharge and followup may be important in el aluating ultimate outcomes. One review (Blotcky, Dimperio \& Gosset, 1984) found mixed results during the first year or two after discharge. There was gradual improvement for most nonpsychotic patients after this period.

A focus on improving strengths and competencies may be especially important in evaluating long term outcomes. Quay (1986) pointed out that most studies have concentrated on change within institutions and immediately after discharge. This led to a neglect of the teaching of generalization and maintenance skills. Such neglect in extreme cases could increase the likelihood of readmission or recidivism by institutionalizing clients. The need for this also was pointed out by Andrews et al. (1990).

Quay (1986) found that generalization from behaviour modification programmes was especially poor. There were three possible reasons for this. First, target behaviours may have been related to inprogramme management instead of post discharge skills and community functioning. Second, treatment placements may have been inappropriate for the level or type of client need. Third, community reinforcers may have served to maintain or reinstate inappropriate nonfunctional and delinquent behaviours. After-care programmes have been shown to improve outcomes (Blotcky, Dimperio \& Gosset, 1984). Current thinking emphasizes the importance of extending programmes into the community after discharge (Andrews et al., 1990). 
Programme/Client Matches

All of the factors described above may have a main effect on outcomes and also may combine with other factors to affect outcomes. The most widely studied of combinations is that of programme and client factors.

Referring workers have long hoped to "focus on fitting services to the individual rather than trying to fit clients into services" (Investing in Children, 1988). The long term purpose of many studies reviewed above is to contribute towards a prescriptive model of treatment that links specific problems with specific treatments. Hoge and Andrews (1986) believed that there was not sufficient empirical evidence for such an approach. Since then there have been many attempts to find such evidence. Many matching theories have been proposed and tested. To this end there have been studies of (a) the process of deciding placements and (b) studies of the outcomes of various types of programme/client matches. Studies of matches and outcomes are reviewed later.

The process of choosing placements has been studied by many researchers since Maas \& Engler in 1959. Little progress appeared to have been made until 1979. Then, Jaffee (in Schwab, Bruce, \& McRoy, 1985) developed a statistical computer model using the judgments of those who regularly referred children to residences. They were asked to base their recommendations on 110 descriptors of children and their families. The results were disappointing. When he attempted to validate the model against actual placements, there were significant differences. He concluded that there was no consensus among social workers about placements. Later, other researchers included judgments of toth referring and admission workers and allowed for up to five matches out of 59. (Schwab, 
Bruce, \& McRoy, 1985). Results using this model had an accuracy rate of 63 per cent. The authors were careful to say they were modelling actual, not ideal, practice and that the results could not be generalized to other jurisdictions and sets of residences.

A five-county Ontario study (Nutter \& Sullivan, 1989) used a more direct method. They surveyed all group homes but excluded Children's Mental Health Centres. The authors asked children's workers and placement chairpersons to complete demographic information, a modified CBCL (Achenbach, 1978; Achenbach \& Edelbrock, 1979) and the reasons why residential placement was considered. The reasons for placement in order were (a) high degree of structure $(82 \%)$, (b) need for treatment $(68 \%)$, (c) assessment (5\%), (d) need for permanency (31\%), (e) difficulty in using less restrictive community options (22\%) and (f) it was the most accessible resource at the time (18\%).

The authors suggest that placements were not sufficiently related to the needs of children. Most children were reported to be unhappy and in need of treatment, yet the main reason for placement was high structure or control. They also say that assessment in residential placement is suspect as it may describe the residence more than the child. Two other concerns were that the need for permanency was not met and that many placements were made only because a more appropriate one was unavailable. This was supported by McClure et al. (1991) who found that $30 \%$ of all placements were made for this reason.

These studies of the process of choosing residential placements have led to continuing concern about finding better ways to match clients and programmes. Also, there have been studies investigating which matches are most important to improve outcomes. 
The effects of client/treatment interactions have been studied widely. There is good evidence that some matches between the type of programme and the characteristics of clients improve the effectiveness of treatment outcome while some matches have not been effective. There is general agreement among researchers and among clinicians that client/programme matches should continue to be investigated. Quay (1977) especially emphasized the importance of matches between the treater, treatment and treated as one of four aspects of programme integrity. He said that blanket applications of almost any treatment without regard for client characteristics are doomed to failure at the outset. He also said that the responsiveness of clients to differing kinds of interventions should be matched with treatment.

Palmer (1974) found that staff judgments of the appropriate placement at the time of client admission were related to outcomes. Recidivism was reduced if clients were placed in either residential or community trcatments according to staff judgments. Two other types of matches (client I-level and disorder type with programmes) led to unclear results. Several studies used matches between clients and treatments based on the I-Level system (Jesness, 1971; Palmer 1974; Jesness, 1975). Only one match reduced recidivism. Manipulators had fewer parole violations following a transactional analysis programme than following a behaviour modification programme.

Another study in a large delinquency institution (Kennedy Youth Center: Cavior \& Schmidt, 1978) matched client disorders and treatments. Conduct disorder clients were given behaviour modification, anxiety withdrawal clients given counselling, socialized aggressive clients given reality therapy and immature clients given transactional analysis. 
No subtype had better outcomes except that the conduct disorder/behaviour modification group improvement was close to significance for parole violations.

Andrews et al. (1990) suggested another way of matching of clients and treatments. Their risk/needs/responsivity theory was based on client/treatment matches. Risk and need matches were described above under client factors. Currently, there is good evidence that levels of risk are related to recidivism among delinquents. It is less clear that risk levels are related to outcomes for other types of residential clients. Also, it is unclear which particular risk factors predict outcomes. It seems reasonable that treatment targets should be derived from the needs of clients. There is not yet, however, sufficient evidence of the outcomes of need/treatment matches.

The responsivity principle of the theory suggested that effective treatment depended upon appropriate matches. These matches were based upon a division of clients into two major groups. The first client group had poor verbal, interpersonal and self reflective skills. They did not have significant problems of neurosis and overcontrol. Most young offenders belonged to this group. Some young offenders may have combined poor skills with emotional problems. For these clients, the need principle suggested that their emotional problems should not be the primary target of treatment as emotional problems are not major crimogenic needs. Clients with low skills and conduct disorders were most responsive to treatments based on behavioral and social learning principles (Quay, 1986; Andrews et al., 1990). Andrews and Kiessling (1980) suggested five applications of these principles as the best treatment for this group of clients. The tive suggested applications were, (a) the use of authority without domination or abuse, (b) anticriminal modelling of 
alternatives to procriminal thinking, feeling and acting and explicit reinforcement, (c) concrete problem solving and systematic skill training, (d) advocacy and brokerage combined with appropriate service, and (e) warm relationships between workers and clients combined with clear support for anticriminal attitudes and behaviours.

The responsivity principle suggested other types of treatment for the second group of clients described by Andrews et al. (1990). These clients had high verbal, interpersonal and self reflective skills and primarily emotional, not conduct, problems. Andrews et al. (1990) suggested that such clients may benefit from nondirective, client-centred, less structured and more relationship-dependent treatments.

The authors believed that most young offenders are of the first group. Therefore, they suggested that some types of treatments should be avoided for almost all young offenders. They believed that group treatment may reinforce procriminal beliefs and attitudes. Therefore, unstructured, peer oriented and permissive relationship-oriented milieu approaches should be avoided. They also believed that the "scared straight" approach was ineffective with young offenders. Two analyses supported both positions (Lipsey, 1990; Andrews et al., 1990).

The Hoge and Andrews (1986) model related client risk levels to the theory of appropriate treatment described above (Andrews et al., 1990). As part of this theory, the risk principle suggested that higher levels of service were best reserved for higher risk cases. Lower risk cases were best assigned to minimal service. The Andrews et al. (1990) meta-analysis showed that high risk/high service matches led to larger effect sizes. 
Lipsey (1990) did not test similar matches. Instead, he tested high risk and high service separately and found small positive effects for each level.

\section{Instruments}

Hoge and Andrews (1986) noted that there were problems of measurement in using their model in research studies. Many variables in their model were difficult to define and to measure. They refer to work such as Moos (1974a) in the description of programme environments and of others in defining therapies, as the beginnings of acceptable measurement. Since 1986 there have been improvements in measures of client problems and of client and family risk factors. More recently, measures have been developed and standardized on Ontario populations.

Client problems were at first recorded unsystematically and in different ways by each residence. The development of the Diagnostic and Statistical Manual (DSM III, American Psychiatric Association., 1980) and of standardized behaviour checklists such as the Child Behavior Checklist (CBCL, Achenbach \& Edelbrock, 1983) provided methods of comparing the problems of clients in different residences.

The first systematic study of the behaviour of all children and youth living in all provincially funded residences in Ontario was by Randall and McClure (1972) and Randall, McClure \& Sone (1974). They used home and school checklists made up of factors from previously standardized instruments. Factors were (a) disruptive behaviour, (b) social withdrawal, (c) social maturity, (d) psychotic behaviour, (e) school learning and (f) coordination difficulties. 
In the last decade, many Ontario treatment centres began to use either the DSM III or a standard behaviour checklist at client admission. The CBCL was the most common measure. Child welfare, maternity and correctional group homes still generally do not use standard measures of client problems at admission.

Offord and his colleagues developed new measures of child problems and of family risk factors (Offord et al., 1987). Both measures were standardized on a large sample of the Ontario population. Their behaviour checklist (CBC, Offord et al., 1987) combined DSM III and CBCL items. It is described in more detail below. Their Family and Household Form (Rae-Grant et al., 1989) provided a standard measure of family risk factors. Both instruments are being adapted for use in residential settings as a Standardized Client Information System (SCIS, Ontario Association of Children's Mental Health Centres, 1992).

Another measure of client and family risks is the Youth Level of Service Inventory (Andrews, Robinson, \& Hoge, 1985, Appendix 1) which provides a reliable measure of risk factors for delinquents. It has been standardized on Ontario correctional groups.

Measures of other factors in the model are still inadequate. There are no widely used, standardized measures of worker, programme or process factors. Also there is no general agreement on appropriate outcome measures for residential services. 


\section{Research Methods}

Some outcomes of treatment have been related to the characteristics of studies including the size of sample and the year of publication. Larger effect sizes were found for smaller samples (Casey and Berman (1985); Lipsey, 1990). Year of publication had no relation to effect sizes in one meta-analysis (Casey and Berman (1985)) and only a minor effect in another (Andrews et al., 1990). In multiple regression, the latter effect, however, was much smaller than the effect of type of treatment. The quality of the research design did not affect outcomes in one meta-analysis (Andrews et al., 1990). In this analysis the authors defined stronger design as random assignment or treatment comparisons for which risk levels could be controlled. Weaker designs were nonrandom assignment without knowledge of risk factors. This result supported the earlier position of Hoge and Andrews (1986) that studies of the appropriateness of treatment were worthwhile even when random control groups cannot be used.

One problem with research methods that has been neglected is that of differences in outcomes due to the reporter. Both Casey and Berman (1985) and Weisz et al. (1987) found that observers, therapists and parents reported more change than did teachers and peers. Casey and Berman (1985) suggested that teachers and peers were biased against accepting real change in behaviour that was seen by others. Another interpretation may be that observers, therapists and parents were biased towards finding positive results.

\section{Summary of Literature Review}

This review suggested five requirements to improve future evaluation research. These were (a) an appropriate treatment model, (b) better classification of disorders, (c) better 
measures of risks and need factors (d) better descriptions of programmes and programme implementation and (e) better outcome measures (Casey and Berman, 1985; Hoge and Andrews, 1986; Quay, 1986).

The Hoge and Andrews (1986) evaluation model seemed appropriate for two reasons. It included most of the variables shown by past research to be related to treatment outcomes. Also, it was sufficiently complex to suggest ways that combinations of factors may have an effect upon outcomes. Studies have repeatedly shown that combinations of factors, especially client/treatment matches, are better predictors than single factors.

Progress has been made since the Hoge and Andrews (1986) paper on the second problem, improved measures and classification of client problems. Widespread use of a psychological behaviour checklist, the CBCL (Achenbach \& Edelbrock, 1983) and the psychiatric classification of DSM III (American Psychiatric Association., 1980) now allows comparisons across studies of small group home and treatment centre programmes. The work of Offord and colleagues has brought these two classification systems together in the CBC. This was an attempt to develop a common language and understanding across professions. Offord et al. (1987) also produced Ontario norms for the CBC based upon rural and urban samples of the general population. This overcomes some setting factor problems noted by Hoge \& Andrews (1986). It also allows clinical groups to be compared to normal groups of their own age and sex. The major remaining problem of measurement and classification is to establish a common instrument to measure problem behaviour in most residences. The Ontario Association of Children's Mental Health Centres is presently helping to encourage the use of the $\mathrm{CBC}$ for this purpose. 
Client risk factors may also be important predictors of the outcomes of residential services. Progress has been made for young offenders in the measurement of risk factors and in the relation of risk factors to programmes and outcomes. Less progress has been made in studies of mental health clients. Rae-Grant et al., (1989) did find correlations between disorders and many factors. They did not, however, find out if any of these factors were predictors of the outcomes of programmes.

The fourth requirement for improved outcome research was better measures of programmes and of programme implementation. The only widely used standardized measures are those that ask clients or staff about their perceptions of the psychological climate of a programme, for example, the work of Moos and colleagues. These measures have proven valuable in finding predictors of outcomes in several settings. No single instrument is commonly used to describe residential programmes. A study using the same instrument across Ontario programmes for young offenders is now underway (Andrews et al., in progress).

The last requirement for improved outcome research was better outcome measures. This is still a major problem. Different homes and centres use different measures that are hard to compare. Outcomes are often defined in vague terms. Many centres rely on client satisfaction as the only outcome. They also should include measurable changes in specific behaviours as another important outcome.

Results of studies do not agree on the effect of matches between type of residential treatment and type of clients on outcomes. Results of matching studies in corrections are equivocal. There are very few well-researched studies of other types of residential 
services. This is surprising, considering the very high cost of such service and the extent to which it disrupts the life of the client and of the client's family. Further development of testable theories is required. These theories should relate factors to each other and to outcomes.

In summary, it appears from this review that many correlates of disorder and many measures of programmes have been used in studies. The question that arises, however, is, "Which of these many factors and combinations of factors are the best predictors of the outcomes of residential placements?" There is agreement on the relationship to outcomes of some factors, disagreement on the relationship of others and not much known about the relation of client/programme matches to outcomes. Except within correctional treatment, very few studies have been done on the factors that are predictors of outcomes of residential treatment. There appears to be a need for such a study. 


\section{METHOD}

\section{Purpose}

The purpose of the study was to find predictors of (a) where clients lived and (b) of client behaviour, following residential child care or intervention programmes. The study was done in two phases. Phase One was conducted during 1990 and Phase Two during 1992. Phase One described clients and programmes in terms of possible predictors of outcomes. These predictors were characteristics of clients, workers and programmes and matches between client needs and available services.

Phase Two examined relationships between the predictors of Phase One and the outcomes at the time of Phase Two. Predictors and outcomes were organized according to the Hoge and Andrews (1986) model of treatment evaluation (Fig. 1). All levels of the model were used except setting factors. These were not included because all clients came from the same community.

\section{Phase One: Descriptions}

Residential services for children and youth in Ottawa-Carleton were studied in detail for the first time in 1990. The Ottawa Regional Office of the Ministry of Community and Social Services (MCSS) funded a residential placement study proposed by the Ottawa-Carleton Residential Placement Advisory Committee (RPAC). The primary purposes of the residential placement study were to investigate the appropriateness of the placements of clients, identify service gaps and make planning recommendations (McClure, Armstrong, Cloutier \& Tillman, 1991). A secondary purpose of the study was to serve as the first phase of the present study. 
The MCSS and RPAC consulted with the area residential care service providers. From that consultation they developed a steering committee for the project that included representatives from:

1. The Ministry of Community and Social Services;

2. Probation and Aftercare Services;

3. Child Welfare Services;

4. Child and family intervention programmes for children under 12;

5. Child and family intervention programmes for children over 12 ;

6. Children's mental health programmes;

7. The RPAC coordinator, who acted as chair for the Committee.

The Steering Committee met regularly. It hired the principal researcher, provided consultation and supervision for him and ensured financial accountability. An associate and an assistant researcher were also hired.

MCSS appointed the researchers as temporary officers of the Ministry for the study. Therefore, they were allowed access to ail records of MCSS-funded agencies. The Steering Committee and principal researcher decided that, because they were seeking systems information, all infor mation collected would be non-identifying and non-intrusive. To be non-identifying, all the information was collected by coded surveys. To be nonintrusive, surveys were completed by agency personnel only. Clients, parents and other community professionals were not asked for information. 


\section{Phase One Sample}

The sample included all residential programmes serving children and youth with behavioral problems from the catchment area of Ottawa-Carleton. It included residences that scrved these cilents but were iocated outside the area, and foster placements in homes with four beds or more. Residences designed primarily for developmentally or physically disabled clients were not included.

Th s siudy included 24 organizations that operated 59 residences. They provided two major types of programmes (a) care and (b) intervention. Care programmes provided child protection and support. They were operated by the Children's Aid Society (CAS) and by group, foster and maternity homes. Intervention programmes provided treatment and custody. They were operated by Children's Mental Health Centres and hospital psychiatric inpatient services. Secure custody was provided in two residences and open custody in 13 residences. There were 31 residences with only English services, 24 with bilingual services, and four with only French services (Table 2).

Most of the protection and support programmes were operated by the Ottawa-Carleton CAS. The 21 CAS residences were designed for emergency placement, for youth homes or for transition to independence. Few emergency clients were included in the present study as they usually did not stay for more than the week required for inclusion. All CAS homes were grouped as child welfare homes in the present study. There were few maternity home clients in the study as most of them were 18 years of age or older.

Group homes included in this study were operated by two Ottawa and 12 out-of-town agencies. Most of their clients were in CAS care. One Ottawa agency operated four 
therapeutic foster homes and another agency operated one as a transition community program for adolescents. One out-of-town agency operated three and another four homes. The remaining 10 out-of-town agencies operated one home each. The total number of group homes in the study was 16 as some did not serve any Ottawa-Carleton clients in the study period. Thirteen of the group homes also served open custody clients.

Treatment and secure custody residences were operated by two Children's Mental Health Centres, the Roberts-Smart Centre (RSC) and the Child Study Centre (CSC). They also were operated by three other agencies, the Youth Services Bureau (YSB), Gateway Children's Centre (GCC), and la Maison Rouyn (MR). The two largest of these, the RSC and YSB, served nearly all of the youth in treatment and custody in Ottawa-Carleton. Eight residences and a foster home were operated by the RSC. Two residences were on campus and the others were in the community. One campus residence was for secure custody. The CSC served clients ages 5 to 12 . It was operated by the University of Ottawa Psychology Department in a separate on-campus building.

Three agencies were classified as treatment and custody centres in the present study because they employ full-time clinical staff and Child and Youth Counsellors (CYC). Also, their programmes are specifically designed for treatment or custody. The YSB operates one centre for detention, observation, secure and open custody. It also operates three community treatment centres and one transition centre for youth. The transition centre helps prepare youth for independent living. It was classified as a group home in this study. Children of 12 years of age and younger were treated by two agencies, the CSC and the GCC. They are located in Ottawa-Carleton. La Maison Rouyn (MR) 
operates one treatment centre and two foster homes in Rouyn-Noranda, Quebec, for French-speaking children and youth.

There were two psychiatric inpatient services in Ottawa, the Royal Ottawa Hospital (ROH) and the Children's Hospital of Eastern Ontario (CHEO). The ROH operated two cottages on campus for children and youth and CHEO operated one ward for youth.

The Phase One sample included (a) all clients who stayed in any of these residences for more than one week between January 1. and June 30, 1990 and (b) clients of all ages to 18. The total number of clients was 411 and responses were received for 381 of them.

\section{Phase One Instruments}

Three questionnaires were used to study the residential programmes, (a) an Agency and Residence Questionnaire (ARQ), (b) the Community Oriented Programme Environment Scale (COPES, Moos, 1974), and (c) a Residential Programme Evaluation Inventory (PEI). The ARQ was designed for the present study, the COPES was a standardized instrument, and the PEI was adapted from the Correctional Programmes Evaluation Inventory (CPEI, Gendreau \& Andrews, 1990). Client risk and need factors were studied using two questionnaires (CRF and RFRL) designed for the study. Client behaviour was studied using the original and revised version of a standardized questionnaire, the Child Behaviour Check List (CBC, Offord et al., 1987; CBC-R, Offord et al., 1990). All questionnaires were translated into French except the CBC-R. Also, they were all reviewed and approved for use by the Steering Committee. 


\section{Residences}

The Agency and Residence Questionnaire (ARQ; Appendix 2) asked for the goals for each programme, staff and client statistics, the characteristics of the preferred type of client (client profile), who referred their clients, and services available at or through the agency. The ARQ was completed by the residence supervisor. It was based on the work of Nutter \& Sullivan, (1989).

The Community Oriented Programme Environment Scale (COPES; Moos, 1974; Appendix 4) asked about the perceived psychological climate of the residence. The COPES included three dimensions and ten scales (Appendix 5). Relationships, the first dimension, included involvement, support and spontaneity. The second dimension, treatment programmes, included autonomy, practical orientation, personal problem orientation, anger and aggression. The third dimension, system maintenance and change, included order and organization, programme clarity and staff control. It was completed by front line staff.

Studies of the psychometric properties of the COPES have not been done. Moos (1974) suggests that results may be generalized to the COPES from extensive studies of a parallel form, the Ward Atmosphere Scale (WAS), designed for psychiatric inpatient settings. The author reports WAS test-retest profile stability over periods ranging from one week to three years and four months, for patients from $r=.70$ to $r=92$ and for staff from $r=83$ to $r=.96$. Correlations of age, sex and length of stay with subscales were found for 365 patients on 14 wards. Only five of thirty correlations were greater than $r=.20$. For 13 staff on the same wards, only three of thirty correlations were 
above $r=.20$. In another sample of 63 staff on eight wards only five of thirty correlations of age, sex and length of stay with subscales were above $r=.20$. For 264 patients on 16 wards, correlations of a social desirability scale with the relationship WAS subscale were very low (mean $r=.12$ ) and it was not significantly correlated with any other subscale. For 94 staff on four wards, four of thirty correlations of social desirability with all WAS scales were above $r=.20$.

The Residential Programme Evaluation Inventory (PEI; Appendix 4) was derived from the CPEI. The CPEI was designed to evaluate correctional programmes. Items were selected based on recent evidence about the characteristics of effective programmes (Andrews, et al., 1990). Higher scores indicated more promising programmes. It provided a total score and scores for each section based on the percentage of acceptable responses. The seven sections of the CPEI used in the present study asked questions about client preservice assessment, programme targets and treatment techniques, therapeutic integrity, relapse prevention, staff characteristics, programme evaluation, ethics and recent changes. The section that was not used from the CPEI described the original implementation of the programme. Implementation questions did not seem relevant as most organizations studied had begun many years ago and had changed drastically since their beginnings. Some questions were modified and some added to have them apply to both mental health and correctional programmes. The PEI was completed during a two-hour interview with the directors or supervisors of seven Ottawa agencies. 


\section{Clients}

The Needs, Risks and Placement Check List (Appendix 6) had three parts. Part A asked for present residential status and the referral source. Part B asked for presenting problems as observed by the residential staff. Part $\mathrm{C}$ was the Client Risk Factors Check List (CRF). It asked about client and family risk and protective factors. These factors were activities and relationships that have been correlated with future emotional and behavioral problems and delinquency (Ontario, MCSS, 1990; Andrews, Robinson, \& Ball, 1986; Andrews, Robinson, \& Hoge, 1985).

Items in Parts B and C were scored 1 for present and 0 for not present or unknown. From Part B, a total presenting problems (need) score was calculated. From Part C, total protective and total risk scores were calculated. The total protective score was the sum of present positive items out of 15 (item numbers 70 to 84 ). The total risk score was the sum of present negative items out of 17 (item numbers 54 to 69) minus the total protective score. Two other need scores were calculated, (a) programme needs and (b) total needs. Programme needs were the total number of those risk factors that might be changed by treatment. Total needs were the total number of presenting problems plus the total programme needs. The staff person who knew the client best completed the CRF.

The Residential Referral Check List (RFRL, Appendix 7) asked child welfare workers for client presenting problems that led the worker to refer a client for residential treatment. It also asked if they had referred a client to a particular residence only because an alternate preferred placement was unavailable. The person who referred each client to the residence completed the RFRL. To keep the study non-intrusive, parents and 
professionals who referred clients and the youths themselves were not asked to complete the RFRL.

The Child Behaviour Check List (CBC: Appendix 8, Part A) was developed for the Ontario Child Health Study (Offord et al., 1987; Boyle et al., 1987). CBC items were derived from both the Diagnostic and Statistical Manual of Mental Disorders ( 31 J. ed.) (DSM III; APA, 1980) and the Child Behaviour Check List (CBCL; Achenbach 1978; Achenbach \& Edelbrock, 1979). The OCHS developed Ontario norms for a large sample of the Ontario normal population. These norms were for six scores - conduct, hyperactivity, emotional and somatization disorders and externalizing and internalizing problems. There are $\mathrm{CBC}$ English and French versions for completion by parents, youths and teachers.

A study of the psychometric properties of the CBC compared a general population sample $(n=1751)$ and a mental health clinic sample $(n=1027)$ from the same urban area (Boyle et al. (in press). The study found that $\mathrm{CBC}$ scales were adequate ordinal level measures of conduct, hyperactivity and emotional disorders. Somatization disorder was dropped as it had been found uncommon in earlier studies (Offord et al., 1987). Item analyses showed good convergent and discriminative validity for individual scale items. The scales were skewed to the positive end of the continuum but they had good internal consistency (all estimates $\geq .74$ ) and test-retest reliability (all estimates $\geq .65$ ). Validity of the scales was tested by multiple regressions predicting general population/clinic status after controlling for age and sex. For 6 to 11 year old subjects all three parent and teacher scales were significantly correlated with status. For 12 to 16 year old subjects, 
only parent and youth conduct and emotional disorder were significantly correlated with status. The variance attributable to all three scales was much higher for parent scales $\left(\mathbf{R}^{2}\right.$ $=.42$, ages $6-11 ; R^{2}=.42$, ages $\left.12-16\right)$ than for teacher $\left(R^{2}=.23\right)$ or youth $\left(R^{2}\right.$ $=.19)$ scales. Hyperactivity contributed the least unique variance to the prediction of clinical status for ages 6 to 11 and almost none for ages 12 to 16. Correlations between conduct and hyperactivity disorders for ages 6 to 11 across teachers and parents $(r=.42)$ were similar to correlations between the same scales $(r=.50)$. Therefore, there was not good discriminant validity between conduct and hyperactivity scales.

Only the English versions of the $\mathrm{CBC}$ have been revised since the OCHS. The English Revised CBC (CBC-R; Appendix 8; Part B) includes all the items of the original CBC and can be scored in the same way. Items have been added to the CBC-R to allow it to be scored for the original OCHS categories and also for DSM III-R categories. The CBC provides scores for the six DSM III-R based disorders of (a) conduct problems, (b) oppositional problems, (c) attention deficit, (d) over-anxious, (e) separation anxiety and depression. The CBC-R also gives two summary scores for (a) externalising and (b) internalising problems. All CBC-R scores are given as raw scores and as percentiles of a large normal Ontario population.

A study of the psychometric properties of the CBC-R (Boyle et al., 1993) used the same general population and clinic samples as the previous study (Boyle et al., in press). Results showed that for the general population the DSM III-R externalizing scores of oppositional and attention-deficit hyperactivity disorders were acceptable. Homogeneity estimates (inter-item correlations) went from .27 to.59 and test-retest reliability was 
greater than $r=.75$, except one teacher measure. Conduct disorder was less homogeneous with parent and youth inter-item correlations from $r=.18$ to $r=.19$ and test-retest reliability from $r=.71$ to $r=.79$. Among the internalizing scores, internal consistency estimates ranged from $r=.68$ to $r=.80$ and test-retest reliability estimates from $r=.55$ to $r=.88$. Validity of the scales was tested by multiple regressions predicting general population/clinic status, after controlling for age and sex. The three parent externalizing scales were significantly correlated with clinical status. The variance attributable to all three scales was much higher for parent scales $\left(R^{2}=.40\right)$, than for teacher $\left(R^{2}=.15\right)$ or youth $\left(R^{2}=.17\right)$ scales. Among internalizing disorders, only the depression scale was significantly correlated with clinical status. The variance attributable to depression was similar for parent $\left(R^{2}=.39\right)$, teacher $\left(R^{2}=.34\right)$, and youth $\left(\mathbf{R}^{2}=.30\right)$ scales. The authors argue that the reliability, validity and other psychometric properties of the CBC-R are comparable to those of the CBCL (Achenbach \& Edelbrock, 1983) and the RBPC (Quay \& Peterson, 1987). They also say that CBC-R has the added advantage of being related to DSM III-R categories that are used by many clinicians.

Parent and teacher versions of the $\mathrm{CBC}$ were used in the present study. French $\mathrm{CBC}$ versions had not yet been revised at the time of the study. Therefore the original CBC was used for French clients and the revised version (CBC-R) for the English clients. OCHS scoring was used for all clients, both French and English, and DSM III-R scoring for the English sample only. 
The parent $\mathrm{CBC}$ and $\mathrm{CBC}-\mathrm{R}$ were used to collect information about each client's behaviour problems within the residence in Phase One. The staff person who knew the client best completed the $\mathrm{CBC}$.

\section{Data Collection}

MCSS informed all agencies of its support for the study and appointed the researcher as an officer of the Ministry for Phase One of this research. A researcher then introduced the study at staff meetings of large agencies and in visits to all single residence agencies.

At these meetings a version of the $\mathrm{CBC}$ for computer administration was demonstrated. This version gives immediate lists of problems and a graph of disorder scores. Staff could choose either computer or paper administration. If they completed it on paper, the researcher scored the checklists and returned item lists and disorder graphs to the residence supervisor.

The COPES, CRF and ARQ were completed on paper and mailed to the researchers. After completion a COPES graph of scores was returned to each residence. In large agencies, supervisors were assured that only aggregate COPES data for the entire agency would be sent to the agency director.

After staff completed all questionnaires, all residence directors or supervisors were interviewed. At these interviews detailed information was sought about 10 per cent of the clients that scored extremely high or extremely low on the behaviour check list (CBC or $\mathrm{CBC}-\mathrm{R}$ ). Comments were also asked for on services for female, native and francophone clients and on perceived gaps in service. Another interview was held with 
directors (or their delegates) of eight large Ottawa agencies, at which time the PEI was completed.

\section{Analysis}

The following scores were calculated:

1. Residence COPES scores for perceived involvement, support, spontaneity, autonomy, practical orientation, personal problem orientation, anger and aggression, order and organization, programme clarity and staff control.

2. Residence PEI total scores and scores for client prescrvice assessment, programme, therapeutic integrity, relapse prevention, staff characteristics, programme evaluation, ethics and recent changes.

3. Client CRF total risk and total protective score.

4. Client CRF total presenting problem, programme need and total need (presenting problem plus programme need) scores.

5. Client total number of criminal acts reported in the CBC or CBC-R.

6. Client CBC and CBC-R scores for six OCHS based disorders of conduct, hyperactivity, emotional and somatization disorders and externalizing and internalizing problems.

7. Client CBC scores for six DSM III-R based disorders of (a) conduct problems, (b) oppositional problems, (c) attention deficit, (d) over-anxious, (e) separation anxiety and depression and two summary scores for (a) externalising and (b) internalising problems. 
8. Client needs and service matches. These matches were the percentage of each client's presenting problems in the CRF that could be served by appropriate services available in the residence, agency and community. The appropriate services for the treatment of each problem were decided by the researcher with the approval of the steering committee (Appendix 9). The extent to which each service was used for each client was not asked. Also, no judgment was made of the quality of each available service.

Comparisons then were made across sex, age and type of agency of programmes, social environment, risk factors, needs, behavioral disorders, criminal acts, and need/service matches.

\section{Phase Two: Predictors of Outcomes}

\section{Data Collection}

The purpose of the study was to find predictors of two outcomes, (a) where clients lived and (b) client behaviour, following residential programmes. The days that clients lived in a child care setting, (family, foster, CAS or group homes, or independently) were defined as successful placement days. Unsuccessful placement days were defined as the days that clients lived in an intervention setting (inpatient psychiatry, treatment centre, or in custody) and days that they were absent without leave from a home or a programme. The outcome placement variable was the percentage of successful placement days from the beginning of Phase Two (June 30, 1990) to the end of Phase Two (July 1, 1992) or to the earlier discharge of each client from CAS care. Successful behaviour 
was defined as significantly lower scores on a Phase Two behaviour checklist than on a Phase One behaviour checklist.

\section{Placement Sample}

More than half the residents in Phase One had been in the care of the CAS $(n=238)$. Records of where they were living were searched from the time they first came to the attention of the CAS until the end of Phase Two or until an earlier discharge. The number of days that each client had lived in child care and intervention residences during that period was calculated. Nineteen clients had been discharged during Phase One and. therefore, before Phase Two. Complete placement data was found for 205 (93.6\%) of the remaining 219 clients. Approximately two-thirds of them (64.9\%) remained in CAS care for the full two years of Phase Two. Nearly three-quarters remained in CAS care for more than 18 months $(71.7 \%)$, nearly five-sixths for more than one year $(83.9 \%)$ and 97.1\% for more than six months.

\section{Behaviour Sample}

Permission was obtained from nine Ottawa agencies to conduct the followup study (CAS, YSB, RSC, ROH, CSC, GCC, and three maternity homes). Out-of-town agencies and private group homes were not included in the sample due to the expense of data collection. Custody clients were not included because of concerns about privacy and CHEO iıpatients were not included as there were too few (5/30) in Phase One to be representative. Those group home clients who had been CAS clients were included (21). Therefore, the followup sample size was nine agencies, 39 residences and 284 clients. 
Parents and clients 16 years and older, were mailed requests to take part in Phase Two of the study. If clients were presently in the care of the CAS, the CAS worker responsible for them was asked to take part. Agencies were asked for the last known address of each client. Clients who had been in more than one agency during Phase One were sent more than one letter. All clients or parents who did not reply were sent two followup letters. Agencies were asked to make followup calls requesting cooperation. Telephone and city directories were searched for recent addresses.

Letters were returned from 25 parents or clients marked address unknown. Replies were received from 113 of the remaining 256 parents or clients. Permission was received from 108 or $42.2 \%$ and refusals from five or $2 \%$ of those likely to have received the request. Those who agreed to take part completed a CBC-R to describe their recent behaviour. Eleven of the CBC-R checklists received were duplicates and seven were incomplete. Therefore the final sample available for analysis was 90 clients out of the 256 possible or $35.2 \%$.

\section{Hypotheses}

\section{Client Factors}

Hypothesis Qne:

Clients with higher disorder scores in Phase One will have higher disorder scores and lower percentages of successful placement days in Phase Two. Hypothesis Two:

Clients with higher risk and need factor scores in Phase One will have higher disorder scores and lower percentages of successful placement days in Phase Two. 


\section{Worker \& Programme Factors}

Hypothesis Three:

Clients who were in Phase One residences with higher percentages of Child and Youth Counsellors (CYC) with CYC diplomas will have lower disorder scores and higher percentages of successful placement days in Phase Two.

Hypothesis Four:

Clients who were in residences with higher COPES scores for practical orientation, order and organization, involvement, support and spontaneity in Phase One will have lower disorder scores and higher percentages of successful placement days in Phase Two. Hypothesis Five:

Clients who were in residences with higher programme evaluation (PEI) scores in Phase One will have lower disorder scores and higher percentages of successful placement da $j$ s in Phase Two.

Hupothesis Six:

Clients with higher numbers of matches between their needs and the available services in Phase One will have lower disorder scores and higher percentages of successful Dlacement days in Phase Two.

Hypothesis Seven:

The prediction of placement and be aviour outcomes will be significantly increased by the addition of staff and programme variables 'o client variables. 


\section{RESULTS \\ Phase One: Descriptions}

\section{Sample}

The study included 24 organizations that operated 59 residences (Table 2). Agencies in Ottawa-Carleton served over 90 per cent of the clients. Large agencies that operated several residences served four-fifths of the clients. The study included 411 clients (Table 3). Behaviour checklist (CBC or CBC-R) responses were obtained for 381 of these clients. There were no responses from one group home $(n=5)$ and only five of a possible 30 responses from one hospital psychiatric ward. Responses were available from all other homes and centres for all except three clients.

\section{Clients}

Most clients were male (60\%), adolescent $(79 \%)$, and English-speaking (83\%). The reported proportion of French-speaking clients was less than that in the Ottawa-Carleton population.

More than half $(n=238,62.5 \%)$ of the sample were CAS clients. Most of them were Society or Crown wards $\mathbf{7 8 . 6 \% ) . ~ T h e ~ o t h e r s ~ w e r e ~ i n ~ c a r e ~ u n d e r ~ S p e c i a l ~ N e e d s ~ o r ~}$ Temporary Care agreements or being given family support but not in care. There were more males than females and more than twice as many youths as children in care. Of the CAS clients, 14 were living independently, approximately half $(49.1 \%)$ were in CAS residences, three-fifths were male (58\%) and three-quarters were youths $(\mathbf{7 3 . 4 \% )}$. 


\section{Bisks and Needs}

Clients were described in terms of sex, age, risk factors, needs, criminal acts and behavioral disorders, and the number of previous placements.

Client Risk Factors (CRF) included 32 family and personal variables that increased the probability of future problems according to past research (Appendix 6, Part C). Risk and protective factor scores were described above. Risk factor scures were not significantly different for sex but were higher for youths, ages 12 to 17 , than for children ages five to 11 (Table 4). Protective factor scores were not different for either sex or age. Risk factor scores varied significantly across types of programmes (Table 5). Risk scores were similar for Group, Child Welfare and Treatment Agency homes, lower for inpatient psychiatry and higher for Maternity and Custody homes. Total protective scores were not significantly different across programmes although they were highest for maternity and lowest for custody.

Three need scores described above were presenting problems, programme needs and total needs. Presenting problems were the perceived needs that had led to clients being referred to the residence. Programme needs were those risks that might be reduced by appropriate programmes. Programme needs included reducing gang membership and running away, and increasing getting along with others, school achievement, friendships and hobby skills and participation. The prosramme need items are noted in Appendix 6, Part C. Total needs were presenting problems plus programme needs. 


\begin{tabular}{|c|c|c|c|c|c|c|c|}
\hline & & Homer" & Welfare & Homes & Psychiatry & & Agenciest \\
\hline Agencie: & 24 & 13 & 1 & 3 & & 2 & 5 \\
\hline Residences & 59 & 16 & 21 & 3 & & 3 & 16 \\
\hline English Only & 31 & 11 & 14 & 1 & & 0 & 5 \\
\hline Bilingual & 24 & 4 & 5 & 2 & & 3 & 10 \\
\hline French Only & 4 & 1 & 2 & 0 & & $\mathbf{0}$ & I \\
\hline
\end{tabular}

- Open Custody: Clients were in 15 group homes and treatment agency residences.

- Secure Custody: Clients were in two tesidences opented by two egencies. 


\begin{tabular}{|c|c|c|c|c|c|c|c|}
\hline \multicolumn{8}{|c|}{ Type of Programme: } \\
\hline & Totals & $\begin{array}{l}\text { Group } \\
\text { Homes }\end{array}$ & $\begin{array}{l}\text { Child } \\
\text { Welfire }\end{array}$ & $\begin{array}{l}\text { Matemity } \\
\text { Homes }\end{array}$ & $\begin{array}{l}\text { Inputient } \\
\text { Psychintry }\end{array}$ & $\begin{array}{l}\text { Treatment } \\
\text { Agencies }\end{array}$ & Custody \\
\hline \multicolumn{8}{|l|}{ Clients } \\
\hline Total & 411 & 74 & 113 & 15 & 70 & 102 & 37 \\
\hline Missing & 30 & 5 & 0 & $\mathbf{0}$ & 25 & 0 & 0 \\
\hline \multicolumn{8}{|l|}{ Sex } \\
\hline Male & 227 & 42 & 65 & 0 & 25 & 67 & 28 \\
\hline Female & 154 & 27 & 48 & 15 & 20 & 35 & 9 \\
\hline \multicolumn{8}{|l|}{ Longuage } \\
\hline French & 63 & 10 & 28 & 0 & 0 & 21 & 4 \\
\hline English & 318 & 59 & 85 & 15 & 45 & 81 & 33 \\
\hline CAS Clients: & 224 & 46 & 110 & 1 & 9 & 41 & 17 \\
\hline
\end{tabular}

- All missing clients were from one group home and one hospital.

- 4 CAS clients were living independently. 
The mean number of presenting problems was similar for age and sex. Across programmes mean presenting problems were lowest for child welfare, moderate for group and maternity homes and inpatient psychiatry and highest for treatment and custody homes. Programme needs were highest for treatment and custody. When programme needs were arided, client total need scores were similar for females and males but were higher for youths than children (Table 4). Total need scores varied significantly across types of programmes (Table 5) but were similar for all except treatment and custody homes, which were higher than the others.

Two other measures may be related to risks of future problems and to treatment outcomes, the number of criminal acts reported and the number of previous out-of-home placements. Males and youths had significantly higher mean numbers of criminal acts than females and children (Table 4). Criminal acts varied significantly across programmes (Table 5) but were similar across all types of centres except, as expected, for those in custody.

The mean number of previous placements in residences was 4.9 (Table 5). The number was similar for sex and age but varied significantly across programmes (Table 5). It was highest in maternity homes and inpatient psychiatry and lowest in child welfare. 
Table 4: Mean Risk Factors By Sex \& Age

\begin{tabular}{|c|c|c|c|c|c|c|c|c|}
\hline & $\begin{array}{l}\text { Femules } \\
n=124\end{array}$ & $\begin{array}{l}\text { Male: } \\
n=197\end{array}$ & Signif. & Enn & $\begin{array}{l}\text { Children } \\
n=106\end{array}$ & $\begin{array}{l}\text { Youth } \\
n=215\end{array}$ & sig. & $E^{2}$ \\
\hline Toul Protective & 4.0 & 3.7 & $n:$ & .00 & 4.1 & 3.7 & $n:$ & .01 \\
\hline Total Risk & 1.3 & 1.2 & $n:$ & .01 & .4 & 1.7 & 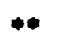 & .02 \\
\hline Presenting & 8.1 & 8.8 & $n=$ & .01 & 8.1 & 8.8 & $n:$ & .01 \\
\hline \multicolumn{9}{|l|}{ Problems } \\
\hline Programme & 12.8 & 12.6 & $n:$ &.$\infty$ & 11.9 & 13.1 & $+\infty$ & .04 \\
\hline \multicolumn{9}{|l|}{ Needa } \\
\hline Total & 21.4 & 20.9 & $n:$ & .00 & 20.0 & 21.9 & $*$ & .02 \\
\hline \multicolumn{9}{|l|}{ Needs } \\
\hline Criminal & 4.0 & $4 . t$ & $n:$ & .01 & 3.9 & 4.6 & $* *$ & .02 \\
\hline No. Placements & 4.9 & 5.0 & $n s$ & .00 & 4.9 & 4.9 & $n:$ & .01 \\
\hline
\end{tabular}

- Significance $p<.05=*, p<.01=* *, p<.001=* * *$. 
Table 5: Mean Risk Factora By Programmes

\begin{tabular}{|c|c|c|c|c|c|c|c|c|c|}
\hline & $\begin{array}{l}\text { Toul } \\
n=321\end{array}$ & $\begin{array}{l}\text { Growp } \\
\text { Homes } \\
n=69\end{array}$ & $\begin{array}{l}\text { Child } \\
\text { Welfare } \\
n=112\end{array}$ & $\begin{array}{l}\text { Malemity } \\
\text { Homes } \\
n=14\end{array}$ & $\begin{array}{l}\text { Inpatient } \\
\text { Paychiatry } \\
n=40\end{array}$ & $\begin{array}{l}\text { Treatment } \\
\text { Agencies } \\
n=60\end{array}$ & $\begin{array}{l}\text { Cuatody } \\
n=26\end{array}$ & Sig: & En $^{2}$ \\
\hline Total & 3.8 & 3.8 & 3.9 & 4.8 & 4.0 & 3.8 & 2.7 & $n:$ & .02 \\
\hline \multicolumn{10}{|l|}{ Protective } \\
\hline Total Risk & 1.3 & 1.2 & 1.0 & 2.0 & -.6 & 1.5 & 4.5 & *+* & .08 \\
\hline Presenting & 8.5 & 8.1 & 7.2 & 9.0 & 8.5 & 10.0 & 11.7 & $* * \bullet$ & .12 \\
\hline \multicolumn{10}{|l|}{ Problems } \\
\hline Programme & 12.7 & 12.1 & 12.7 & 12.7 & 12.1 & 13.1 & 14.5 & 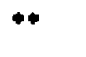 & .04 \\
\hline \multicolumn{10}{|l|}{ Needs } \\
\hline Tolal Needs & 21.2 & 20.2 & 19.9 & 21.1 & 20.6 & 23.1 & 26.2 & $\infty$ & .10 \\
\hline Criminal & 4.3 & 3.7 & 4.5 & 3.1 & 3.9 & 4.0 & 6.7 & $*+*$ & .14 \\
\hline \multicolumn{10}{|l|}{ Acts } \\
\hline No. of & 4.9 & 5.2 & 4.1 & 6.4 & 6.3 & 4.7 & 5.1 & $+4 *$ & .23 \\
\hline \multicolumn{10}{|l|}{ Previous } \\
\hline Placements & & & & & & & & & \\
\hline
\end{tabular}

- Significnnce $p<.05=*, p<.01=*, p<.001=* \cdots$. 


\section{Behaviour Disorders}

The behaviour problems of clients were reported by front-line staff using the CBC-R for English-speaking clients and the CBC for French-speaking clients. Both checklists were used to list criminal acts and scored according to the six OCHS categories of conduct, hyperactivity, emotional, somatization, externalizing and internalizing disorders.

The CBC-R was scored according to the DSM categories of conduct, oppositional, attention deficit, overanxious, separation anxiety, depressive, externalizing and internalizing disorders.

OCHS and DSM disorder scores for sex and age were similar in some ways (Table 6). For both, total disorder scores were not significantly different for females and males or children and youth. Also, for all OCHS and DSM scores there were no significant differences between children and youth. All OCHS disorder scores were significantly different, however, for females and males (Table 6). The highest mean disorder score was conduct for both OCHS and DSM categories. Males had higher mean scores for OCHS externalizing disorders of conduct and hyperactivity and females were higher for OCHS internalizing disorders of emotion and somatization. This difference between mean disorder scores of males and females is the same in all types of programmes (Table 8). Similarly, DSM mean scores were higher for males for externalizing and conduct disorders and for females for internalizing, separation anxiety, and depressive disorders. There were no significant differences between males and feriales for mean DSM externalizing, oppositional, attention deficit, and overanxious disorders scores. 
There were also some similarities when OCHS and DSM mean scores were compared across programmes (Table 9). The rank order for programmes of both for mean externalizing and conduct disorders scores were similar. They were lowest for maternity homes, and hospitals, moderate for group homes and child welfare and highest for treatment and custody homes. OCHS mean hyperactivity was low for maternity, moderate for group homes, child welfare and hospitals and highest for treatment and custody homes. DSM mean attention deficit was similar for all centres except for custody, which was higher. DSM mean oppositional disorder was lowest for maternity, highest for custody and moderate for all others.

The rank order for programmes for OCHS and DSM mean internalizing disorder scores were different. For OCHS mean internalizing scores, custody scores were lowest, group, child welfare and maternity moderate and hospital and treatment homes highest. For DSM mean internalizing, overanxious, separation anxiety and depressive disorder scores, all programmes were similar. For OCHS mean emotional scores, maternity homes were lowest, group, child welfare and custody next highest, hospitals higher and treatment homes highest. For OCHS mean somatization scores, custody was lowest, group homes, child welfare and hospitals moderate and maternity and treatment homes highest.

Table 8 shows that mean externalizing scores were higher for males than for females for all programmes and higher for CAS clients than for non-CAS clients for all programmes except maternity. Mean internalizing disorder scores were lower for males than for females and for CAS clients than for non-CAS clients for all programmes. 
Table 6: Behaviour Disorden By Sex Age $(n=378)$

\begin{tabular}{|c|c|c|c|c|c|c|}
\hline $\begin{array}{l}\text { Females } \\
n=154\end{array}$ & $\begin{array}{l}\text { Males } \\
n=224\end{array}$ & Sig.: & $\mathbf{E} \boldsymbol{w}^{2}$ & $\begin{array}{l}\text { Children } \\
n=108\end{array}$ & $\begin{array}{l}\text { Youth } \\
n=270\end{array}$ & Sig. \\
\hline
\end{tabular}

Ontario Child Health Study Calegories: Mean Scores

$n=378$ (misuing $=3$ )

\begin{tabular}{|c|c|c|c|c|c|c|c|c|}
\hline Conduct & 8.6 & 12.7 & $+*$ & .07 & 10.6 & 11.2 & $n$ &.$\infty$ \\
\hline Hyperactivity & 4.5 & 6.2 & $* * *$ & .05 & 6.2 & 5.2 & $n=$ & .01 \\
\hline Emotional & 9.3 & 7.7 & $\bullet$ & .02 & 8.2 & 8.4 & $n:$ & .00 \\
\hline Somatization & 2.9 & 1.7 & $\bullet \bullet$ & .05 & 1.5 & 2.5 & $n=$ & .02 \\
\hline Extermalizing & 13.3 & 18.8 & $\bullet \bullet$ & .08 & 16.9 & 16.4 & $n:$ & .00 \\
\hline Intemalizing & 12.3 & 9.4 & $\infty+$ & .04 & 9.6 & 10.9 & $n=$ & .00 \\
\hline Toul Score & 25.4 & 28.2 & $n:$ & .00 & 26.5 & 27.3 & $n:$ & .00 \\
\hline
\end{tabular}

DSM III-R Disorders: Percentile Scores

$\mathrm{n}=294$ (missing $=87 \mathrm{Y}$

\begin{tabular}{|c|c|c|c|c|c|c|c|c|}
\hline & $n=130$ & $n=164$ & & & $\mathrm{n}=70$ & $n=224$ & & \\
\hline Conduct & 68.5 & 77.3 & $\infty$ & .06 & 73.6 & 73.4 & $n:$ & .00 \\
\hline Oppositional & 61.8 & 62.5 & $n:$ & .00 & 62.9 & 62.0 & $n:$ & .00 \\
\hline Attention Deficit & 57.0 & 58.9 & $n=$ & .00 & 58.9 & 57.8 & $n$ & .00 \\
\hline Overanxious & 57.7 & 54.1 & $n$ & .01 & 52.9 & 56.6 & $n:$ & .00 \\
\hline Separation Anxiety & 60.1 & 53.7 & $++\infty$ & .05 & 57.2 & 56.3 & $n:$ & .00 \\
\hline Depresesive & 59.7 & 53.7 & $* *$ & .06 & 54.6 & 56.9 & $n=$ & .00 \\
\hline Externalizing & 66.4 & 70.6 & $n=$ & .01 & 68.4 & 68.8 & n: & .00 \\
\hline Intermalizing & 62.9 & 55.7 & 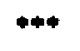 & .06 & 57.6 & 59.3 & $n:$ & .00 \\
\hline Total Score & 60.8 & 60.1 & $n \mathrm{~s}$ & .00 & 60.0 & 60.5 & $n:$ & .00 \\
\hline
\end{tabular}

- Significance $p<.05=\bullet, p<.01=\cdots, p<.001=\cdots *$.

- French CBC checkliats could not be scored for DSMIII-R calegories. The CBC-R had not yet been tranalated at the time of the stu 
Table 7: Beheviour Dieorders By Programmes

\begin{tabular}{|c|c|c|c|c|c|c|c|c|c|}
\hline & $\begin{array}{l}\text { Total } \\
n=381\end{array}$ & $\begin{array}{l}\begin{array}{l}\text { Group } \\
\text { Homes }\end{array} \\
\mathrm{n}=69\end{array}$ & $\begin{array}{l}\begin{array}{l}\text { Child } \\
\text { Welfare }\end{array} \\
n=113\end{array}$ & $\begin{array}{l}\text { Malemity } \\
\text { Homes } \\
n=15\end{array}$ & $\begin{array}{l}\text { Inpatient } \\
\text { Paychiatry } \\
n=45\end{array}$ & $\begin{array}{l}\text { Treatment } \\
\text { Agencies } \\
n=102\end{array}$ & $\begin{array}{l}\text { Open } \\
\text { Clowed } \\
\text { Custody } \\
n=37\end{array}$ & Sig.: & $E n^{2}$ \\
\hline \multicolumn{10}{|c|}{$\begin{array}{l}\text { Ontario Child Health Study Calegories: Mean Senres } \\
\qquad n=378 \text { (misuing }=3 \text { ) }\end{array}$} \\
\hline Conduct & 11.0 & 9.6 & 10.4 & 6 & 7.2 & 14.9 & 16.5 & $+\infty$ & .14 \\
\hline Hyperectivily & 5.5 & 5.1 & 4.9 & 3.7 & 4.8 & 6.6 & 6.6 & $\infty$ & 08 \\
\hline Emotional & 8.4 & 7.2 & 7.2 & 6.6 & 8.5 & 11.0 & 7.4 & $\cdots$ & .10 \\
\hline Somatization & 2.2 & 2.1 & 1.7 & 2.8 & 2.2 & 3.2 & 1.1 & + & .05 \\
\hline Extemalizing & 16.5 & 14.7 & 15.3 & 9.7 & 12.0 & 19.9 & 23.0 & $\omega+\infty$ & .13 \\
\hline Internalizing & 10.6 & 9.3 & 8.9 & 9.4 & 10.7 & 14.1 & 8.5 & 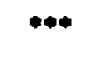 & .09 \\
\hline $\begin{array}{l}\text { Toul Score } \\
\text { Diucrders }\end{array}$ & 27.1 & 24 & 24.2 & 19.1 & 22.7 & 34.1 & 31.6 & $\cdots$ & .12 \\
\hline \multicolumn{10}{|c|}{$\begin{array}{l}\text { DSM III-R Disonders: Percentile Score: } \\
294 \text { (missing }=87 \mathrm{~V}\end{array}$} \\
\hline Conduct & 73.4 & 72.5 & 73.7 & 59.7 & 66.6 & 77.4 & 83.9 & $\bullet$ & .10 \\
\hline Oppositional & 62.2 & 60.9 & 63.7 & 61.0 & 59.7 & 58.9 & 69.8 & $\mathrm{n}:$ & .05 \\
\hline $\begin{array}{l}\text { Attention } \\
\text { Deficit }\end{array}$ & 58.0 & 58.4 & 58.9 & 55.7 & 55.1 & 56.1 & 63.4 & ns & .03 \\
\hline Overanxious & 55.7 & 56.5 & 53.1 & 57.3 & 59.2 & 59.0 & 51.1 & n s & .01 \\
\hline $\begin{array}{l}\text { Separntion } \\
\text { Anxiety }\end{array}$ & 56.5 & 57.5 & 54.8 & 56.7 & 57.0 & 63.8 & 57.6 & $\mathrm{~ns}$ & .01 \\
\hline Depressive & 56.4 & 55.6 & 55.8 & 56.0 & 60.1 & 57.1 & 55.5 & ns & .02 \\
\hline Extermalizing & 68.7 & 67.5 & 69.3 & 62.7 & 63.0 & 68.5 & 80.3 & $\bullet$ & .07 \\
\hline Internalizing & 58.9 & 60.1 & 56.7 & 59.7 & 63.7 & 58.2 & 57.2 & n s & .03 \\
\hline $\begin{array}{l}\text { Toul Mean } \\
\text { Disonder }\end{array}$ & 60.4 & 60.3 & 59.8 & 57.7 & 59.8 & 60.9 & 63.5 & ns & .01 \\
\hline
\end{tabular}

- Significance $p<.01=\cdots, \quad p<.001=\cdots \cdots$

- French CBC checkliats could not be scored for DSMIII-R categories. The CBC-R had not yet been tranalated at the time of the audy. 
Table 8: Baheviour Disonders By Sex, CAs Cliento \& Programmes

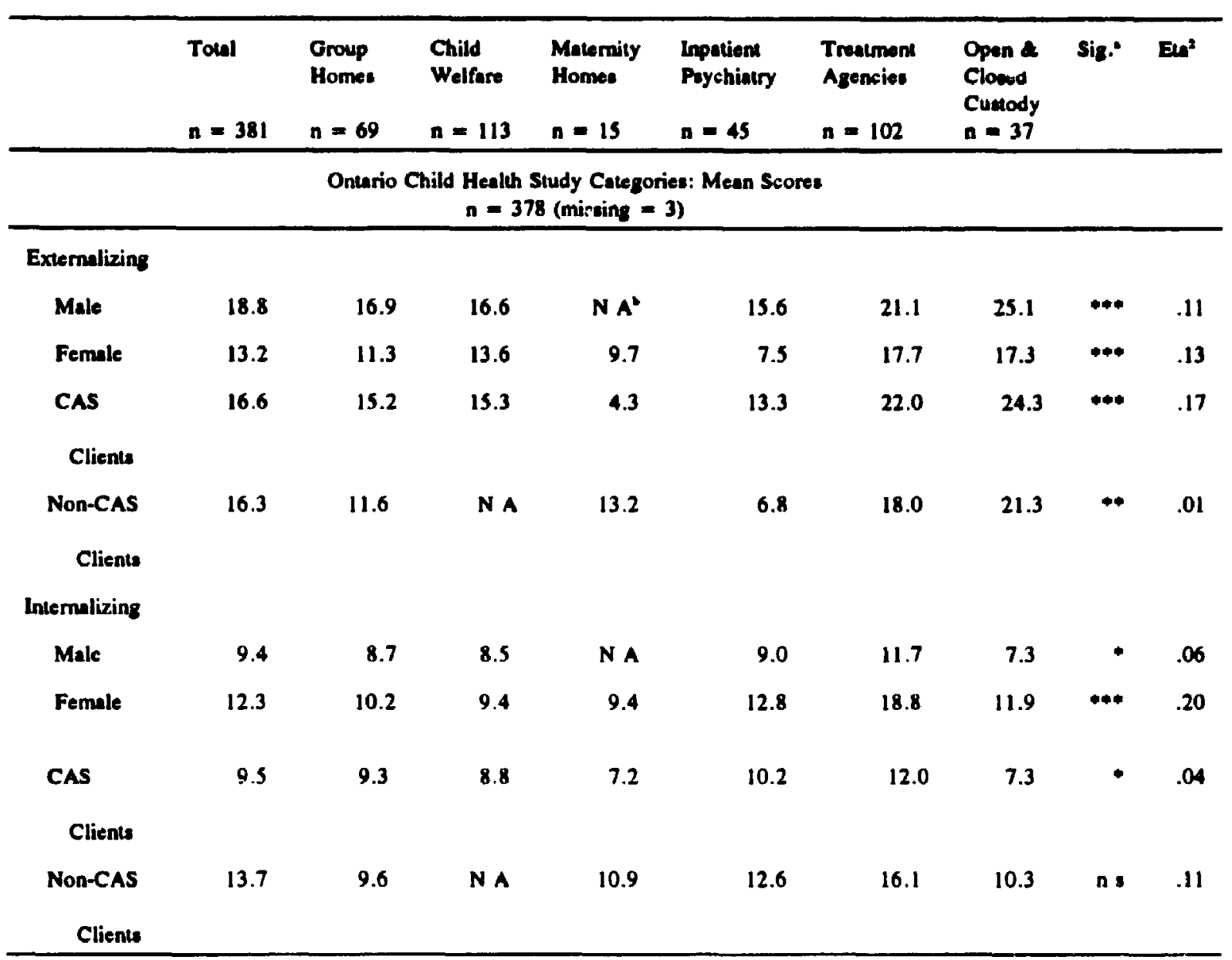

Significance $p<.01=* *, p<.001=* * *$.

- $\quad$ N A $=$ Not applicable. 


\section{Residences}

$=$ aff

The percentage of Child and Youth Counsellors with a CYC Diploma was calculated for each residence (Table 9). The percentage of CYC with diplomas was significantly different across programmes. It was lowest for maternity and custody and was moderate for others, except inpatient psychiatry, where all CYC had diplomas.

\section{Propramme}

Programmes were assessed with the Programme Evaluation Inventory (PEI, Appendix 3). PEI scores were obtained from only eight of the largest agencies that operated 40 residences. This sample did not include any group homes. Too few clients were included in custody $(n=8)$ and maternity $(n=2)$ programmes to be representative. Therefore, results are reported from only six agencies, three types of programmes and 38 agencies (client $n=248$ ). All mean PEI scores varied significantly across programmes.

The programme process was evaluated by the perceived social environment of each residence measured by the COPES (Appendix 4). All mean COPES scores varied significantly across programmes. Mean COPES scores were converted to percentile staff norms reported by Moos (1974b). All percentile scores were above the reported staff mean, except autonomy, which was at the 34 th percentile. 
Table 9: CYC Education by Programme:

\begin{tabular}{|c|c|c|c|c|c|c|c|c|c|}
\hline CYC & $\begin{array}{l}\text { Total } \\
n=393\end{array}$ & $\begin{array}{l}\text { Group } \\
\text { Homes } \\
n=97\end{array}$ & $\begin{array}{l}\text { Child } \\
\text { Welfore } \\
n=90.5\end{array}$ & $\begin{array}{l}\text { Maternity } \\
\text { Homes } \\
n=13\end{array}$ & $\begin{array}{l}\text { Inpatient } \\
\text { Psychiatry } \\
n=15\end{array}$ & $\begin{array}{l}\text { Treatment } \\
\text { Agencies } \\
n=159.5\end{array}$ & $\begin{array}{l}\text { Cuntody } \\
n=18\end{array}$ & Sig." & $E u^{2}$ \\
\hline $\begin{array}{l}\text { Percentage } \\
\text { Diploma CYCs }\end{array}$ & 56.7 & 68.4 & 60.6 & 29.4 & 100 & 43.8 & 28.5 & $* *$ & .36 \\
\hline
\end{tabular}


All mean COPES scores varied significantly across programmes. Some differences across programmes were large. Maternity homes were higher than all others on involvement, spontaneity, autonomy, personal problem orientation and anger and aggression. Treatment agencies were highest on support and on programme clarity, inpatient psychiatry was highest on staff control and custody homes were highest on practical orientation.

Programme/Client Matches

Each of the presenting problems was matched with available services that might help in reducing the problem (Appendix 8). Then the percentage of problem/service matches out of the possible number of matches was calculated for each client.

Most clients appeared to have available appropriate services for their reeds. Approximately two-thirds of the clients had over $90 \%$ of their problems matched and only 10.4 per cent of clients had less than two-thirds of their problems matched (Table 12). There were no significant differences between percentages of matches for females and males and for children and youths. The percentage of matches was significantly higher for intervention than for care programmes. There were significant differences among the six types of programmes with the fewest matches in maternity homes. Programmes for French-speaking clients had significantly fewer matches of services and problems than did English programmes. The 10.4 per cent of clients with the fewest services for their problems were investigated individually during interviews with supervisors. Supervisors reported that there were insufficient services for natives, recent immigrants, and female youths as well as for Francophones and young mothers. 
Table 10: PEI Programme Evaluation Scores By Programmes

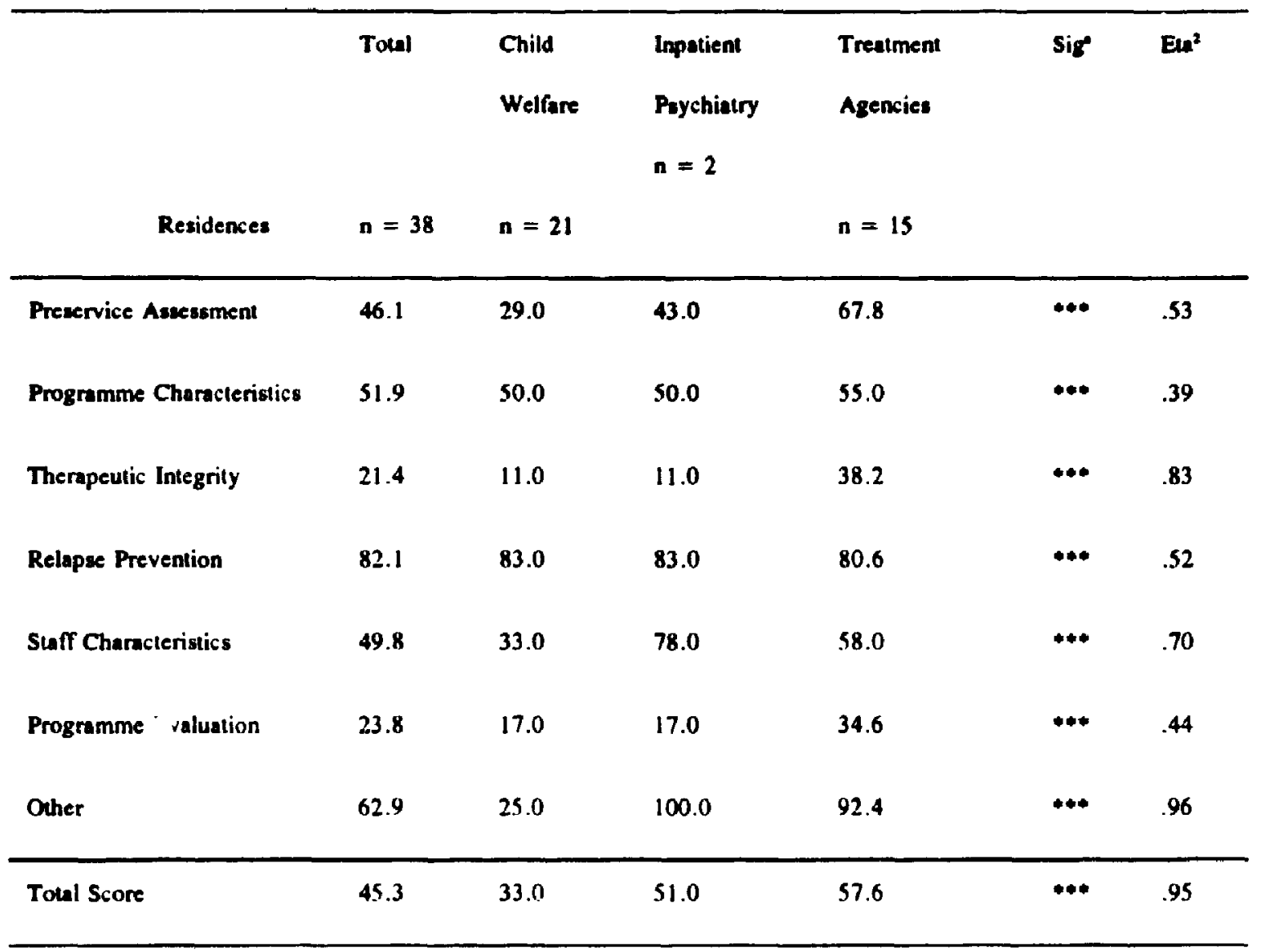

- All differences across programmes were significant $(p<.001)$. 
Table 11: Mean COPES Environment Scores \& Programmes -

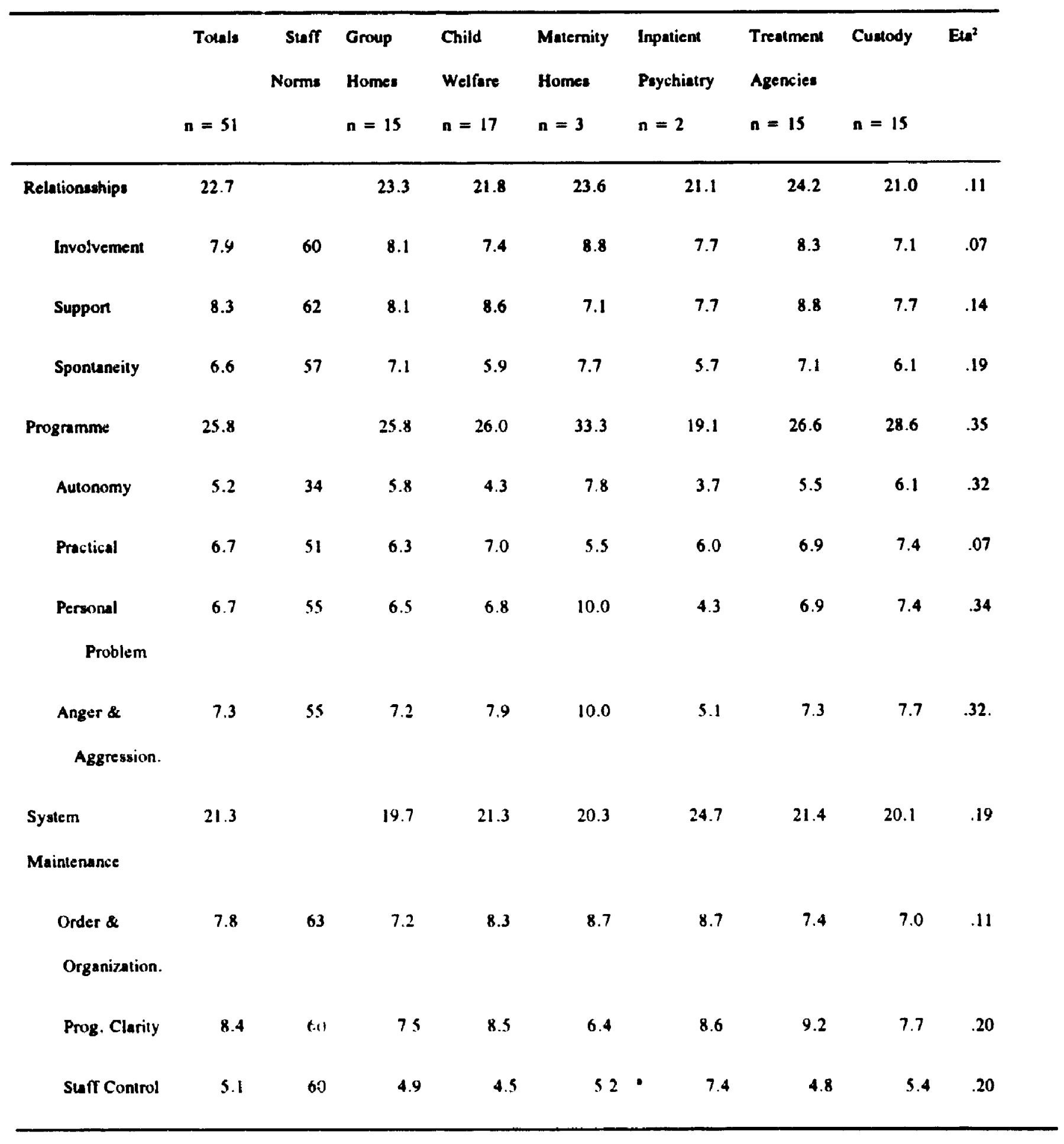

- All differences across programmes were significant $(p<.001)$.

- Missing data from 7 residences- 4 Child Welfare, 1 Treatment, 1 Inpatient Psychiatry and 1 Closed Custody. 
Table 12: Pereenlages of Matches in Service \& Presenting Problems

\begin{tabular}{|c|c|c|c|c|c|c|}
\hline $\begin{array}{l}\text { Matches } \\
\text { Cliente }\end{array}$ & & $\begin{array}{c}<50 \% \\
3.2\end{array}$ & $\begin{array}{c}50-66 \% \\
7.2\end{array}$ & $\begin{array}{c}67-90 \% \\
23.4\end{array}$ & $\begin{array}{c}>90 \% \\
66.2\end{array}$ & \\
\hline \multicolumn{3}{|c|}{ Care Programmes } & \multicolumn{3}{|c|}{ Intervention Programme: } & \\
\hline \multicolumn{3}{|c|}{85.0} & \multicolumn{3}{|c|}{93.1} & \\
\hline $\begin{array}{l}\text { Group } \\
\text { Homes } \\
\mathrm{n}=69\end{array}$ & $\begin{array}{l}\text { Child } \\
\text { Welfore } \\
n= \\
113\end{array}$ & $\begin{array}{l}\text { Matemity } \\
\text { Homes } \\
n=15\end{array}$ & $\begin{array}{l}\text { Inpaticnt } \\
\text { Paychistry } \\
n=45\end{array}$ & $\begin{array}{l}\text { Treatment } \\
\text { Agencies } \\
n=102\end{array}$ & $\begin{array}{l}\text { Open \& } \\
\text { Closed } \\
\text { Cuntody } \\
n=37\end{array}$ & Sig." \\
\hline \multirow[t]{3}{*}{83.3} & 87.1 & 76.2 & 100 & 90.4 & 89.1 & $+\infty$ \\
\hline & French & & & English & & \\
\hline & 80.9 & & & 89.8 & & $+4 *$ \\
\hline
\end{tabular}

\footnotetext{
- Significance $p<.05=*, p<.01=*, p<.001=* * *$.
} 


\section{Phase Two: Predictors of Outcomes}

The purpose of the study was to find predictors (a) of where clients lived and (b) of client behaviour following residential child care or intervention programmes. To do this, the variables of Phase One were compared with the outcomes of Phase Two. These comparisons tested the seven hypotheses listed above and explored other possible relationships.

\section{Placement Outcomes}

The mean percentage of successful placement days was calculated by sex, children and youth, and type of agency (Tables 13 and 14). A higher mean percentage of successful days was found for children than for youth. Percentages were related to the type of Phase One programme. The highest mean percentage of successful days was after group homes and the lowest percentage after custody programmes. The mean percentage of successful placement days by programmes (in Table 13) was in the same rank order as the rank order of externalizing disorder by programmes (Table 7) except inpatient psychiatry. Psychiatry was in the middle ranking for successful placement days but lowest in mean externalizing disorders. It was the second highest in internalizing disorders, however. 
Table 13: Mean Percentage of Successful Placements Days by Client Variables

\begin{tabular}{|c|c|c|c|c|c|c|}
\hline & & & Mean & S D & sig." & $\mathbf{E w}^{2}$ \\
\hline Toul & & 224 & 70 & 37 & & \\
\hline \multicolumn{7}{|l|}{$\operatorname{sex}$} \\
\hline & Male & 130 & 66.9 & 36.7 & & \\
\hline & Femule & 94 & 73.8 & 32.4 & $n:$ & .01 \\
\hline \multicolumn{7}{|l|}{ Age } \\
\hline & Children 5-11 & 59 & 81.4 & 35.2 & & \\
\hline & Youth $12-17$ & 165 & 65.6 & 36.4 & 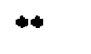 & .04 \\
\hline \multicolumn{7}{|c|}{ Total Risk Score } \\
\hline & Low & 96 & 77 & 34 & & \\
\hline & High & 114 & 66 & 38 & $*$ & .01 \\
\hline \multicolumn{7}{|c|}{ Externalizing } \\
\hline \multicolumn{7}{|c|}{ Diworder } \\
\hline & Low & 106 & 81.8 & 30.0 & & \\
\hline & High & 116 & 60.0 & 38.3 & $4 * 4$ & .09 \\
\hline \multicolumn{7}{|c|}{ Internalizing Disorder } \\
\hline & Low & 120 & 74.0 & 34.5 & & \\
\hline & High & 102 & 66.2 & 37.9 & n s & .01 \\
\hline
\end{tabular}

\footnotetext{
- Significance $p<.05=*, p<.01=*, p<.001=\cdots \cdots$
} 
Table 14: Mean Percenlage of Successful Placement Days by Programme Variables

\begin{tabular}{|c|c|c|c|c|c|c|}
\hline & & $n$ & Meen & S D & Sig: & $\mathbf{E n}^{2}$ \\
\hline Total & & 224 & 70 & 37 & & \\
\hline \multicolumn{7}{|l|}{ CYC Education } \\
\hline & Low & 88 & 54.5 & 40.0 & & \\
\hline & High & 98 & 78.0 & 33.0 & $* * *$ & .09 \\
\hline \multicolumn{7}{|l|}{ Programmes:- } \\
\hline \multirow[t]{2}{*}{ Two types } & Care & 157 & 83.6 & 25.7 & & \\
\hline & Intervention & 67 & 37.4 & 38.2 & $+\infty$ & .33 \\
\hline \multicolumn{7}{|l|}{ Six Types } \\
\hline & Group Homes & 46 & 91.4 & 20.5 & & \\
\hline & Child Welfare & 110 & 80.5 & 27.2 & & \\
\hline & Psychiatric & 9 & 66.7 & 50.0 & & \\
\hline & Trealment & 41 & 34.2 & 34.8 & & \\
\hline & Custody & 17 & 29.8 & 34.8 & 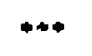 & .38 \\
\hline
\end{tabular}

CYC Education

- Signifi. $\quad .<\ldots,=*, p<.01=* *, p<.001=* * *$.

- Matemity was no! reported as only one client was also a CAS client with known placement. 


\section{Correlates or Placengerit}

Correlations were calculated between the Phase Two outcome of the percentage of successful placement days and Phase One client, worker, programme and match variables (Tables 15, 16 \& 17). Correlated client variables were being older, presenting problems, risk factors, programme needs, total needs, criminal acts (Table 15) and behaviour disorders (Table 16). Correlations with placement were calculated separately for children and youth because age was correlated with risks, programme and total needs and criminal acts (Table 15). For all except crime, correlations with placement were higher for youth than for children. Correlations of Phase One disorders with placement were significant for all OCHS and DSM III-R externalizing disorders (Table 16). The only internalizing disorder significantly correlated with placement was the OCHS emotional disorder. Correlations of Phase One disorders with placement were calculated separately for males and females because sex was correlated with disorders (Table 16). For externalizing disorder, correlations with placement were higher for males than females. Internalizing disorder was not correlated with placement for either males or females.

The correlated worker variable was the percentage of CYC with CYC diplomas (Table 17). Correlated programme variables were the type of agency (Table 17), PEI evaluation scores and COPES environmental scores (Tables 19 and 20). Client variables that were not correlated with placement were sex, number of previous placements, protective factors, OCHS somatization disorder and DSM III-R overanxious, separation anxiety, depression and internalizing disorders. 
Table 15: Correlations of Client Age, Sex \& Risk Factors With Outcomes

\begin{tabular}{|c|c|c|c|c|c|c|c|c|}
\hline & \multicolumn{4}{|c|}{ Placement } & \multicolumn{2}{|c|}{ Externalizing } & \multicolumn{2}{|c|}{ Intemalizing } \\
\hline & $\mathbf{n}$ & $\mathbf{r}$ & sig. & $\mathbf{n}$ & $\mathbf{r}$ & aige. & $\mathbf{r}$ & mig. \\
\hline Clients & 230 & & & 89 & & & & \\
\hline Being Older & & -.18 & $*$ & & -.14 & $n:$ & -.12 & n: \\
\hline Being Female & & .09 & ns & & -.21 & $n:$ & .17 & n: \\
\hline No. of Previous Placements & & -.06 & $n:$ & & -.00 & $n$ & -.13 & $n=$ \\
\hline Risks & 209 & & & 84 & & & & \\
\hline Prewenting Problem: & & -.39 & $\omega *$ & & .37 & $\omega *$ & .25 & $n:$ \\
\hline Total Protective & & .10 & $n=$ & & -.33 & $\bullet$ & -.14 & $n:$ \\
\hline Toul Risks & & -.16 & - & & .25 & n: & .09 & $\mathbf{n}:$ \\
\hline Children & & -.09 & n s & & .04 & n s & -.06 & ns \\
\hline Youth & & -.12 & ns & & .09 & ns & .04 & ns \\
\hline Program Needs & & -.23 & $++\infty$ & & .31 & $\cdots$ & .13 & ns \\
\hline Children & & -.07 & $\mathrm{~ns}$ & & .47 & +4 & .003 & $n:$ \\
\hline Youth & & -.24 & $*$ & & .29 & ns & .22 & $\mathbf{n} \mathbf{3}$ \\
\hline Total Needs & & -.38 & $\cdots *$ & & .38 & $* *$ & .22 & n: \\
\hline Children & & -.29 & ns & & .49 & $* *$ & -.07 & ns \\
\hline Youth & & -.39 & $\cdots$ & & .40 & $* \infty$ & .33 & $*$ \\
\hline Criminal Acts & 224 & -.31 & $+\infty *$ & 89 & .29 & $*$ & .09 & ns \\
\hline Children & & -.34 & $*$ & & .18 & ns & -.16 & n: \\
\hline Youth & & -.29 & $+* *$ & & .34 & $\cdots$ & .18 & ns \\
\hline
\end{tabular}

- Significance, $p<.05=*, p<.01=*, p<.001=* *$. 
Table 16: Correlations of Client Disorden with Outcomes

\begin{tabular}{|c|c|c|c|c|c|c|c|c|}
\hline & \multicolumn{3}{|c|}{ Plecement } & \multicolumn{3}{|c|}{ Externalizing } & \multicolumn{2}{|c|}{ Internalizing } \\
\hline & $\mathbf{n}$ & $r$ & sig. & $\mathbf{n}$ & $\mathbf{r}$ & sige. & $\mathbf{r}$ & vig. \\
\hline OCHS Dieorder Score: & 224 & & & 88 & & & & \\
\hline Conduct & & -0.35 & $* * *$ & & .48 & 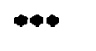 & .18 & $n:$ \\
\hline Hyperactivity & & -0.24 & $\infty$ & & .51 & $\infty$ & .24 & $n:$ \\
\hline Emotional & & -0.16 & +4 & & .09 & $n:$ & .42 & $+\infty$ \\
\hline Somatization & & -0.08 & $n$ & & .10 & $\mathrm{n}:$ & .26 & $* *$ \\
\hline Extemalizing & & -0.36 & 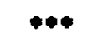 & & .53 & $\cdots *$ & .21 & $n$ \\
\hline Male & & -.36 & $\cdots * *$ & & .45 & 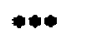 & .16 & $n:$ \\
\hline Fermale & & -.31 & +4 & & .57 & $\leftrightarrow \bullet$ & .32 & $n=$ \\
\hline Internalizing & & -0.09 & ns & & .03 & $n:$ & .40 & $n:$ \\
\hline Male & & -.14 & n: & & .002 & $n:$ & .30 & $n=$ \\
\hline Female & & -.19 & n $\mathbf{x}$ & & .19 & n: & .41 & $\cdots$ \\
\hline DSM III-R Diworder Scores & 173 & & & 66 & & & & \\
\hline Conduct & & -0.28 & $\bullet$ & & .50 & $* * *$ & .23 & n: \\
\hline Oppositional & & -0.24 & $\cdots$ & & .43 & $* * *$ & .22 & $n:$ \\
\hline Attention Deficit & & -0.20 & $*$ & & .46 & $\cdots+$ & .25 & ns \\
\hline Overanxious & & 0.03 & ns & & .09 & ns & .51 & $\infty$ \\
\hline Separation Anxiely & & 0.02 & ns & & .04 & ns & .27 & $\mathrm{~ns}$ \\
\hline Depression & & -0.08 & ns & & .03 & .n s & .37 & $* *$ \\
\hline Externulizing & & -0.31 & $+\infty$ & & .52 & $*+*$ & .26 & ns \\
\hline Internalizing & & 0.01 & ns & & .06 & $n:$ & .44 & 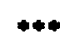 \\
\hline
\end{tabular}

- Significance, $p<.05=*, p<.01=*, p<.001=* *$. 
Table 17: Correlations of Residence Variables With Outcomes

\begin{tabular}{|c|c|c|c|c|c|c|}
\hline & \multirow{2}{*}{\multicolumn{2}{|c|}{ Piacement }} & \multirow{2}{*}{\multicolumn{2}{|c|}{$\begin{array}{l}\text { Extermalizing } \\
\text { Bchaviour }\end{array}$}} & \multirow{2}{*}{\multicolumn{2}{|c|}{$\begin{array}{l}\text { Inlernalizing } \\
\text { Behaviour }\end{array}$}} \\
\hline & & & & & & \\
\hline & $r$ & sig. & $\mathbf{r}$ & sig." & $\boldsymbol{r}$ & ais. \\
\hline Worker & \multicolumn{2}{|l|}{$n=183$} & \multicolumn{2}{|c|}{$n=75$} & & \\
\hline CYC education & 0.25 & $\infty$ & -.22 & n: & -.10 & $n:$ \\
\hline Children & -.05 & ns & -.39 & $\bullet$ & .07 & $n:$ \\
\hline Youth & .38 & $\infty \omega^{\infty}$ & -.23 & $n:$ & -.16 & $n:$ \\
\hline Agency & \multicolumn{2}{|l|}{$n=232$} & \multicolumn{2}{|c|}{$n=85$} & & \\
\hline Six Types: & -.56 & $\cdots$ & .01 & ns & -.10 & $n s$ \\
\hline \multicolumn{7}{|l|}{ Group Home to custody } \\
\hline Two Types: & -.57 & $\cdots$ & .28 & $*$ & .08 & ns \\
\hline \multicolumn{7}{|l|}{ Care va Intervention } \\
\hline Matches & $\mathrm{n}=203$ & & $n=7$ & & & \\
\hline Client Needs / Service & -.10 & ns & -.07 & n s & .04 & n s \\
\hline
\end{tabular}

- Significance, $p<.05=*, p<.01=*, p<.001=* *$. 
The programme variable not correlated with placement was service matches, the percentage of appropriate services available for each client's needs (Table 17). Some programme environment (COPES) scores and all programme evaluation (PEI) scores were correlated with Phase Two placements but many were in an unexpected direction. For many COPES and PEI measures higher scores were associated with lower percentages of successful placement days.

To understand better these unexpected negative relationships, programme scores were correlated with six types of programmes (Table $18 \& 20$ ). These correlations were very high for most PEI programme scores, except relapse prevention, which was not significantly related to the type of agency. After removing the effects of type of programme only four PEI scores remained significantly correlated with successful placement. These PEI scores were correlated highly with each other. For example, Preservice Assessment was correlated with Evaluation ( $r$ $=.85)$, and Relapse Prevention $(r=-.80)$ Staff $(r=.57)$ and Other $(r=.59)$. Seven out of ten COPES scores were moderately correlated with type of programme but after the effects of type had been removed none of them were significantly correlated with placement.

The only score that was significantly correlated with Phase Two behaviour was COPES autonomy. Higher scores on autonomy were associated with lower perrentages of successful days. 
Table 18: PEI Correlalions With Outcomes \& Programme Type

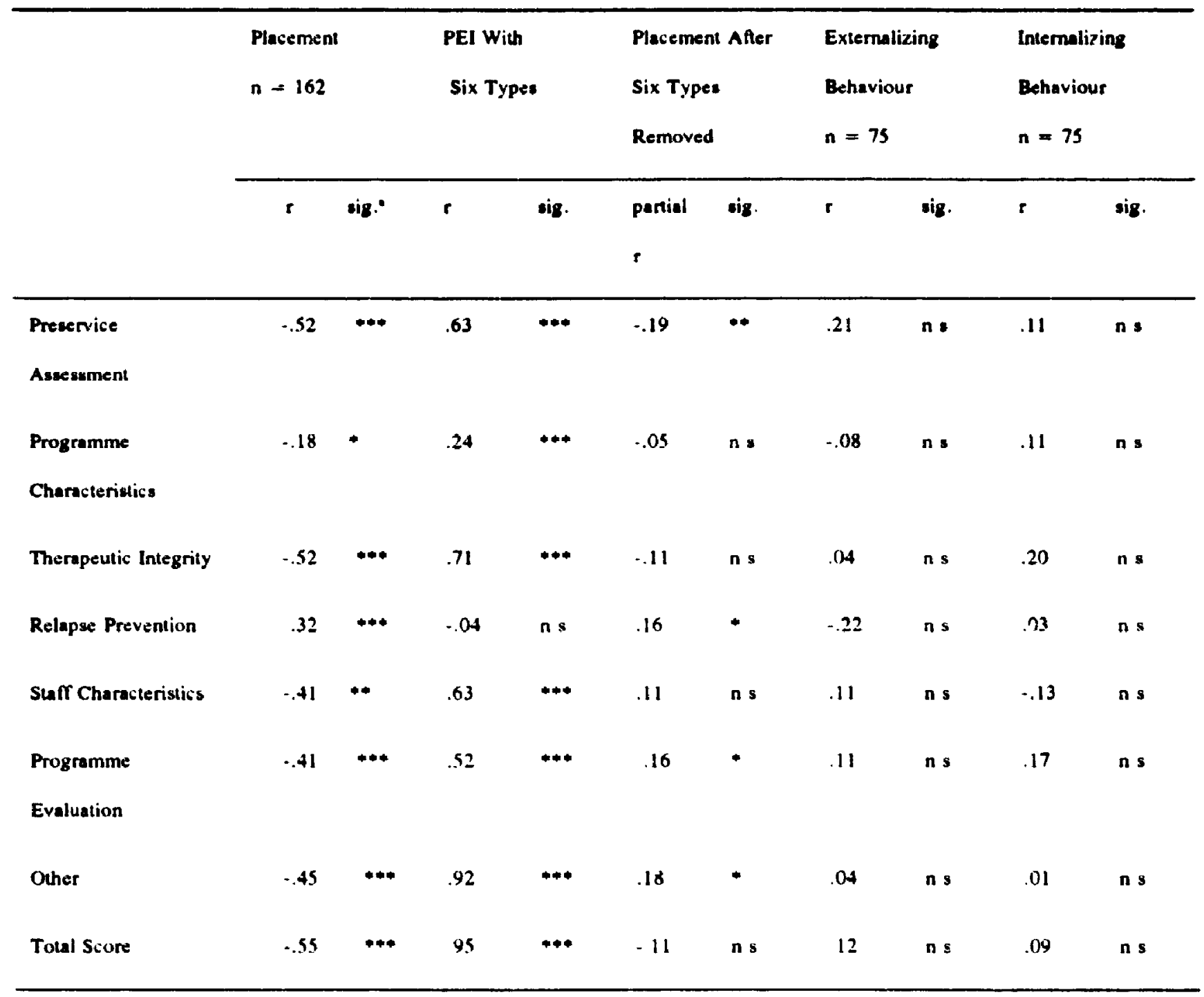

- Significance, $p<.05=* . p<.01=* *, p<.001=* *$. 

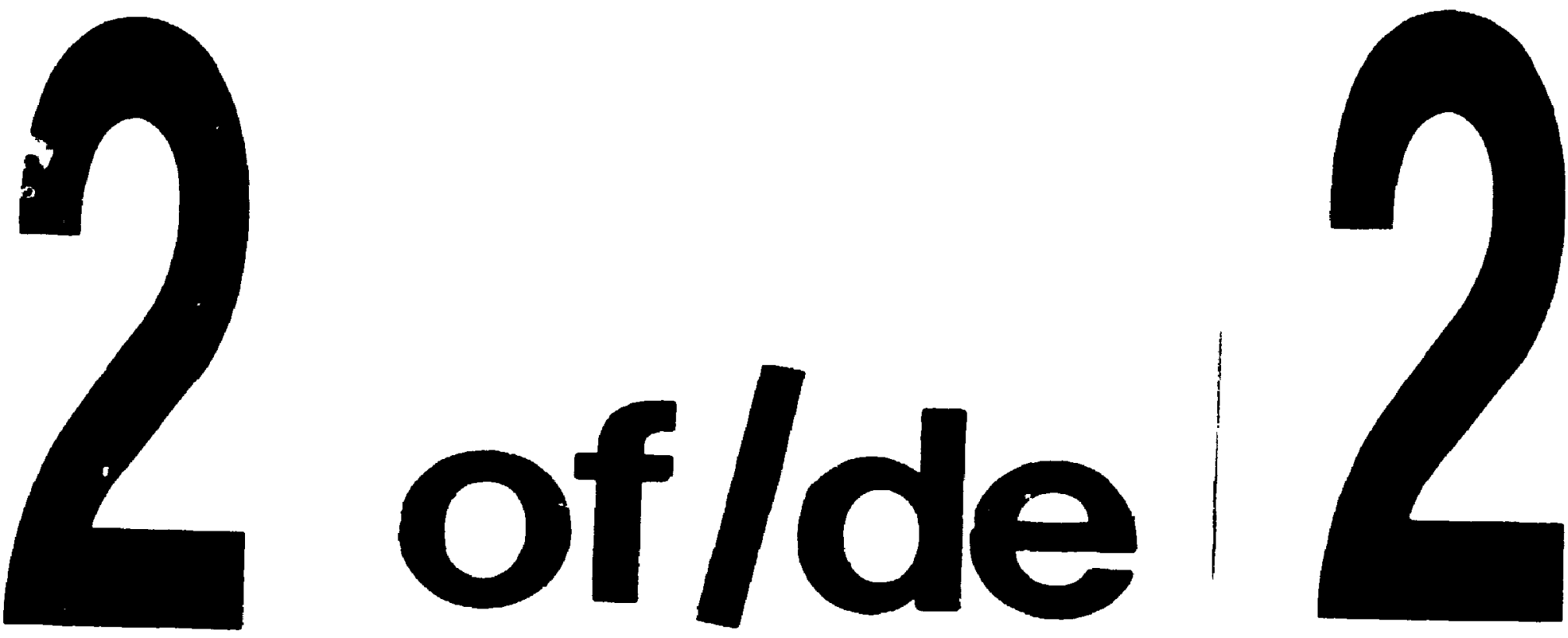

PM-1 3\%" X4" PHOTOGRAPHIC MICAOCOPY TARGET NBS 1010a ANSI/ISO *2 EOUIVALENT

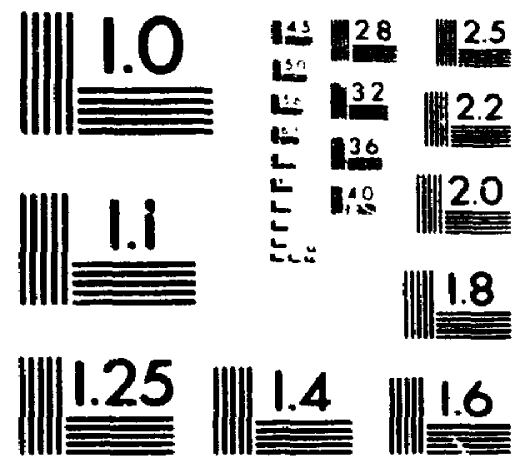

PAECISIONSM RESOLUTION TARGETS 
Table 19: COPES Correlations With Oulcomes

\begin{tabular}{|c|c|c|c|c|c|c|c|c|c|c|}
\hline & \multicolumn{2}{|c|}{$\begin{array}{l}\text { Placement } \\
n=196\end{array}$} & \multicolumn{2}{|c|}{$\begin{array}{l}\text { COPES With } \\
\text { Six Types }\end{array}$} & \multicolumn{2}{|c|}{$\begin{array}{l}\text { Plecement After } \\
\text { Six Types Removed }\end{array}$} & \multicolumn{2}{|c|}{$\begin{array}{l}\text { Externalizing } \\
\text { Behaviour } \\
\mathrm{n}=75\end{array}$} & \multicolumn{2}{|c|}{$\begin{array}{l}\text { Intemalizing } \\
\text { Beheviour } \\
\mathrm{n}=75\end{array}$} \\
\hline & $\mathbf{r}$ & sig: & $\mathbf{r}$ & sig. & partial $\mathbf{r}$ & sig & $\mathbf{r}$ & sig. & $\mathbf{r}$ & sig. \\
\hline Involvement & .14 & $*$ & .24 & $* *$ & .10 & ns & -.09 & $n s$ & -.03 & n s \\
\hline Suppent & .00 & ns & .004 & $\mathrm{n} \mathbf{s}$ & .003 & ns & -.09 & ns & .24 & ns \\
\hline Spontaneily & 0.5 & n s & .31 & $+\infty$ & .004 & ns & -.02 & ns & -.07 & n 8 \\
\hline Autonomy & -.02 & ns & .29 & $* * *$ & .02 & $n s$ & -.28 & $*$ & .03 & n: \\
\hline Practical Orientation & .11 & ns & -.10 & ns & .08 & ns & .03 & n s & -.05 & $n s$ \\
\hline Problem Orientation & -.13 & $*$ & -.09 & ns & -.03 & ns & -.03 & ns & -.04 & $n:$ \\
\hline Anger & .08 & ns & -.28 & $\cdots$ & 01 & ns &. .04 & ns & .03 & ns \\
\hline Order \& Organization & .18 & +4 & -.30 & $+\infty$ & 06 & n s & -.13 & $n:$ & -08 & ns \\
\hline Programme Clarily & -.06 & $\mathrm{~ns}$ & .23 & $* *$ & .08 & $n s$ & .17 & ns & .11 & n: \\
\hline Suff Control & -.11 & + & .18 & $*$ & -.000 & ns & .07 & ns & .03 & $\mathrm{~ns}$ \\
\hline
\end{tabular}

- Significance, $p<.05=*, p<.01=* *, p<.001=* *$. 


\section{Behaviour Outcomes}

\section{Sample Bias}

Completed CBC-R checklists were received from clients or parents of approximately one-third of the intervention agency clients (inpatient psychiatry and tr atment agencies) and from approximately one-quarter of the child care agency clients (CAS, group and maternity homes) Comparisons were made between responding anc non-responding clients on Phase One characteristics. Characteristics on which they were compared were sex, age, numbers of previous placements, presenting problems, risk factors, need, criminal acts, OCHS and DSM III$\mathbf{R}$ behaviour disorder scores.

For the child care agencies, there were no significant differences between respondents and non-respondents on any of the 23 variables except risk factors, where respondents had higher scores. For the intervention agencies, there were no differences on nine variables (sex, age, number of previous placements, OCHS hyperactivity, emotional, somatization, internalizing and total disorder scores and DSM III-R overanxious, separation anxiety, depression, internalizing and total disorder scores. There were significant differences in 14 variables (number of presenting problems, risk and need factors, criminal acts, OCHS conduct and externalizing disorder scores and DSM III-R conduct, opposition, attention deficit, externalizing and total disorder scores). In all significant differences the respondents' scores were higher than the scores of the non-respondents. 


\section{Correlates of Disorders}

Correlations were calculated between the outcome of Phase Two externalizing and internalizing behaviour disorder scores and client, worker and programme variables (Tables 16 to 20). Phase One client variables that were correlated with Phase Two externalizing disorder were presenting problems, programme and total needs, number of criminal acts, and all OCHS and DSM III-R externalizing disorders. Phase One client variables that were not correlated with Phase Two externalizing disorders were, being older, sex, number of previous placements, protective factors and OCHS and DSM III-R internalizing disorders (Tables 16 and 17). Correlations with disorders were calculated separately for children and youth because age was correlated with risks, programme and total needs and criminal acts (Table 15). For programme and total needs, the correlation with Phase Two externalizing disorder was higher for children than for youth For crime the correlation was higher for youth. The only significant risk or need correlation with Phase Two internalizing disorder was for total needs of youth. Correlations of Phase One disorders with Phase Two disorders are shown in Table 16. For disorders, only Phase One externalizing disorders were correlated with Phase Two externalizing disorder. Phase One internalizing disorders correlated with Phase Two internalizing disorder were OCHS emotional and somatization disorders and DSM III-R over-anxious, depression and internalizing disorders. Correlations of Phase One disorders with Phase Two disorders were calculated separately for males and females because sex was correlated with disorders (Table 15). For Phase One externalizing disorder, correlations with Phase Two externalizing disorder were higher for females than for males. Phase One internalizing disorder was correlated significantly with Phase Two internalizing disorder only for females. 
CYC education was not correlated with externalizing disorder except for children (Table 17). Programme variables correlated with Phase Two externalizing disorder were care vs. intervention and COPES autonomy. Programme variables not correlated with externalizing disorder were all other COPES scores, all PEI scores and six types of programmes. No worker and programme variables were correlated with Phase two internalizing disorder.

\section{Combined Predictors of Outcomes}

The present study was based on a multi-factor, snultilevel model (Figure 1, Hoge and Andrews, 1986). The model suggests that combinations of client, worker, programme and process factors are the best predictors of the outcomes of interventions. To analyze results using multiple regression, it was necessary to select a small number of factors, no more than onetwentieth of the number of cases (Tabachnik \& Fidell, 1983) for blockwise multiple regression analysis. No more than eleven possible predictors could be selected based upon the 224 cases for whom placement information was available. Missing information on each of the possible predictors limited the number of cases in each analysis

\section{Predictors of Placement}

The following process was used to select variables. First, correlations were calculated among Phase One variables and between each variable and the outcome of percentage of successful placement days. When several variables were similar in meaning and highly correlated with each other, one was selected that was the most independent of the other variables. Some variables were selected to test findings of previous studies.

The client total risk factor score was used because it included protective scores. Other risk scores of presenting problems, programme need and total need scores and criminal acts were 
dropped because they were highly corielated with each other and with OCHS externalizing disorder. Among client behaviour factors OCHS and DSM III-R behaviour disorder classifications were based upon many of the same items and were highly correlated (OCHS \& DSM III-R externalizing disorders, $r=91$ ). Because the $C B C$ had not been translated, DSM III-R scoring was only available for English-speaking clients. Therefore, OCHS scores were used as predictors. Because all programme measures were highly correlated with the type of agency, selection was based upon partial correlations after agency type was removed (Tables 19 and 20). PEI relapse pievention was retained because it was the only PEI score not correlated with programme type. Also, after type was removed it was the most independent of the four PEI scores with significant partial correlations (Table 18). COPES involvement was retained because the partial correlation was higher than other COPES scores and because past research had suggested it was related to outcomes (Table 19). COPES scores of order and organization, and practical orientation, were used because they had also been related to outcomes. The two types of agencies, care and intervention, were used instead of the six types, because the two types were more clearly different in their missions. Being older, total risk score, OCHS externalizing disorder, the percentage of CYC with CYC diplomas, involvement, order and organization, practical orientation, relapse prevention and two types of agencies were retained.

Because more data were available for COPES $(n=164)$ than for PEI $(n=112)$ programme scores, two multiple regressions were calculated. Both were hierarchical regressions used to decide if characteristics of workers and programmes improved the prediction of placement following residential care or intervention beyond that of client characteristics. For the first regression the order of entry was, (a) client being older, (b) client total risk score, (c) client 
externalizing disorder, (d) the percentage of CYC with CYC diplomas, (e) COPES scores of involvement, order and organization, and practical orientation, and (f) whether the mission of the agency was care or treatment.

Table 20 shows the correlations between variables, the regression coefficients and intercepts, the semi-partial correlations and $\mathbf{R}, \mathbf{R}^{2}$, and adjusted $\mathbf{R}^{2}$ after entry of all variables. $\mathbf{R}$ was significantly different from zero at the end of each step after step one (step two, $p<.01$; steps three to eight, $p<.001)$. After step eight, with eight variables in the equation, $R=.66, F(8$, 156) $=15.0, \mathrm{p}<.001$.

After step three, with client being older, total risk and externalizing disorder scores entered, $R^{2}=0.15 F(3,161)=10.4, p<.001$. After step eight, with staff and programme variables ratio added, $R^{2}=.44$, adjusted $R^{2}=.41, F(8,156)=15.0, p<.001$. Six variables, increased $R^{2}$ significantly, involvement $(p<.05)$, total risk, CYC education and practical orientation $(p<.01)$ and externalizing disorder, agency type $(p<.001)$. Neither being older, nor order and organization, increased $\mathbf{R}^{2}$ significantly.

The addition of staff and programme variables to client variables did result in a significant increase in $R^{2}, F_{i n c}(5,159)=24.1, p<.001$. Therefore, programmes with more CYC with diplomas, a practical orientation and better client involvement appeared to have more successful residential placements independently of client total risk score and externalizing disorder scores. As expected, clients who had been in intervention programmes in Phase One were more likely to be in those programmes during Phase Two than clients who had been in child care programmes during Phase One. 
Because less data was available for PEI $(n=112)$ than for COPES $(n=164)$ programme scores fewer variables could be included in the second multiple regression. This also was a hierarchical regression used to decide if characteristics of workers and PEI programme scores improved the prediction of placement following residential care or intervention beyond that of client characteristics. Being older was not included in the regression as it had not had a significant effect in the first regression. For the second regression the order of entry was, (a) client total risk score, (b) client externalizing disorder, (c) the percentage of CYC with CYC diplomas, (d) PEI relapse prevention, and (e) whether the mission of the agency was care or treatment.

Table 21 shows the correlations between variables, the regression coefficients and intercepts, the semi-partial correlations and $R, R^{2}$, and adjusted $R^{2}$ after entry of all variables. $R$ was significantly different from zero at the end of each step after step one (steps two to five, $p$ $<.001)$. After step five, with five variables in the equation, $R=.57, .(5,106)=10.1$, $\mathrm{p}<.001$ 


\begin{tabular}{|c|c|c|c|c|c|c|c|c|c|c|c|c|}
\hline$n=164$ & $\begin{array}{l}\text { Place- } \\
\text { ment }\end{array}$ & $\begin{array}{l}\text { Being } \\
\text { Older }\end{array}$ & $\begin{array}{l}\text { Toul } \\
\text { risk }\end{array}$ & Extermal. & $\begin{array}{l}\text { CYC } \\
\text { Ed. }\end{array}$ & $\begin{array}{l}\text { Order } \\
\& \\
\text { Organ }\end{array}$ & $\begin{array}{l}\text { Practic. } \\
\text { Orient. }\end{array}$ & Involv. & B & $\boldsymbol{\beta}$ & $a^{2}$ & $\begin{array}{l}\text { Sig. F } \\
\text { Change }\end{array}$ \\
\hline Being Older & -.15 & & & & & & & & -.02 & -.11 & .02 & $n:$ \\
\hline Total risk & -.19 & .03 & & & & & & & -.002 & -.03 & .03 & $*$ \\
\hline $\begin{array}{l}\text { Externalizing } \\
\text { Disorder }\end{array}$ & .37 & -.04 & .50 & & & & & & .01 & -.24 & .11 & $\infty+$ \\
\hline $\begin{array}{l}\text { CYC } \\
\text { education }\end{array}$ & .28 & -.31 & -.06 & -.07 & & & & & .12 & .11 & .05 & $\bullet$ \\
\hline $\begin{array}{l}\text { Order \& } \\
\text { Orgenization }\end{array}$ & .18 & -.13 & -.14 & -.11 & .13 & & & & -.002 & -.01 & .01 & $n \cdot$ \\
\hline $\begin{array}{l}\text { Practical } \\
\text { Orientation }\end{array}$ & .10 & .17 & -.13 & -.03 & -.27 & -.05 & & & .02 & .07 & .02 & $\bullet$ \\
\hline Involvement & .20 & -.15 & .16 & .13 & .03 & .15 & .30 & & .02 & .11 & .03 & $*$ \\
\hline $\begin{array}{l}\text { Intervention } \\
\text { or Care }\end{array}$ & -.58 & .02 & .10 & .27 & -.29 & -.27 & -.07 & -.16 & -.38 & -.46 & .16 & $*+$ \\
\hline & & & & & . & \multicolumn{7}{|c|}{ Intercept 1.26} \\
\hline Means & .71 & 13.7 & 1.2 & 16.2 & .56 & 7.8 & 6.8 & 7.7 & \multicolumn{4}{|c|}{$R^{2}=.44$} \\
\hline $\begin{array}{l}\text { Sundand } \\
\text { Deviation }\end{array}$ & .37 & 22 & 4.3 & 9.3 & .35 & 2.2 & 2.0 & 1.8 & \multicolumn{4}{|c|}{$\begin{array}{l}\text { Adjusted } \\
\mathrm{R}^{2}=.41\end{array}$} \\
\hline
\end{tabular}


- After ste $e_{i}$ two, with client total risk and externalizing disorder scores entered, $R^{2}=0.11 F(2$, $109)=7.0, p<.001$. After step five, with staff and programme variables added, $R^{2}=.32$, adjusted $R^{2}=.29, F(5,106)=10.1, p<.001$. Four variables, increased $R^{2}$ significantly, CYC education $(p<.05)$ and externalizing disorder, relapse prevention and agency type $(p<.001)$. Client total risk scores did not increase $R^{2}$ significantly.

The addition of staff and programme :ariables to client variables did result in a significant increase in $R^{2}, F_{\text {nc }}(5,159)=24.1, p<.001$. Therefore, programmes with more CYC with diplomas, and a relapse prevention programme had more successful residential placements independently of client total risk score and externalizing disorder scores. As expected, clients who had been in intervention programmes in Phase One were more likely to be in those programmes during Phase Two than clients who had been in child care programmes during Phase One.

\section{Predictors of Phase Two Behaviour Disorders}

Phase Two behaviour checklists had been received from only 90 or $35.2 \%$ of clients approached. Other data was missing for some of these clients. Therefore, only four variables could be included in multiple regressions on behaviour disorders. Because more than a third of the clients had missing PEI or COPES programme data, the effects of programme environment and evaluation variables were not explored. Instead, a hierarchical regression was used to decide if the percentage of CYC with CYC diplomas in the residence improved the prediction of behavisur following residential care or intervention beyond that predicted by client characteristics. Client age was included in this regression because previous studies and results of the present study had found an interaction between age and worker training (Table 17). 
Regressions on Phase Two externalizing and internalizing behaviours were done. For the externalizing behaviour regression the order of entry was, (a) client being older, (b) client total risk score, (c) client Phase One externalizing disorder, and (d) the percentage of CYC with CYC diplomas. 


\begin{tabular}{|c|c|c|c|c|c|c|c|c|c|c|}
\hline$n=111$ & $\begin{array}{l}\text { Place- } \\
\text { ment }\end{array}$ & $\begin{array}{l}\text { Total } \\
\text { risk }\end{array}$ & External. & $\begin{array}{l}\text { CYC } \\
\text { Ed. }\end{array}$ & $\begin{array}{l}\text { Relapie } \\
\text { Prevention }\end{array}$ & $\begin{array}{l}\text { Inter } \\
\text { or } \\
\text { Care }\end{array}$ & $\mathbf{B}$ & $\beta$ & $\mathbf{s}^{2}$ & $\begin{array}{l}\text { Sig. F } \\
\text { Chunge }\end{array}$ \\
\hline Tchal risk & -.15 & & & & & & -.001 & .01 & .02 & $n:$ \\
\hline $\begin{array}{l}\text { Extemelizing } \\
\text { Dinonder }\end{array}$ & -.37 & .52 & & & & & .01 & -.18 & .09 & $\bullet \bullet$ \\
\hline $\begin{array}{l}\text { CYC } \\
\text { education }\end{array}$ & .20 & -.02 & -.06 & & & & .04 & .03 & .03 & $\bullet$ \\
\hline $\begin{array}{l}\text { Relapse } \\
\text { Prevention }\end{array}$ & .44 & -.23 & -.36 & .60 & & & .003 & .10 & .09 & $* \bullet$ \\
\hline \multirow[t]{2}{*}{$\begin{array}{l}\text { Intervention } \\
\text { or Care }\end{array}$} & -.52 & .04 & .27 & -.24 & -.64 & & -.32 & -.40 & .08 & $\bullet+\infty$ \\
\hline & & & & & & \multicolumn{2}{|c|}{ Intercept .98} & & & \\
\hline Means & .66 & .89 & 16.5 & .54 & 70.8 & 1.3 & & \multicolumn{2}{|c|}{$\mathrm{R}^{2}=.32$} & \\
\hline $\begin{array}{l}\text { Sundard } \\
\text { Deviation }\end{array}$ & .38 & 4.3 & 9.6 & .34 & 1.3 & .47 & & \multicolumn{2}{|c|}{$\begin{array}{l}\text { Adjusted } \\
\mathbf{R}^{2}=.29\end{array}$} & \\
\hline & & & & & & & & \multicolumn{2}{|c|}{$R=.57$} & \\
\hline
\end{tabular}


Table 22 shows the correlations between variables, the regression coefficients and intercepts, the semi-partial correlations and $R, R^{2}$, and adjusted $R^{2}$ after entry of all variables. $R$ was significantly different from zero at the end of each step after step one (step two, $p<.05$, step three and four, $p<.001)$. After step four, with four variables in the equation, $R=.53, F(4$, $67)=6.5, p<.001$.

After step three, with cuent being older, total risk and externalizing disorder scores entered, $\mathbf{R}^{2}=0.25 \mathrm{~F}(3,68)=7.4, \mathrm{p}<.001$. After step four, with CYC education variable added, $\mathbf{R}^{2}$ $=.28$, adjusted $R^{2}=.23, F(4,67)=6.5, p<.001$. Two variables that increased $R^{2}$ significantly were total risk $(p<.01)$ and externalizing disorder $(p<.001)$. Client being older and CYC education did not increase $\mathrm{R}^{2}$ significantly.

The addition of CYC education to client variables did not result in a significant increase in $\mathbf{R}^{2}$. Therefore, programmes with more CYC with diplomas did not have clients with lower Phase Two externalizing disorder scores independently of client being older, total risk and Phase One externalizing disorder scores. 


\begin{tabular}{|c|c|c|c|c|c|c|c|c|c|}
\hline$n=71$ & $\begin{array}{l}\text { Phase } \\
\text { Two } \\
\text { External. }\end{array}$ & $\begin{array}{l}\text { Being } \\
\text { Older }\end{array}$ & $\begin{array}{l}\text { Total } \\
\text { risk }\end{array}$ & $\begin{array}{l}\text { Phase } \\
\text { One } \\
\text { External. }\end{array}$ & $\begin{array}{l}\text { CYC } \\
\text { Education }\end{array}$ & $\mathbf{B}$ & $\beta$ & $\pi^{2}$ & $\begin{array}{l}\text { Sig. F } \\
\text { Change }\end{array}$ \\
\hline Being Older & -.06 & & & & & -1.83 & -.23 & .004 & $n:$ \\
\hline Total Risk & .30 & .14 & & & & .03 & .006 & .10 & $*$ \\
\hline $\begin{array}{l}\text { Phese One } \\
\text { Externulizing } \\
\text { Diconder }\end{array}$ & .47 & .15 & .57 & & & .74 & .43 & .14 & $\cdots$ \\
\hline \multirow{2}{*}{$\begin{array}{l}\text { CYC } \\
\text { education }\end{array}$} & -.25 &.- .47 & $\cdot .35$ & -.33 & & -11.3 & -.22 & .03 & n: \\
\hline & & & \multicolumn{7}{|c|}{ Intercept 89.2} \\
\hline Means & 73.6 & 13.8 & 1.8 & 20.3 & .47 & \multicolumn{4}{|c|}{$R^{2}=.28$} \\
\hline $\begin{array}{l}\text { Standard } \\
\text { Deviation }\end{array}$ & 19.3 & 2.5 & 4.9 & 11.4 & .38 & \multicolumn{4}{|c|}{$\begin{array}{l}\text { Adjusted } \\
\mathbf{R}^{2}=.23\end{array}$} \\
\hline & & & & & & \multicolumn{4}{|c|}{$R=.53$} \\
\hline
\end{tabular}


Another regression on Phase Two behaviour was used to decide if the percentage of CYC with CYC diplomas in residences improved the prediction of Phase Two internalizing behaviour beyond that predicted by client characteristics. For the internalizing behaviour regression the order of entry was, (a) client being older (b) client total risk score, (c) client Phase One internalizing disorder, and (d) the percentage of CYC with CYC diplomas.

Table 23 shows the correlations between variables, the regression coefficients and intercepts, the semi-partial correlations and $R, R^{2}$, and adjusted $R^{2}$ after entry of all variables. $R$ was significantly different from zero at the end of each step after step two (step three and four, $p$ <.05). After step four, ...ith. Sur variables in the equation, $R=.38, F(4,68)=2.9, p<.05$.

After step three, with client being older, total risk and externalizing disorder scores entered, $\mathbf{R}^{2}=0.12 F(3,69)=3.2, p<.05$. After step four, with CYC education variable added, $\mathbf{R}^{2}$ $=.15$, adjusted $\mathrm{R}^{2}=.10, \mathrm{~F}(4,68)=2.9, \mathrm{p}<.05$. Only internalizing behaviour increased $\mathrm{R}^{2}$ significantly, $(\mathrm{p}<.01)$. The client being older, total risk score and CYC education did not increase $R^{2}$ significantly.

The addition of CYC education to client variables did not result in a significant increase in $\mathbf{R}^{2}$. Therefore, programmes with more CYC with diplomas did not have clients with lower Phase Two internalizing disorders independently of client being older, total risk and Phase One interualizing disorder scores. 


\begin{tabular}{|c|c|c|c|c|c|c|c|c|c|}
\hline$n=72$ & $\begin{array}{l}\text { Phase } \\
\text { Two } \\
\text { Internal. }\end{array}$ & $\begin{array}{l}\text { Being } \\
\text { Older }\end{array}$ & $\begin{array}{l}\text { Total } \\
\text { risk }\end{array}$ & $\begin{array}{l}\text { Phase } \\
\text { One } \\
\text { Internal. }\end{array}$ & $\begin{array}{l}\text { CYC } \\
\text { Education }\end{array}$ & B & $\boldsymbol{\beta}$ & $x^{2}$ & $\begin{array}{l}\text { Sig. F } \\
\text { Change }\end{array}$ \\
\hline Being Oldu. & -.09 & & & & & -1.22 & -.18 & .007 & $n:$ \\
\hline Total risk & .04 & .16 & & & & -.09 & -.03 & .003 & $n$ \\
\hline $\begin{array}{l}\text { Phese One } \\
\text { Internalizing } \\
\text { Dieorder }\end{array}$ & .34 & .05 & .11 & & & .82 & .33 & .11 & $\bullet$ \\
\hline \multirow{2}{*}{$\begin{array}{l}\text { CYC } \\
\text { education }\end{array}$} & -.11 & -.47 & -.36 & -.07 & & -8.0 & -.18 & .02 & n: \\
\hline & & & \multicolumn{7}{|c|}{ Intercept 70.4} \\
\hline Meana & 58.4 & 13.8 & 2.0 & 10.8 & .47 & & $\mathbf{R}^{\mathbf{2}}=$ & 15 & \\
\hline \multirow[t]{2}{*}{$\begin{array}{l}\text { Sundard } \\
\text { Deviation }\end{array}$} & 16.4 & 2.5 & 5.1 & 6.7 & .38 & & $\begin{array}{l}\text { Adju } \\
\mathbf{R}^{2}=\end{array}$ & & \\
\hline & & & & & & & $\mathbf{R}=$ & .38 & \\
\hline
\end{tabular}


Hypotheses

\section{Placement Outcomes}

Hypothesis one. The hypothesis that clients with higher disorder scores in Phase One would have lower percentages of successful placement days in Pnase Two was supported for all externalizing disoluers (Table 16). Externalizing disorders included OCHS conduct, hyperactivity and, externalizing disorders, and DSM III-R conduct, oppositional, attention deficit and externalizing disorders. The strongest correlations were for OCHS and DSM III-R externalizing disorders. The hypothesis that clients with higher Phase One internalizing disorder scores would have lower percentages of successful placement days was not supported for any disorders except OCHS emotional disorder (Table 16). All correlations were highly significant $(p<.001)$ except attention deficit and emotional disorders $(p<.01)$.

Hypothesis two. The hypothesis that clients with higher total risk scores in Phase One would have lower percentages of successful placement days in Phase Two was supported (Table 15, $r$ $=-.16, \mathrm{p}<.05)$. The hypothesis that clients with higher protective scores would have higher percentages of successful placement days was not supported.

Hypothesis three. The hypothesis that clients in Phase One residences with more CYC with diplomas would have higher percentages of successful placement days in Phase Two was supported for the total group and for youth but not for children, ages 5 to 12 (Table 17).

Hypothesis four. The hypothesis that clients in residences in Phase One with higher practical orientation and involvement scores, on the COPES (Moos, 1974b) would have higher percentages of successful placement days in Phase Two was supported (Table 20). The hypothesis that clients 
with higher COPES order and organization, support and spontaneity scores would have higher percentages of successful placement days was nut supported.

Hypothesic five. The hypothesis that clients who were in Phase One residences with higher programme evaluation (PEI) scores would have percentages of successful placement days in Phase Two was not supported except for the Relapse Prevention score (Table 18).

Hypothesis six. The hypothesis that clients with more matches between their needs and appropriate services available in their residence in Phase One would have higher percentages of successful placement days in Phase Two was not supported (Table 17).

Hypothesis Seven. The prediction of Phase Two percentage of successful placement days was significantly increased by the addition of more CYCs with CYC diplomas, an after-care relapse prevertion programme, good client involvement and a practical orientation of the programme (Tables 20 and 21).

Other Predictors of Placement Outcome. Clients who were older, had more presenting problems and criminal acts and were in residences with higher COPES scores of problem orientation and staff control had lower percentages of successful placement days (Tables 16 and 20).

\section{Behavioral Qutcomes}

Hypothesis one. The hypothesis that Clients with higher Phase One disorder scores would have higher Phase Two disorder scores was supported for all disorders except DSM III-R separation anxiety (Table 15). This was expected because Phase One and Phase Two behaviour disorder scores were repeated measures. All correlations were highly significant $(p<.001)$ except correlations with somatization and depression disorders $(p<.01)$. 
Hypothesis two. The hypothesis that clients with higher Phase One total risk scores would have higher Phase Two externalizing disorder scores was not supported by simple correlations (Table16). With client age controlled for however, clients with higher Phase One total risk scores had higher Phase Two externaliziny disorder scores (Table 22). Those clients with higher Phase One total protective scores had lower Phase Two externalizing scores (Table 15). Clients who had higher Phase One programme and total need scores, had higher Phase Two externalizing scores (Table 15). None of the Phase One risk, protective or need scores were correlated with Phase Two internalizing disorder scores.

Hypotheses three to six. The hypotheses that clients who were in Phase One residences with more CYC with diplomas, higher COPES or PEI scores and client service/need matches would have lower Phase Two externalizing or internalizing disorder scores was not supported except for the percentage of CYC diplomas for children (Tables 18, 19, $23 \& 24$ ).

Hypothesis Seven. The prediction of Phase Two behaviour was not significantly increased by the addition of the percentage of CYCs with CYC diplomas, to client variables (Tables 23 \& 24).

Other Predictors of Disorders Clients with more reported Phase One criminal acts (Table 15) and clients in intervention instead of care programmes (Table 15) had higher Phase Two externalizing disorder scores. Being older and being female were not correlated with Phase Two disorder scores.

\section{Combined Predictors}

Programmes with more CYC with diplomas, a practical orientation and better client involvement appeared to have more successful residential placements independently of client total risk score and externalizing disorder scores (Table 20). As expected, clients who had been in 
intervention programmes in Phase One were more likely to be in those programmes during Phase Two than clients who had been in child care programmes during Phase One.

Programmes with more CYC with diplomas and a relapse prevention programme appeared to have more successful residential placements independently of client total risk score and Phase One externalizing or internalizing disorder scores (Table 21). Programmes with more CYC with diplomas did not have clients with lower ir hase Two externalizing or internalizing disorder scores independently of client being older, total risk scores and Phase One externalizing or internalizing disorder scores (Tables 22 and 23). 


\section{DISCUSSION}

\section{Limitations of the Study}

The major limitation of the present study was that the length of residential or other type of service was not recorded. A complete history of social agency invclvement for each client would clarify comparisons among types of programmes, predictors and outcomes.

Another major limitation of the present study was the difference in informants between Phase One and Phase Two. Phase One behaviour checklists were completed by the front-line residence staff person who knew the client best. Phase Two behaviour checklists were completed by the parent or by clients aged 16 or more. Mean cross-informant correlations have been reported to be low in a review of 119 behaviour checklists (Achenbach, McConaughy, \& Howell, 1987, parent \& worker, $\mathrm{r}=.24$, worker $\&$ client, $\mathrm{r}=.27$ ). Cross-informant correlations were higher in the present study (Phase One worker with Fhase Two parent or client externalizing disorder, $\mathrm{r}=.53$ and internalizing disorder, $\mathrm{r}=.39$ ). Despite the higher correlations, informant differences limited the predictive value of the Phase One checklists.

The samples of the present study had three important limitations. First, only two-thirds of the psychiatric inpatients responded. One hospital (A) had responses for all inpatients but the other hospital (B) had responses for only one-sixth of the inpatients. This bias of the psychiatric sample should be noted when interpreting any comparisons between psychiatric and other programmes. A second limitation of the samples was that only one-third of the possible subjects completed behaviour checklists in Phase Two. Respondents had higher Phase One risk and externalizing behaviour disorder scores than non-respondents. A third sample limitation was that 
Phase One DSM III-R disorders could only be calculated for English-speaking clients as the CBC-R had not been translated then.

Another limitation of the present study was inadequate descriptions of programmes. Both of the measures used, COPES and PEI scores, varied significantly across programmes (Tables 10 and 11). Correlations for types of programmes with PEI scores were especially high (Table 18). Therefore, except Relapse Prevention, PEI scores were not useful predictors of outcomes across several types of child care and intervention programmes. This result may have been due to inadequate data collection. The PEI was completed during a one to two hour interview. Because there was no probing of responses it was difficult to compare reports of different supervisors. A similar problem may have affected the presenting problems/available services matching variable. Although an appropriate service may have been available, supervisors were not questioned about implementation, which is how much service was provided and for which clients. The match viriable was useful in describing gaps in the residential system in a previous report (McClure, Armstiong, Cloutier \& Tillman, 1991) but not useful as a predictor of outcomes in the present study.

\section{Phase One: Descriptions}

The present study was unusual because it included all types of residences for behavioral probleıns of children and youth within one Ontario region. Previous studies of group homes had not included CAS and maternity homes. Also, only one study had included residential correctional centres and children's mental health centres (Randall and McClure, 1972). Comparisons between the clients, families and programmes should be useful for planning referrals and services if the same measures are used across all types of residences. When this 
was done in the present study, significant differences were found between types of residences on client, family, worker and programme factors.

Larger differences in client behaviour disorders were found among types of programmes in the present study than within each type (Table 7). Such differences were not found by Randall and McClure (1972). They found larger differences in mean disorders within each type of centre than among types of centre. They also found no difference in mean disorders between clients in training schools and those in children's mental health centres. Perhaps, better diagnoses and placement decisions have been made recently than in the past. It has been suggested that better assessments and expansion of children's services followed the Randall and McClure study. This may have helped improve service placements by showing that many training school residents had mental health problems (Naomi Rae-Grant, personal communication, 1989).

There were one and one-half times as many boys as girls in residences. The reasons for this imbalance were not accounted for by differences in total disorder scores, client needs or family and client risk factors (Tables 3,4 and 6). Results of the present study were similar to two previous Ontario studies (Offord et al., 1987 and Fulton \& Braseliten, 1991). Both previous studies found that the total level of disorder of males and females was similar in the Ontario population and among residence clients, although the type of disorder was different for each sex. Instead, the major reason for being in residences was externalizing disorder, which was more common among boys than girls, instead of internalizing disorder. Only psychiatry and one of the two large adolescent treatment agencies appeared to have similar mean scores for both types of disorder. 
Results of comparisons between sexes in group homes and mental health centres were similar for boys, but different for girls, than in a previous study. Sunday \& Moore (1986) found that in group homes and mental health centres, boys were equally disturbed but girls were less disturbed in group homes. In the present study, disorder scores of both males and females were similar in group homes and the psychiatric hospital but lower in group homes than in treatment agencies. Externalizing disorders for males also were similar in group homes and psychiatric ho.spital and lower in group homes than in treatment agencies. For girls, however, externalizing disorders were higher in group homes than in the psychiatric hospital, although lower in group homes than in tr satment agencies. Differences between present and past studies may be due etiher to differences in the areas studied or due to an increase in female externalizing disorder among residents in recent years. This increase was reported by several supervisors in the present study.

There were twice as many youths as children in residences. The reason for this was not related to differences in either total disorder scores or type of disorder (Table 6). Instead, it was related to risk factor scores, which are much higher for youths than for children (Table 4). Risk factor scores were the sum of some client and family problems minus client strengths (Appendix 6, Part C). Perhaps, family difficulties such as parental conflict and violence and parental disorder and criminal activities combined with client gang membership and low school achievement lead to increasing problems over time. Adolescents with problems may be more difficult than children for dysfunctional families to manage.

Fulton and Braseliten, (1991) also found that, within residential services, CAS wards and young offenders were more socially impaired than others. In the present study, young offenders 
in group homes had the highest mean disorder scores for externalizing disorder. CAS clients who were psychiatric inpatients or in treatment agencies had lower externalizing scores than non-CAS inpatients or clients (Table 10). CAS clients who were psychiatric inpatients had higher internalizing disorder scores than non-CAS inpatients.

The results of the present study suggested that comparisons among types of programmes and among agencies within each type of programme should take account of at least four factors besides sex, age and guardianship. These four factors were client and family risk factors and the type and degree of client behaviour disorders. Results showed differences in four programmes, custody, psychiatry, treatment agencies and maternity hornes, which illustrate the importance of these factors.

Clients in custody had the highest mean externalizing disorder score, as expected, and the lowest mean internalizing disorder score (Table 7) but they also had the highest mean risk score. High levels of family problems may make it difficult to involve families in treatment. Client problems and lack of competencies may suggest specific treatment targets for them. It should be noted that the list of risk factors used in the present study did not include anti-social attitudes, family functioning and parenting skills, which also have been suggested as treatment goals in corrections (Andrews et al., 1990).

Inpatients in psychiatry had the lowest mean externalizing disorder and risk scores and an average mean internalizing score. However, it should be noted that only one of the two hospitals (hospital A) was fully represented in the sample. The other hospital (B) may have received more clients with internalizing disorders, including suicidal behaviour and psychoses. This appeared reasonable because hospital B was a ward in a general hospital and received referrals 
only from physicians while hospital $A$ had two cottage programmes with a three-month time limit and received referrals from many sources.

Maternity home programmes illustrated the importance of considering type of disorder, mean disorder and mean risk scores (Table 8). Compared to other female clients they had the second lowest mean externalizing score. Only female inpatients in psychiatry (largely from hospital A) had a lower mean externalizing score. They and child welfare clients had the lowest mean internalizing disorder score. To understand the needs of maternity clients, however, it is necessary to note that they had a higher mean risk score than all others except custody clients. The number of family problems was similar for maternity and custody clients.

To understand treatment agency programmes, it was necessary to compare them with other types of programmes and, also, to compare different treatment agencies with each other. The total group of treatment agencies had the second highest mean score for externalizing disorder, after custody, and the highest mean internalizing score. The mean risk score was the third highest, after custody and maternity programmes. Comparisons were made also among treatment agencies. These were reported to agency directors in confidence. Two youth treatment agencies differed in the type of client disorders; one had similar mean scores for externalizing and internalizing scores while the other had a higher mean score for externalizing and a lower mean score for internalizing disorder. Two child treatment agencies had similar disorder scores but one was much higher than the other in mean risk score. These differences in type of disorder and mean risk scores should influence the type of treatment provided and should be considered in comparing the effectiveness of agency programmes. 
The number of previous residential placements also may be important in planning a treatment programme. Psychiatric and maternity programmes had the highest mean numbers of previous placements (Table 5). The range was from none to 17 previous placements with 8 per cent of the clients having been in seven or more. After so many residences clients must find it hard to be involved in the programme.

\section{Phase Two: Predictors of Outcomes}

The most important result of the present study was that seven factors were important predictors of successful placement and improved behaviour after residential services. These factors were client age, risk factor and externalizing disorder scores, CYC education, and programmes that involved clients and had a practical orientation and an after-care relapse prevention aspect. These seven measures would be appropriate measures for use in the evaluation of programme effectiveness. Changes in worker and programme factors might be used in studies to see if they could improve programme outcomes. 


\section{Client Factors}

There were higher percentages of successful placement outcomes for children than for youth (Table 12). This also was found by Weisz et al. (1987). The present study did not find more successful outcomes for boys than for girls, unlike the resulis found in a review of previous studies (Blotcky, Dimperio \& Gusset, 1984). Phase Two placement and disorder outcomes were not significantly related to sex or age in the present study.

The higher the Phase One externalızing disorder score, the lower the percentage of Phase Two successful placement days $\left(\mathrm{r}=-.37 ; \mathrm{R}^{2}\right.$ change $\left.=11\right)$. Phase One internalizing disorder scores were not related to Phase Two percentage of successful placement days but were related to higher Phase Two internalizing disorder scores. Lower percentages of successful placement outcomes were correlated with externalizing but not with internalizing disorders (Table 15). This result supported most previous findings.

Perhaps, residential treatment was primarily used to control ant:-social behaviour and then, after discharge from a residence, internalizing problems were helped by counselling and day-care programmes. Equally, continuing service may not have been provided for internalizing disorders, once externalizing disorders were under control.

The higher the client Phase One total risk factors score, the higher the Phase Two externalizing scores $\left(r=.30 ; R^{2}\right.$ change $\left.=.10\right)$. Total risk factors score also had a significant but much smaller effect on successful placement $\left(r=-.19 ; \mathbf{R}^{2}\right.$ change $\left.=.03\right)$. Results of the present study supforted six recent risk factor studies reviewed by Andrews, Bonta \& Hoge, (1990). They found good prediction of outcomes using four risk factor instruments. These instruments included conduct or delinquency items. Similar items were in the Child Behaviour 
Checklist (CBC) in the present study. The selection and combir $\because$ nn of several appropriate risk factors, including conduct items, may be required for good prediction of outcomes.

Further examination of the relaticns of individual risk factors to outcomes is needed. It may be useful to study separately the relationships Letween family and client risk factors and outcomes of treatment. Also, the predictive value of the Youth Level of Services Inventory (YLSI) should be tested across mental health and child care centres. The YLSI has been shown to predict recidivism in correctional centres. The YLSI items that were left out of the present study were ones that required persc nal interviews and clinical judgements. These personality and attitude items may be the crucial predictors of outcomes.

It has been suggested that protective factors (positive items, Appendix 6, Part C) were predictors of outcome (Rae-Grant et al., 1989). Results of this study showed only a small, nonsignificant correlation between these factors and placement outcome but a significant correlation between them and Phase Two externalizing behaviour $(r=-.33)$. Further study of the relationships between client competence and treatment outcomes may be worthwhile. Programme needs, the subset of risks that could be changed by treatment, were correlated with successful placement $(r=-.23, p<.001)$ and with Phase Two externalizing disorder $(r=.31, p<.01)$. These results suggested that it may improve later placements and behaviour if specific risk factors for sach client are used as treatment targets.

\section{Worker Factors}

The effect of Child and Youth Counsellor (CYC) education on predicting outcomes was clearer than in previous studies. The percentage of CYC's with CYC diplomas in earh residence was correlated significantly with placement for the total group $(r=.29)$, and for youth $(r=$ 
.38) but not for children (Table 17). CYC education was also correlated significantly with Phase Two externalizing disorder for children $(r=39)$ but not for the total group or for youth (Table 17). Weisz et al. (1987) had studied the relation of training to effect sizes in a meta-analysis of 108 outcome studies. They found $r$. main effect for the amount of training on treatment effect size but they did find interactions between client age and training for graduate students and paraprofessionals. These two groups were more effective with children than youths. Professional therapists were equally effective with all ages. Increased training of professional therapists did not improve their effectiveness, however. The effect of having a higher percentage of CYC with diplomas in a residence is similar to having more professionals for the placement outcome. The same effect seemed similar to having more paraprofessionals for the disorder outcome. Anyhow, there is a significant improvement in placement outcome for residences that have more CYCs with diplomas beyond that predicted by age, risk and externalizıng disorder $\left(\mathbf{R}^{2}\right.$ change $=.05 ;$ Table 20)

\section{Programme Factors}

Previous researchers have emphasized the importance of descriptions of programmes and programmie implementation and the lack of agreement on which variables are the most appropriate to use. The present study investigated the relationship of four programme variables to placement and behaviour outcomes. The variables studied were (a) the type or mission of the programme, (b) matches between client needs and available services (c) seven measures of programme evaluation (PEI) and (d) ten measures of the perceived social environment of the residences (COPES). 
The strongest predictor of placement outcomes was the mission of the programme, either child care or intervention $(r=.57)$. Part of the strength of the predictor may have been because clients in intervention programmes, except psychiatry, had higher risk and externalizing disorder scores than clients in child care programmes. But the type of programme added a large amount to the prediction of placement beyond the effects of client, worker and other programme factors $\left(R^{2}\right.$ change $\left.=.16\right)$. There may be important unmeasured differences between programme types that predicted placements. For example, there may have been a labelling effect. Once a client had been a psychiatric inpatient, in a treatment centre or in custody the client may have become labelled as a person with behaviour disorders. Especially if some improvement in behaviour had been shown in these centres, therapists may tend to keep the client in residential treatment or return the client to it, instead of providing other types of care.

There was also a high correlation for six types of programme, group homes to custody, with placement $(r=-.56)$. The mean percentage of Phase Two successful placement days (Table 12) was highest for group homes (91.4) and lowest for custody (29.8). These results were probably due to both direct and indirect effects of the types or mission of the programme. Type of programme decided the choice of clients, staffing and costs. Significant relationships were reported above among six types of programme and CYC education, risk factors, needs, number of CAS clients, criminal acts, previous placements, behaviour disorders, need/service matches, and PEI and COPES scores.

Results of matches between client needs and available services as predictors of outcomes were disappointing. No significant relationship between matches and placement or between matches 
and behavioral outcomes was found. Previous studies have found matches to be effective but different types of matches were studied.

In the present study, supervisors were asked which services were available to meet each client's needs - not which services were provided for each client. Nor were they asked the amount of each service that was provided. Better measures of implementation may be required to study the relationship of need/service matches to outcomes.

Three programme evaluation and social climate measures of programmes predicted placement outcome. Of these, the PEI Relapse Prevention score was the strongest predictor $\left(r=.44, R^{2}\right.$ change $=.09$, Table 21). This was encouraging. It was reasonable to assume that after-care programmes would help maintain clients in home and child care, instead of returning to psychiatric, treatment or custody residences, but it was helpful to have evidence of the effectiveness of such programmes. These results suggested that after-care programmes were well worth their cost.

There was only weak evidence $f c$ - the effect on placement of the practical orientation of programmes $\left(r=10 ; R^{2}\right.$ change $\left.=.02\right)$ and higher client involvement $\left(r=.20 ; R^{2}\right.$ change $=$ .03). Results did suggest, however, that it may be useful to include these two measures in comparative outcome evaluation studies. It also may be worthwhile to attempt to measure these two social climate variables, attempt to improve them, and then see if changes in COPES scores are correlated with improved client outcomes.

\section{Methods}

Five requirements for improved outcome studies have been suggested. These were (a) an appropriate treatment model, (b) better classification of disorders, (c) better measures of risks 
factors and needs, (d) better descriptions of programmes and programme implementation, and (e) better outcome measures (Casey and Berman, 1985; Hoge and Andrews, 1986; Quay, 1986).

The work of other researchers has provided improvements in the first three requirements as a basis for the present study. A better model was provided by Hoge \& Andrews (1986) and better classification of disorders hv Offord et al. (1987). Improved measures of risks and needs have been developed and related to the general Ontario population (Rae-Grant et al., 1989) and to recidivism in correctional agencies (Andrews, Robinson \& Hoge, 1985).

Results of the present study provided additional evidence that some risk and need factors were related to residential programme outcomes. Much more work is needed to understand which risk and need factors predict outcomes separately and in combination with other factors.

Results of the present study also provided a small contribution to improved methods for the descriptions of programmes. Seven measures were found to be reliable predictors of programme outcomes. These were, (a) total risk score, (b) externalizing disorder score, (c) the percentage of CYC with CYC diplomas, (d) after-care Relapse Prevention, (e) practical orientation of the programme, (f) client involvement in the programme and $(\mathrm{g})$ the type (or mission) of the agency.

Further progress in evaluating the effectiveness of groups and treatment residences requires detailed measures of programme implementation and programme integrity. Differences between agency policy and prescribed programme and the actual programme provided require investigation.

Results of the present study contribute to improved outcome measures. The number of days that clients live (a) independently, in family, foster or CAS homes, or (v) in psychiatric 
treatment, custody centres, or AWOL from home or programme, is a reliable measure that is personally and socially relevant. It also is easier to investigate than measures of behaviour disorders.

Results for the outcome of behaviour disorders were difficult to interpret because only approximately one-third of the eligible clients responded. It seems unlikely that a higher proportion would respond in future studies unless they were interviewed individually and paid for their cooperation.

The present study was unusual because information from Phase One was available for an almost complete sample. Therefore, respondents and nonrespondents could be compared on their levels of disorder at Phase One. Respondents had significantly higher levels of disorders than nonrespondents at the time of Phase One. Perhaps some clients or their parents did not respond because the clients had overcome their previous problems. 


\section{IMPLICATIONS FOR TREATMENT PROGRAMMES}

There is a preponderance of males and of clients with externalizing disorders in residences. It may be better to have a mixture of sexes and of types of problems within each residence. This might prevent the inadvertent reinforcement of delinquent peer relationships and gang memberships. It is also possible that residences that include both sexes and both externalizing and internalizing disorders would have reduced management problems. On the other hand it may be better to have different agencies specialize in treating different types of disorders. This was the situation in 1990 . In either case it may be important to provide more services for females through non-residential or residential services as their needs are equal to those of males.

More youths are in residence than children and they have similar mean disorder scores. It could be argued that there should be more treatment places for children. If there were more places, residential treatment could include clients with lower disorder scores and families and clients at higher risk for future problems. The hope would be that short-term residential treatment in childhood would reduce the need for treatment of adolescents. Both high disorder and high risk scores should be considered reasons to treat children and families. For example, because maternity homes have low disorder scores but high risk scores, treatment of disorders should be an integral part of their services.

Treatment for individual clients and families should be based partly on information on disorders, risks and needs from standardized instruments completed at intake by parents, clients and, with permission, by teachers. If several agencies used the same checklists irformation would be easily exchanged when clients were transferred. Risk factor items and disorder scores would allow therapists to apply the latest findings on effective treatment to particular clients and 
families. Basic standardized information would also allow agencies or groups of agencies to do self-evaluation studies to improve their programmes.

The prevention of repeated treatment or custody is an extremely important and clear goal for residential services. Results of the present study suggest several approaches that may help achieve this goal. There should be increased formal and informal training of CYC. It may be worthwhile to include the use of social climate measures as part of this training. It is usually interesting and may be helpful for staff and clients to know how others perceive the residence programme. There should be well-financed after-care in all programmes. After-care could help reduce client relapses and provide feedback to help improve programmes.

The purpose of the present study was to provide preliminary information as a base for future studies of the effectiveness of residential care. Its immediate purpose was to identify the characteristics of programmes and clients from which outcomes of residential placements might be predicted. Prase One of the study showed an economical way of comparing residential clients, families and programmes and described the Ottawa-Carleton residential services system during the first half of 1990 . Results of Phase Two showed that seven client, wcrker and programme characteristics were predictors of the percentage of successful placement days and of behaviour following residential services. The usefulness of the study depends on whether it has provided an improved base for future studies that describe or evaluate residential programmes. 


\section{REFERENCES}

Achenbach, T. M. (1978). The child behavior profile: I, Boys aged 6-11. Journal of Consulting and Clinical Psychology. 46 (3), 478-488.

Achenbach, T. M. \& Edelbrock, C. S. (1979). The child behavior profile: II. Boys aged 12-16 \& girls aged 6-11 \& 12-16. Journal Consulting \& Clinical Psychology. 47 (2), 223-233. Achenbach, T.M. \& Edelbrock, C.S. (1983). Manual for the Child Behavior Checklist \& Revised Child Behavior Profile. Burlington, Vermont: Univ. of Vermont.

Achenbach, T.M., McConaughy, S.H., \& Howell, C.T. (1987). Child/adolescent behavioral and emotional problems: Implications of cross-informant correlations for situational specificity. Psychological Bulletin, 101 (2), 213-232.

American Psychiatric Association. (1980). Diagnostic and Statistical Manual of Mental Disorders (3rd ed.). Washington, D.C.: Author.

Andrews, D.A., Robinson, D., \& Hoge, R.D. (1985). The Youth Level of Service Inventory (YLSI-2) Manual, A report of the children and youth services project., Ottawa: Department of Psychology, Carleton University.

Andrews, D.A., Bonta, J. \& Hoge, R.D. (1990). Classification for effective rehabilitation: Rediscovering psychology. Criminal Justice and Behavior, 17(1), 19-52.

Andrews, D.A., Bonta, J. \& Wormith, J.S. (1989). Criminal Behaviour: Notes for 49.342.

Ottawa: Carleton University.

Andrews, D.A., Zinger, Ivan, Hoge, R.D., Bonta, James, Gendreau, Paul, \& Cullen, Francis T. (1990). Does correctional treatment work? A clinically-relevant and psychologicalıyinformed meta-analysis. Criminology 28(3), 369-404. 
Andrews, D.A. \& Kiessling, J.J. (1980). Programme structure and effective correctional practice: a summary of the CaVIC research. In R.R. Ross \& P. Gendreau (Eds.) Effective Correctional Treatment. Toronto: Butterworth.

Andrews, D.A. \& Robinson, D. (1984). The Level of Supervision Inventory: Second Report. A report to Research Services (Toronto) of the Ontario Ministry of Correctional Services. Andrews, D.A., Robinson, D., \& Balla, Michael. (1986). Risk principle of case classification and the prevention of residential placements: An outcome evaluation of the Share the Parenting programme. Journal of Criminology and Clinical Psychology, 54, 203-207.

Blotcky, M.J., Dimperio, T.L. \& Gosset, J.T. (1984). Followup of children treated in psychiatric hospitals: A review of studies. American Journal of Psychiatry 141 (12), 1499 1507.

Boyle, M. H., Offord, D. R., Hoffmann, H. G., Catlin, G. P., Byles, J. A., Cadman, D. T., Crawford, J. W., Links, P. S., Rae-Grant, N. I., Szatmari P. (1987). Ontario Child Health Study: Methodology. Archives of General Psychiatry, 44, 826-831.

Boyle, Michael H., Offord, David R., Racine, Yvonne, Sanford, Mark, Szatmari, Peter \& Fleming, Jan E. (in press). Evaluation of the original Ontario Child Health Study Scales. Journal Child Psychology \& Psychiatry .

Boyle, Michael H., Offord, David R., Racine, Yvonne, Fleming, Jan E, Szatmari, Peter \& Sanford, Mark, (1993). Evaluation of the revised Ontario Child Health Study Scales. Journal of Child Psychology \& Psychiatry . 
Byles, John, Byrne, Carolyn, Boyle, Michael H., \& Offord, David R. (1988). Ontario Child Health Study: Reliability and validity of the general functioning subscale of the McMaster family assessment device. Family Process, 27, 97-104.

Casey, R.J. and Berman, J.S. (1985). The outcome of psychotherapy with children. Psychological Bulletin. 98, 388 - 400.

Cavior, H.E. \& Schmidt, A.A. (1978). Test of the effectiveness of a differential treatment strategy at the Robert F. Kennedy Centre. Criminal Justice and Behavior, 5, 131-139.

Cohen, P. \& Brook, J. (1987). Family factors related to the persistence of psychopathology in childhood and adolescence. Psychiatry, 5, 332-335.

Cohen, P., Brook, J.S., Cohen, J., Velez, N. \& Garcia, M. (1990). Common and uncommon pathways to adolescent psychopathology and problem behavior. In Robins, L.N. \& Rutter, M. (eds.) (1990). Straight and devious pathways from childhood to adulthood New York: Cambridge.

Difrancesco, Angelo (1987). Statistical summary of all children in group homes in Durham, Kawartha-Haliburton and Northumberland. Children's Aid Society, Durham.

Dore, M. M., Young, T.M. \& Pappenport, D.M. (1984). Comparison of basic data for the national survey of residential group care facilities: 1966-1982. Child Welfare 63(6) 485-495. Endler, Norman S. (1980). Person-situation interaction \& anxiety in Kutash, I.L. \& Schawsinger, L.B. (eds). Handbook on Stress \& Anxiety: Contemporary knowledge, theory San Francisco, Josey-Basse, 249-266.

Epstein, M. H., \& Cullinan, D. (1983). Academic performance of behaviorally disordered and learning disabled pupils. Journal of Special Education. 17, 303-307. 
Fineberg, B.L., Sowards, S.K. \& Kettlewell, P.W. (1980). Adolescent inpatient treatment: A literature review. Adolescence, 15 (60), 913-925.

Fulton, R. \& Braseliten, C (1991), Risk in Perspective, Toronto: Ontario Association of Children's and Youth Institutions.

Gendreau, P. \& Andrews, D.A. (1990). Tertiary prevention: What the meta-analyses of the offender treatment literature tell us about "what works". Canadian Journal of Criminology 32, 174-184.0.

Gendreau, P. \& Andrews, D.A. (1990). Correctional Programmes Evaluation Inventory (CPEI). Carleton University: Author.

Glueck, S. and Glueck, E. Unravelling Juvenile Delinquency, Cambridge, Harvard University Press, 1950.

Hobbs, N. (1966). Helping disturbed children: Ecological and psychological strategies. American Psychologist, 21, 1105-1115.

Hoge, Robert D. \& Andrews, D. A. (1986). A model for conceptualizing interventions in social service agencies. Canadian Psychology, 27 (4).

Hudson, Paul, MacLeod, Cheryl, Nutter, Brenda, Lowe, Helen, Sullivan, Kevin (1988). Group Home Task Force: Interim report to executive committee. Children's Aid Society of Peterborough.

Jesness, C.F. (1971). The Preston typology study: An experiment with differential treatment in an institution. Journal of Research in Crime and Delinquency, 8, 38-52.

Jesness, C.F. (1975). Comparative effectiveness of behavior modification and transactional programmes for delinquents. Journal of Consulting and Clinical Psychology, 43, 758-779. 
Kassebaum, D., Ward, D. \& Wilner, D. (1971). Prison treatment and parole survivali an empirical assessment. New York: Wiley.

Leschied, Alan W., Austin, Gary W., \& Jaffe, Peter, G. (1989). Report Number 2: Toward the development of risk as:sessment in young offender recidivism: A necessary concept in juvenile justice policy. In Assessing outcome of special needs young offenders under new Canadian Juvenile Justice Legislation: A summary of research supported by the Sick Children's Hospital Foundation, London, Ontario: London Family Court Clinic Inc.

Links P. S., (1983) Community surveys of the prevalence of childhood psychiatric disorders: A review. Child Development 54 (3), 531-548.

Lipsey M.W. (1990). Juvenile delinquency treatment: A meta-analytic inquiry into the variability of effects. Paper prepared for the Russell Sage Foundation.

Loeber, R. \& Dishion, T. (1983). Early predictors of male delinquency: A review. Psychological Bulletin, 94(1).

Magura, Stephen \& Moses, Beth Silverman (1986). Outcome Measures for Child Welfare. Child Welfare League of America.

Maas, H.S. \& Engler, R.E. Jr. (1959). Children in need of parents. New York: Columbia. McClure, Gordon \& Ferguson, H. Bruce (1989). Predictors of children's school placements following psychiatric day treatment and special education programmes, Presented to Ontario Educational Research Council.

McClure, Armstrong, Cloutier and Tillman, (1991). Choosing residential treatment for children and youths in Ottawa-Carleton, Ottawa: Residential Placement Advisory Committee. 
McGee, Rob, Silva, Phil A. \& Williams, Sheila (1984b). Perinatal, neurological, environmental and developmental characteristics of seven-year-old children with stable behaviour problems. Journal of Child Psychology and Psychiatry, 25, 573-586.

Moos, R. (1974a). Evaluating treatment environments: A social ecological approach. New York: Wiley and Sons.

Moos, R.H. (1974b). Community-Oriented Programmes Environment Scale: Manual. Palo Alto: Consulting Psychologists.

Moos, R.H. and Trickett, E.J. (1974). Classroom Environment Scale: Manual. Palo Alto: Consulting Psychologists.

Nutter, Brenda \& Sullivan, Kevin (1989). Children's Aid Society placements in group homes: Placement patterns and a needs study of seventy-two children. The Journal 33(7) 11-16.

Offord, D.R. \& Boyle, M.H.(1989). Ontario Child Health Study: Correlates of disorder. Journal of the American Academy of Child and Adolescent Psychiatry, 28, 856-860.

Offe.d, David R., Boyle, Michael B., \& Jones, Beverly R. (1987). Psychiatric disorder and poor school performance among welfare children in Ontario. Canadian Journal of Psychiatry, $32,518-525$.

Offord, D.R., Boyle, M.H., Racine, Y.A., Szatmari, M.D. \& Fleming, J.E. (1990). Qutcome. prognosis and risk in a longitudinal followup study. Unpublished manuscript. ChedokeMcMaster Hospitals, Hamilton ON. 
Offord, D. R., Boyle, M. H., Szatzmari, P., Rat-Grant, N. I., Links, P. S., Cadman, D. T., Byles, J. \& Byrne, Crawford, J.W., Munroe Blum, H., Thomas, H., \& Woodward, C.A. (1987). Ontario Chila Health Study: Six-month prevalence of disorder and rates of service utilization. Archives of General Psychiatry, 44, 832-836.

Ontario Association of Children's Mental Health Centres, 1992), Standardized Client Information System (SCIS) version 1.0, Toronto: Author.

Ontario Ministry of Community \& Social Services (1988). Investing in children: New directions in child treatment and child and family intervention. Toronto: Queen's Printer.

Ontario Ministry of Community and Social Services (1989). Ontario Child Health Study: Summary of Initial Finc..ugs. Toronto: Queen's Printer for Ontario.

Ontario Ministry of Community and Social Services (1990). Ontario Child Health Study: Children at risk. Toronto: Queen's Fıinter for Ontario.

Palmer, T. (1974). The Youth Authority's Community Treatment Project. Federal Probation, 38, 3-14.

Persons, R. (1966). Psychological and behavioral change in delinquents following psychotherapy. Journal of Clinical Psychology, 22, 337-340.

Quay, H.C. (1977). The three faces of evaluation: What can be expected to work. Cri 'nal Justice and Behavior, 4 (4), 341-354.

Quay, H.C. (1986). Residential Treatment in Quay, H.C. \& Werry, J.S. (eds) Psychopathological disorders of childhood. Toronto: Wiley. 
Rae-Grant, Naomi, Thomas, Helen, Offord, David R., \& Boyle, Michael H. (1989). Risk, protective factors, and the prevalence of behavioral and emotional disorders in children and adolescents. Journal of the American Academy of Child and Adolescent Psychiatry, 28(2), 262-268.

Randall, D.R., McClure, G. \& Sone (1974). Residential Care Study. Toronto: Ontario Ministry of Health, Child Services.

Randall, D. R \& McClure, G. (1972). Degree \& Pattern of behavioral disturbance in residential settings for children in Ontario. Toronto: Ontario Ministry of Health, Children's Services Division.

Raush, H., Dittman, A. \& Taylor, T. (1959). Person, setting and change in social interaction, Human Relations, 12, 361-378.

institutionalized delinquent females. Journal of Abnormal Psychology, 82, 85-86.

Robins, L.N. (1974). Deviant children grown up: A sociological and psychiatric study of sociopathic personality. Krieger, Huntingdon, N.Y.

Robins, L.N. \& Rutter, M. (eds.) (1990). Straight and devious pathways from childhood to adulthood. New York: Cambridge.

Ro-Trock, G.K., Wellisch, D. \& Schoolar, J. (1977). A family outcome in an inpatient setting. American Journal of Orthopsychiatry, 47, 514-522.

Rutter, M., Cox, A., Tupling, C., Berger, M., \& Yule, W. (1975). Attainment and adjustment in two geographical areas: 1. The prevalence of psychiatric disorder. British Journal of Psychiatry, 126, 493-509. 
Rutter, M.J., Maugham, B., Mortimer, P., \& Ouston, J. (1979). Eifteen Thousand Hours: secondary schools \& their effects. Cambridge: Harvard University.

Rutter, M., Tizard, J., Yule, W., Graham, P., \& Whitmore, K. (1976). Isle of Wight Studies, 1964-1974. Psychological Medicine, 6, 313-332.

Scott, D. (1985). The Youth Level of Supervision Inventory in probation. Unpublished honours thesis, Carleton University.

Schwab, J.A. Jr., Bruce, M.E. \& McRoy, R.G. (1985). A statistical model of child placement decisions. Social work research and abstracts. 21(2) 28-34.

Shore, M. and Massino, J. (1973). After ten years: A followup study of comprehensive vocationally oriented psychotherapy. American Journal of Orthopsychiatry, 43, 128-132.

Star, S.A. \& Kuby, A.M. (1967). Numbers and kinds of children's residential institutions. Washington, D.C., Children's Bureau.

Sunday, Eugene \& Moore, Peter (1986). An examination of the "mental health needs" of adolescents referred to group homes. Kinark Child and Family Services.

Sutherland, Mary \& Docherty, Jim (1987). Private for profit operations - Residential service provision. Ontario Ministry of Community \& Social Services, Kingston Office.

Tabachnik, B.G. and Fidell, L.S. (1983). Using Multivariate Statistics. New York: Harper \& Row.

Tramontana, Michael G. (1980). Critical review of research on psychotherapy outcome with adolesce.ts: 1967-1977. Psychological Bulletin, 88 (2), 429.450.

Trites, Ronald L., Dugas, Erika, Lynch, George, \& Ferguson, H. Bruce (1979). Prevalence of hyperactivity. Journal of Pediatric Psychology, 4(2), 179-188. 
128

Voluntary Children's Services Coordinating Committee. (1985). A study of children's \& adolescent mental health services in Ottawa-Carleton. Ottawa: Ottawa-Carleton Regional District Health Council.

Weiss, John R., Weisss, Bahr; Alike, M.R., Klotz, M.L. (1987). Effectiveness of psychotherapy with children and adolescents: A meta-analysis for clinicians. Journal of Consulting \& Clinical Psychology 55 (4), 542-549.

YM/YWCA (1990). Youth in conflict with the law, Ottawa YMCA, Working paper. 
Appendix 1: YLSI Youth Level of Service Inventory

(Andrews, Robinson \& Hoge, 1985).

Delinquent History

. Police Contacts

- Court Appearances

- Ever Probations

. Current Probation

. Training School

. Group Home for Delinquency

. Shoplifting

. Stealing (Except Shoplifting)

. Engages in Cooperative Stealing

. Vandalism

. Break-Enter-Theft

. Assault/Violence

. Robbery

. Drugs (Specify

. Drinking

. Trespassing

. Sex Misconduct

- Engages in Malicious Mischief

. Engages in Gang Activity

. Other (Specify

Education

. Truancy

. Punctuality

- Poor Classroom Behaviour

. Poor Schoolyard Behaviour

- Poor School Achievement

. Failed Grades

. Homework Incomplete

- Diagnosed Learning Disability

- Ever Expelled/Suspended

- Poor Participation/Performance

. Poor Relations with Peers

. Poor Relations with Teachers

Family Finances

. Poor Situation

- Receives Social Assistance
Family

. Family Composition Unstable

. Poor Relations with Mom

. Poor Relations with Dad

. Poor Relations with Siblings

- Scapegoat of Family

- Inadequate Supervision of Children

- Difficulties Controlling Child's

Behaviour

. Inappropriate Discipline of Children

- Inconsistency in Parenting

- Poor Family Communication

. Lack of Family Cohesion

. Runs from Home

.Subject Currently in Residential Care

- Subject Ever in Residential Care

. Delinquent History Sibling

. Mental Health Problem Sibling

. Alcohol/Drug Problem Sibling

. Sibling Ever in residential Care

. Siblings Currently in

Residential Care

. Stays Out late at Night

. Too Often Absent from Home

Parents

. Criminal History Dad

. Criminal History Mom

. Mental Health Problem Dad

. Mental Health Problem Mom

. Alcohol/Drug Problem Dad

. Alcohol/Drug Problem Mom

. Abusive Dad (Physical/Sexual)

. Abusive Mom (Physical/Sexual)

. Other History (Specify

. Marital Conflict

. Parents

Poor Self-Image/Confidence

Poor Problem-Solving Ability 
Accommodations

. Housing Problems

. Frequent Changes of Address

. High-Crime Neighbourhond

Leisure/Recreation

- Limited Organized Participation

. Limited Participation in Informal

Peer Activities

.Could Make Better Use of Time

.No Personal Interests

(hobbies, sports, etc.)

Companions

. Some Delinquent Acquaintances

. Some Delinquent Friends

. None or Few Anti-Criminal

Acquaintances

. None or Few Anti-Criminal Friends

. Strong Allegiance to Selected Peers

- Associates with Peers Outside of

Age Range
Personality/Skills

- Poor Physical Appearance

. Poor Physical Health

.Weight Problem (Under/Over)

- Smokes Tobacco

. Sense of Inferiority

. Inflated Self-Esteem

. Withdrawn

. A Social Isolate

. Physically Aggressive

. Tantrums

. Manners/Etiquette

. Unable to Express Her/Himself

- Short Attention Span

. Frustration Tolerance

. Uses Inappropriate Attention Seeking

. Sexual Awareness

. Worries

. Has Inadequate Guilt Feelings

- Irritable

- Verbally Aggressive, Impudent

. Difficulties in Completing Tasks

- Obscene, Uses Foul Language

. Feels Persecuted,

Believes Others Unfair

- Callous, Little Concern for Others

. Defies Authority

. Trouble Getting Along with Others

. Initiates Fights

. Other

Attitudes/Orientation

. Supportive of Delinquency

Supportive of

Unconventional Attitudes

.Not Actively Seeking Necessary Help

Actively Rejecting Help 
Appendix 2: ARQ Agency \& Residence Questionnaire

$$
\begin{gathered}
\text { Residential Placement Study } \\
\text { Agency \& Residence Questionnaire }
\end{gathered}
$$

The first purpose of this study is assist Ottawa/Carleton agencies and professionals to match better the needs of troubled children with the available residential care resources. The second purpose is to find gaps in the types and quantities of residential services available.

\section{Instructions:}

Please answer the following questions for each residential programme that you offer for Ottawa/Carleton children. Do not include services that are primarily for the developmentally handicapped or chronically ill (Cnildren includes youth up to 18 years of age.)

This questionnaire should be completed by the director of the agency or delegate. If there is more than one residence in the agency, the supervisor of each residence also should complete the first two sections, 1) objectives and 2) statistics only.

Agency: $\quad 1$

Name of the residence: 2

Address:

3

4

Telephone number(s): $\quad 5$

Supervisor: $\quad 6$

7 The objectives of the programme

Instructions: Please state briefly. 
ARQ

\section{Statistics}

\section{Children}

Instructions: Complete blanks

Capacity

Since January 1990

8

Total in residence

boys

girls

Total on waiting list boys girls

Average length of stay

9

10 -

11

$12-$

$13-$

\section{Staff}

Instructions: Complete blanks

All in full time equivalents

How many staff total

14

Administration

15

Supervisors

Child care workers (diploma)

CYC (non-diploma)

Teachers (Section 27)

Clerical

Housekeeping

$16-$

17

18

$19-$

20

21

22

Others (specify type \& qualification or degrees)

Consultants (specify type \& qualification or degrees) 23 
Appendix 3: PEI Programme Evaluation Inventory

[Adapted from Correctional Program Evaluation Inventory (1992) Hoge, Leschied and Andrews]

1. CLIENT PRESERVICE ASSESSMENT

Appropriate clientele

Rational exclusions

Reasonable risk, need

responsivity

Quality of assessment

Risk level summary

Needs assessed

Responsivity

Subtotal

2. THERAPEUTIC INTEGRITY

Housing/location

Level of Involvement

Intensity/Risk

Match Client

Match staff

Client input

Ratio reward/punish

Variety rewards

Criminal sentiments

Subtotal 


\section{RELAPSE PREVENTION}

Monitor

Rehearse

Practice

Booster

Advocacy/Brokerage

Train Support Therapist

Subtotal

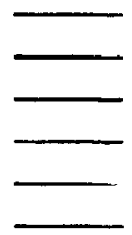

12

\section{STAFF CHARACTERISTICS}

Education

Aree of study

Experience

Personal qualities

Stability

Staff Assessment

Training

Staff input

Advisory Committee

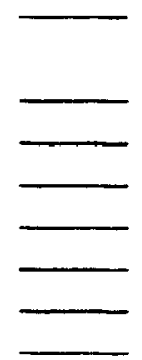

Subtotal 
5. EVALUATION

Quality Assurance

Consumer Satisfaction

Outcome (ind or aggregate)

Outcome (timing)

Process Evaluation

Internal/External

Subtotal

6. OTHER

Ethical guidelines

Programme change

Funding change

Community support

Subtotal

8

TOTAL

82

NOTE: ALL ITEMS ARE SCORED $0=$ NO $2=$ YES, UNLESS OTHERWISE SPECIFIED 
Appendix 4: COPES

Community Oriented Programmes Environment Scale (Moos, 1974)

Nole: A manual is available from the author.

1. Members put a lot of energy into what they do around here.

2. The healthier members here help take care of the less healthy ones.

3. Members tend to hide their feelings from one another.

4. There is no membership government in this program.

5. This program emphasizes training for new kinds of jobs.

6. Members hardly ever discuss their sexual lives.

7. It's hard to get people to argue around here.

8. Members' activities are carefully planned.

9. If a member breaks a rule, he knows what the consequences will be.

1 0 . Once a schedule is arranged for a member, the member must follow it.

11. This is a lively place.

12 . Staff have relatively little time to encourage members-

13. Members say anything they want to the staff.

14. Members can leave here anytime without saying where they are going.

IS. There is relatively little emphasis on teaching members solute ons to practical problems.

16. Personal problems are openly talked about.

17. Member often criticize or joke about the staff.

18. This is a very well organized program.

19. If a member's program is changed, staff always tell him why.

20. The staff very rarely punish members by, taking away their privileges.

21. The members are proud of this program.

22. Members seldom help each other.

23. It is hard to tell how members are feeling here. 
24. Members are expected to take leadership here.

25. Members are expected to make detailod, specific plans for the future.

26. Members are rarely asked personal questions by the staff.

27. Members here rarely argue.

28. The staff make sure that this place is always neat.

29. Staff rarely give members a detailed explanation of what the program is about.

30. Members who break the rules are punished for it.

31. There is very little group spirit in this program.

32. Staff are very interested in following up members once they leave the program.

33. Members are careful about what they say when staff are around.

34. The staff tend to discourage criticism from members.

35. There is relatively little discussion about exactly what members will be doing after they leave the program.

36. Members are expected to share their personal problems with each other.

37. Staff sometimes argue openly with each other.

38. This place usually looks a lıttle messy.

39. The program rules are clearly understood by the members.

40. If a member fights with another member, he will get into real trouble with the staff.

41. Very few members ever volunteer around here.

42. Staff always compliment a member who does something well.

43. Members are strongly encouraged to express themselves freely here.

44. Members can leave the program whenever they want to.

45. There is relatively little emphasis on making specific plans for leaving this program.

46. Members talk relatively little about their past.

47. Members sometimes play practical jokes on each other,.

48. Members here follow a regular schedule every day. 
49. Members never know when staff will ask to see them.

S0. Staff don't order the members around.

51. A lot of members just seem to be passing time here.

52. The staff know what the members want.

53. Members spontaneously set up their own activities here.

54. Members can wear whatever they want.

55. Most members are more concerned with the past than with the future.

56. Members tell each other about their intimate personal problems.

57. Staff encourage members to express their anger openly here.

58. Some members look messy.

59. The members always know when the staff will be around.

60. It is important to carefully follow the program rules here.

61. This program has very few social activities.

62. Staff sometimes don't show up for their appointments with members.

63. When members disagree with each other, they keep it to themselves.

64. The staff almost always act on members' suggestions.

65. Members here are expocted to demonstrate continued concrete progress toward their goals.

66. Staff are mainly interested in learning about members' feelings.

67. Staff here never start arguments.

68. Things are sometimes very disorganized around here.

69. Everyone knows who's in charge here.

70. Members can call staff by their first names.

71. Members are pretty busy all of the time.

72. There is relatively little sharing among the members.

73. Members can generally do whatever they feel like here.

74. Very few members have any responsibility for the program here. 
75. Tembers are taught specific new skills in this program.

76. The members rarely talk with each other about their personal problems.

77. Members often gripe.

78. The dayroom or living room is often untidy..

79. People sir. always changing their minds here..

80. Members inay internupt staff when they are talking.

81. Discussions are very interesting here.

82. Members are given a great deal of individual attention here.

83. Members tend to hide their feelings from the staff.

84. Members here are very strongly encouraged to be independent.

85. Staff care more about how members feel than about their practical problems.

86. Members are rarely encouraged to discuss their personal problems here.

87. Staff here think it is a healthy thing to argue.

88. Members are rarely kept waiting when they have appointments with staff.

89. Members never quite know when they will be considered ready to leave this program.

90. Members will be transferred or discharged from this program if they don't obey the rules.

91. Members often do things together on weekends.

92. The staff go out of their way to help new members get acquainted here.

93. Members are strongly encouraged to express their feelings.

94. Staff rarely give in to pressure from members.

95. Members must make detailed plans before leaving this program.

96. Staff strongly encourage members to talk about their pasts

97. Members here rarely become angry.

98. The staff strongly encourages members to be neat and orderly here.

99. There are often changes in the rules here.

100 The staff make and enforce all the rules here. 
Appendix 5: COPES Subscales Definitions

Community oriented Programmes Environment Scale (Moos, 1974)

1. Involvement measures how active members are in the day-to-day functioning of their programme. (spending time constructively, being enthusiastic, du. $\rightarrow$ tivings on their own initiative).

2. Support measures the extent to which members are encouraged to be helpful and supportive toward other mambers and how supportive staff are toward members.

3. Spontaneity measures the extent to which the programme encourages members to act openly and to express their feelings openly.

4. Autonomy assesses how self-sufficient and independent members are encouraged to be in m.king decisions about their personal affairs (what they wear, where they go) and in their relationships with the staff.

5. Practical Orientation assesses the extent to which the member's environment orients him toward preparing himself for release from the programme. Such things as training for new kinds of jobs, looking to the future, and setting and working toward goals are considered.

6. Personal Problem Orientation measures the extent to which members are encouraged to be concerned with their personal problems and feelings and to seek to understand them.

7. Anger and Aggression measures the extent to which a member is allowed and encouraged to argue with members and staff, to become openly angry, and to display other aggressive behaviour.

8. Order and Organization measures the importance of order and organization in the programme in terms of members (how do they look), staff (what they do to encourage order), and the house itself (how well it is kept).

9. Programme Clarity measures the extent to which the member knows what to expect in the day-to-day routine of this programme and explicitness of the programme rules and procedures.

10. Staff control assesses the extent to which the staff use measures to keep members under necessary controls (e.g. in the formulation of rules, the scheduling of activities, and in the relationships between members and staff). 
Appendix 6: CRF Risk \& Need Factors

RPS2

AGENCY:

RESIDENCE:

CASE CODE:

(First \& last letter of family name, first \& last letter of given name.)

DATE OF BIRTH:

(yy/mm/dd) 
CRF: Part A

\section{NEEDS, RISKS \& PLACEMENT}

1. Case Code:

First \& last letters of family name, first \& last letters of given name \& Date of Birth (yy/mm/dd).

2. Agency \& Residence:

3. Wardship:

Instructions: Circle y for Yes where appropriate.

Placement

Presently in residence

YES

On waiting list to enter residence

$4 y$

On waiting list for placement elsewhere

Discharged

How many previous residential placements?

$5 \mathrm{y}$

$6 y$

$7 \mathrm{y}$

8

Who referred the chiid?

Parent

Child

Neighbour

$11 \mathrm{y}$

School

Children's Aid Society

$13 y$

Physician

$14 y$

General Hospital

$15 y$

Outpatient Clinic

$16 y$

Inpatient service

$17 \mathrm{y}$

Psychiatric hospital

$18 \mathrm{y}$

Children's Mental Health Centre

Court

Independent Professional - specify

Other agency - specify

Other - specify

Name Of Referring Person: 24

Name Of Referring Agency: 25

NOTE: Another questionnaire (RFRL) is to filled out by the referring worker. 


\section{CRF: Part B}

\section{Scoring Key:}

Items were scored 1 for present and 0 for not present or unknown. The sum was the total presenting problems score.

\section{PRESENTING PROBLEMS WHEN CHILD WAS REFERRED}

Instructions: Circle y for Yes where appropriate.

In the priority column number the three most important problems in order.

Handicaps

\author{
Medical problems \\ Physical problems \\ Intellectual handicap \\ Borderline \\ Below borderline \\ Trainable \\ Organic Impairments \\ Speech \\ Young mother
}

School Problems

\section{YES \\ PRIORITY}

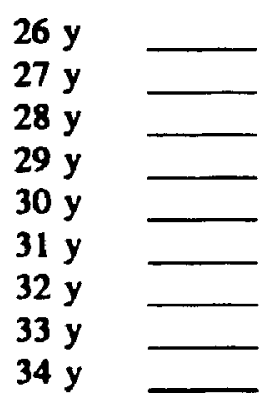

35 y

$36 y$

$37 \mathrm{y}$

$38 \mathrm{y}$

$39 \mathrm{y}$

$40 y$

$41 y$

$42 y$

$43 y$

$44 y$

$45 y$

$46 y$

$47 y$

$48 y$

$49 y$

$50 y$

$51 \mathrm{y}$

$52 y$

If you wish, describe the problems in more detail below. 


\section{CRF: Part C}

\section{Scoring Key:}

Items were scored 1 for present and 0 for not present or unknown. From Part B a total presenting problems score was calculated. From Part C total protective and total risk scores were calculated. The total protective score was the sum of present positive items out of 15 (item numbers 70 to 84). The total risk score was the sum of present negative items out of 17 (item numbers 54 to 69) minus the total protective score. Two other need scores were calculated, (a) programme needs and (b) total needs. Programme needs were the total number of those risk factors (marked with an asterisk) that might be changed by treatment. Total needs were the total number of presenting problems plus the total programme needs.

\section{RISK \& PROTECTIVE FACTORS}

Instructions:

Low SES

Family Problems

Parental Problems

Child Problems

Gets Along

School Achievement
Circle $\mathbf{y}$ for Yes where appropriate.

Mother $<$ grade 8 education

Low family income

Overcrowded home

Subsidized rent

Welfare

Unemployed parent

Family conflict

Family violence

53 y

$54 y$

$55 y$

56 y

57 y

58 y

$59 \mathrm{y}$

$60 \mathrm{y}$

One or both parents

ever treated for nerves ever arrested

Chronic health problems

$61 \mathrm{y}$

62 y

$63 \mathrm{y}$

*Gang membership

*Delinquent friends

* Older friends

* Chronic running away

Physical or sexual abuse

Convicted of an offence

64 y

$65 \mathrm{y}$

$66 \mathrm{y}$

$67 y$

$68 \mathrm{y}$

$69 y$

Child gets on well with

"parents
"teachers
"peers
*others

$70 y$

$71 \mathrm{y}$

$72 \mathrm{y}$

$73 \mathrm{y}$

Never failed a grade

$74 \mathrm{y}$

Never had remedial education $\quad 75$ y

*Good or excellent student

Friendships 
- Regular activities with friends

*Has a confidant

Competence

Good skills in

*oports *music

*other hobbies

Participates in adult led activities *sports
$77 \mathrm{y}$

$78 \mathrm{y}$

$79 \mathrm{y}$

$80 \mathrm{y}$

$81 \mathrm{y}$

82 y

$83 y$

$84 y$ 
Appendix 7: RFRL Referrals

RFRL

AGENCY:

RESIDENCE:

CASE CODE:

DATE OF BIRTH:

(yy/mm/dd) 
RFRL

REASONS FOR REFERRAL OF CHILD

1. Referring person \& agency:

2. Case Code:

First \& last letters of family name, first \& last letters of given name \& Date of Birth (yy/mm/dd).

3. Agency \& residence placement:

4. Wardship:

Instructions: Circle $y$ for YES for reason for referral to the present residence.

Under priority number the three most important reasons in order. REASONS

Type of Treatment

Crisis intervention

Assessment

Specialized treatment - specify

In natural family

in adoption home

in foster home

Unavailable Alternative

Other Reasons For Referral
Appropriate foster home

Less restrictive

Treatment

Assessment

Need for

Court order

$$
\begin{aligned}
& \text { structure } \\
& \text { treatment } \\
& \text { permanency }
\end{aligned}
$$

Previous multiple placements

family

foster

residences

CAS

open custody

Parental interference in foster home

Chronic runner

Suicidal behaviour

Professional recommended

Most accessible placement

Other - specify
$5 y$

$6 y$

$7 y$

$8 y$

$9 y$

$10 y$

$11 y$

$12 y$

$13 y$

$14 y$

$15 \mathrm{y}$

$16 y$

$17 y$

$18 \mathrm{y}$

$19 y$

$20 y$

$21 \mathrm{y}$

$22 y$

$23 y$

$24 \mathrm{y}$

$25 \mathrm{y}$

$26 y$

$27 y$

$28 y$ 
Appendix 7: Client Needs \& Available Services

RPSS

\section{Client Profile}

Instructions: $\quad$ circle sexes \& ages

24 Sex male female both

25 Ages 1-5, 6-8, 9-10, 11-12,

13-14 15-16

17-18

Instruction
Placement

circle yes $(y)$ or no $(n)$

YES NO

voluntary

involuntary

26 y n

27 y n

Handicaps

medical problems

physical problems

intellectual handicap

borderline

below borderline

organic impairments

speech problems

young mothers (less than 16 years)

28 y n

29 y n

30 y n

31 y n

32 y n

33 y n

34 y n

35 y n

\section{School}

problems

attendance

36 y n

37 y n

38 y n

achievement

school placement unavailable

learning disabilities

39 y n

$40 y \quad n$

Behaviour

problems

disorders

conduct

emotional

hyperactivity

somatization

multiple disorders

substance abuse

high level of physical aggression

suicidal behaviour

41 y n

$42 y \quad n$

43 y n

$44 y \quad n$

$45 \mathrm{y} n$

$46 \mathrm{y} \quad \mathrm{n}$

$47 y \quad n$

$48 y$ n

Priority

severe problems

$49 \mathrm{y} \quad \mathrm{n}$

moderate problems

50 y n

Attitude

accepting of house rules

51 y n

accept treatment

motivated

family willing to be involved

$52 y$

$53 y$

$54 y$

n

n

Clinical

child - potential for change

$55 y$

n 
judement child - needs appropriate for

family - potential for change

56 y n

57 y n

Lenpth of

crisis intervention

59 y n

short term < 6 months

moderate term 6-18 months

60 y n

61 y n

long term > 19 months

$62 y \quad n$

Cultural

French
English
Native

63 y n

64 y n

$65 y$ n

Other client characteristics - specify

66 y n 


\section{Referrals}

Instructions: Circle who you receive referrals for residence places from (f) AND/OR to (t) whom you refer.

FROM

$67 \mathrm{f}$

$69 \mathrm{f}$

$71 \mathrm{f}$

$73 \mathrm{f}$

$75 \mathrm{f}$

77 f

79 f

$81 \mathrm{f}$

$83 \mathrm{f}$

$87 \mathrm{f}$

$91 \mathrm{f}$

$93 \mathrm{f}$

$95 \mathrm{f}$

$97 \mathrm{f}$
TO

68 t

70 t

$72 \mathrm{t}$

$74 \mathrm{t}$

$76 \mathrm{t}$

$78 \mathrm{t}$

80 t

82 t

84 !

88 t

92 t

94 t

$96 \mathrm{t}$

98 เ 


\section{Services available}

Instructions: Circle $y$ (for yes) under (IN) if within the agency OR $y$ under (OUT) if available outside the agency.

Write in the profession of the person providing the service.

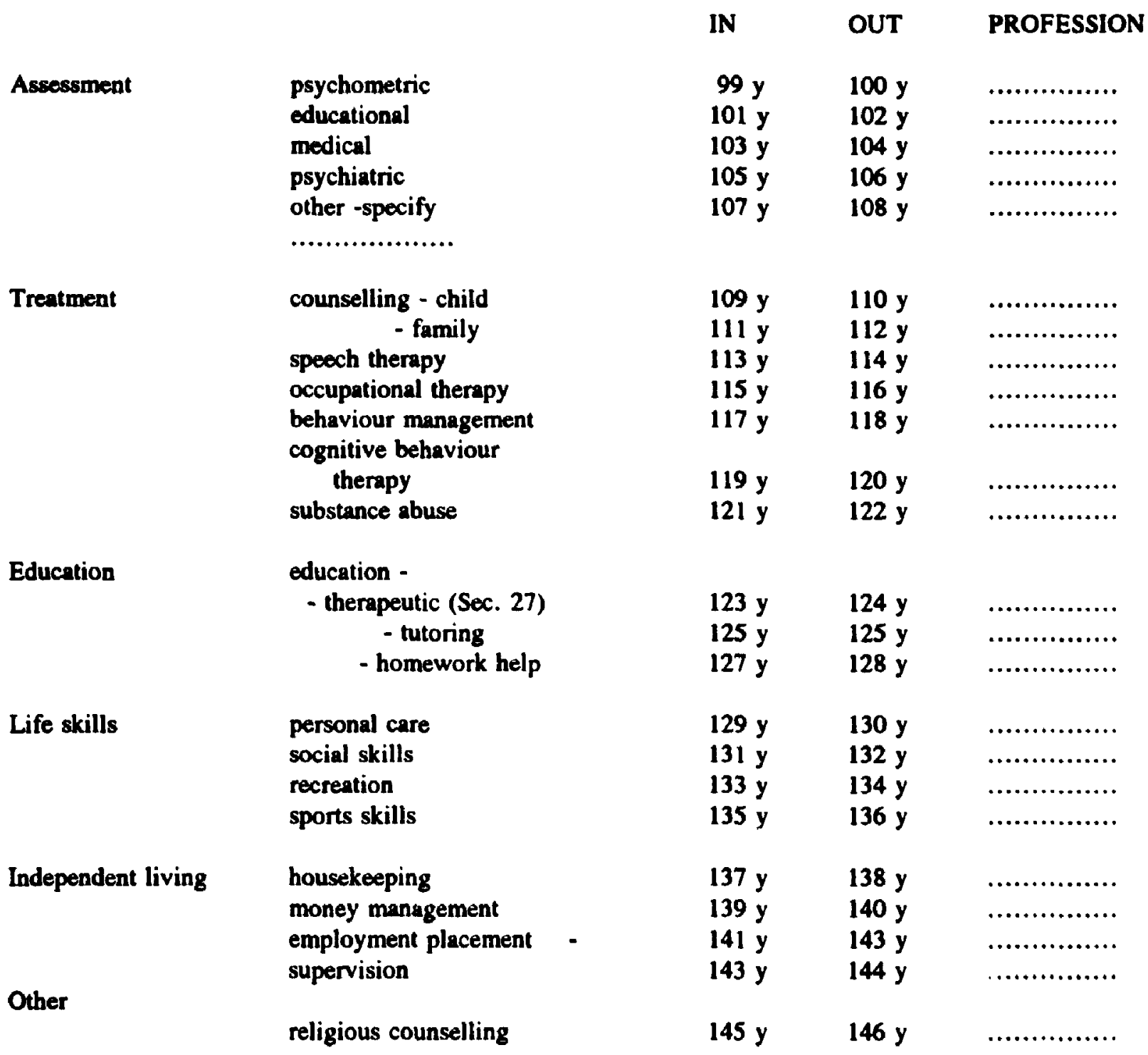


Appendix 8: Service/Needs Matching Criteria

Residential Placement Study

(McClure, Armstrong, Cloutier \& Tillman, 1991)

Note: Only the service match was used in the present study.

A. Types of Matching

1. Profile match:

-correspondence between presenting problems of the child

(RPS2) and client profile of the agency (RPS5)

2. Service match:

-corresponder.ze between presenting problems of the child

(RPS2) and services available through the agency (RPS5)

3. Referral match:

-correspondence between reasons for referral of the child

(RPS4) and services available through the agency (RPS5)

B. Matching Scores Formulas

Please note that each item presented in the formulas below are defined in detail in subsequent sections. Basically, the formulas work as follows: are present.

a) A match score is determined by assigning one point every time a problem and a corresponding service

b) Since some children will have more problems than other children, and thus a need for more services, the match score is divided by the total number of possible matches involved for a given child. This will provide a proportional score which can be compared across children.

c) Finally, proportional ":ores are converted to percentages in order to simplify interpretation oi the final score. A score of $100 \%$ indicates a perfect match between the child's problems and the services available (as measured by this study). A score of $0 \%$ indicates a total absence of compatibility. Scores in-between indicate varying degrees to which a match exists.

1. Profile match percentage score $=100 *$ (profile match total raw score / number of possible matches)

2. Service match percentage score $=100 *$ (service match total raw score / number of possible matches)

3. Referral match percentage score $=100 *$ (referral match total raw score / number of possible matches) 
D. Service match total raw score (0-93)

Listed below are the items which were matched to make up the service match total raw score. Again, presenting problems were taken from the Needs, Risks and Placements questionnaire completed by the key worker or case manager. Services available to the children (either from within the agency or from an outside source) are listed from the Agency and Residence Description questionnaire, completed by the director of the agency or a delegate. When a problem was indicated as being present for a given child, and the corresponding agency provided the service indicated, a match score of one was given. (In some cases, a match score of one was given if at least one particular type of service was offered -- for example, at least one of the four independent living services.) If the problem was not present, or if the problem was present but the agency did not provide the corresponding service, the resulting score was zero. A total of 24 problems were matched with anywhere from one to seven services per problem. Thus, $t$. tal scores could range from 0 to 93.

Presenting Problem

Medical problems

Physical problems

Borderline Itellectual handicap
Services Available

Medical assessment

Independent living:

-housekeeping

-money management

-employment

-supervision

Medical assessment

Independent living:

-housekeeping

-money management

-employment

-supervision

Occupational therapy

Score

Educational assessment

Psychometric assessment

Independent living:

-housekeeping

-money management

-employment

-supervision

Life skills

-personal care

-social skills

-recreation

-sports skills 
Presenting Problem

Below borderline intellectual handicap

Organic impairments

Speech problems

Young mother

School attendance

School behaviour

School achievement

Out of school

Home teaching

School suspension
Services Available

Score

Educational assessment

Psychometric assessment

Independent living:

-housekeeping

-money management

employment

-supervision

Life skills:

-personal care

-social skills

-recreation

-sports skills

Medical assessment

Independent living:

-housekeeping

-money management

employment

-supervision

Speech therapy

1

Independent living:

-housekeeping 1

-money management 1

employment 1

-supervision 1

Behaviour management 1

Cognitive behaviour therapy 1

Behaviour management 1

Cognitive behaviour therapy 1

Therapeutic education 1

Tutoring

Homework help

Therapeutic education

Tutoring

1

Therapeutic education

Tutoring

l

Therapeutic education

Tutoring
1

1

1 
Presenting Problem

Leaming disabilities

Conduct disorder

Hyperactivity disorder

Emotional disorder

Somatization disorder
Services Available

Score

Educational assessment

Medical assessment

Psychometric assessment

Tutoring

Homework help

1

1

1

Psychintric assessment 1

Child counselling 1

Behaviour management 1

Cognitive behaviour therapy 1

Life skills:

-social skills

-recreation

-sports skills

Medical assessment

1

Psychiatric assessment 1

Child counselling 1

Behaviour management 1

Cognitive behaviour therapy 1

Life skills:

-social skills

-recreation

-sports skills

Psychiatric assessment

Child counselling $\quad 1$

Behaviour management 1

Cognitive behaviour therapy 1

Life skills:

-social skills

-recreation

-sports skills

Medical assessment 1

Psychiatric assessment 1

Child counselling 1

Behaviour management 1

Cognitive behaviour therapy 1

Life skills:

-social skills

-recreicion

-sports skills 
Presenting Problem

Multiple problems

Sexually abuses others

Substance abuse

Eating disorders

High aggression

Suicidal behaviour
Services Available

Score

Psychiatric assessment

Psychometric assessment

1

1

Psychiatric assessment

Psychometric assessment

Child counselling

Family counselling

Behaviour management

Cognitive behaviour therapy

1

1

1

1

1

1

Substance abuse treatment

1

Psychiatric assessment

Psychometric assessment

Child counselling

Family counselling

Behaviour management

Cognitive behaviour therapy

Psychiatric assessment 1

Psychometric assessment 1

Child counselling 1

Family counselling 1

Behaviour management 1

Cognitive behaviour therapy 1

Psychiatric assessment 1

Psychometric assessment

Child counselling

Family counsellinz:

Behaviour management

Cognitive behaviour therapy

Psychiatric assessment

Psychometric assessment

Child counselling

Family counselling

Behaviour management

Cognitive behaviour therapy

1

1

\section{6}


Appendix 9: Child Behaviour Checklist (Offord et al., 1987).

OCHS 3B

CONFIDENTIAL

(when completed)

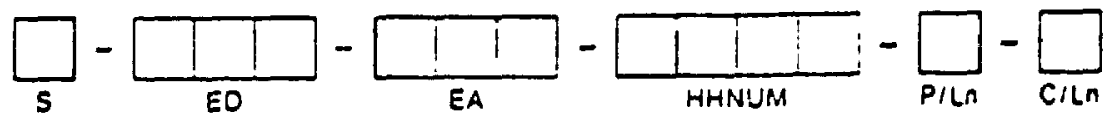

\section{Ontario Child Health Study Child Behaviour Checlint \\ (For'ages 4 to 16)}
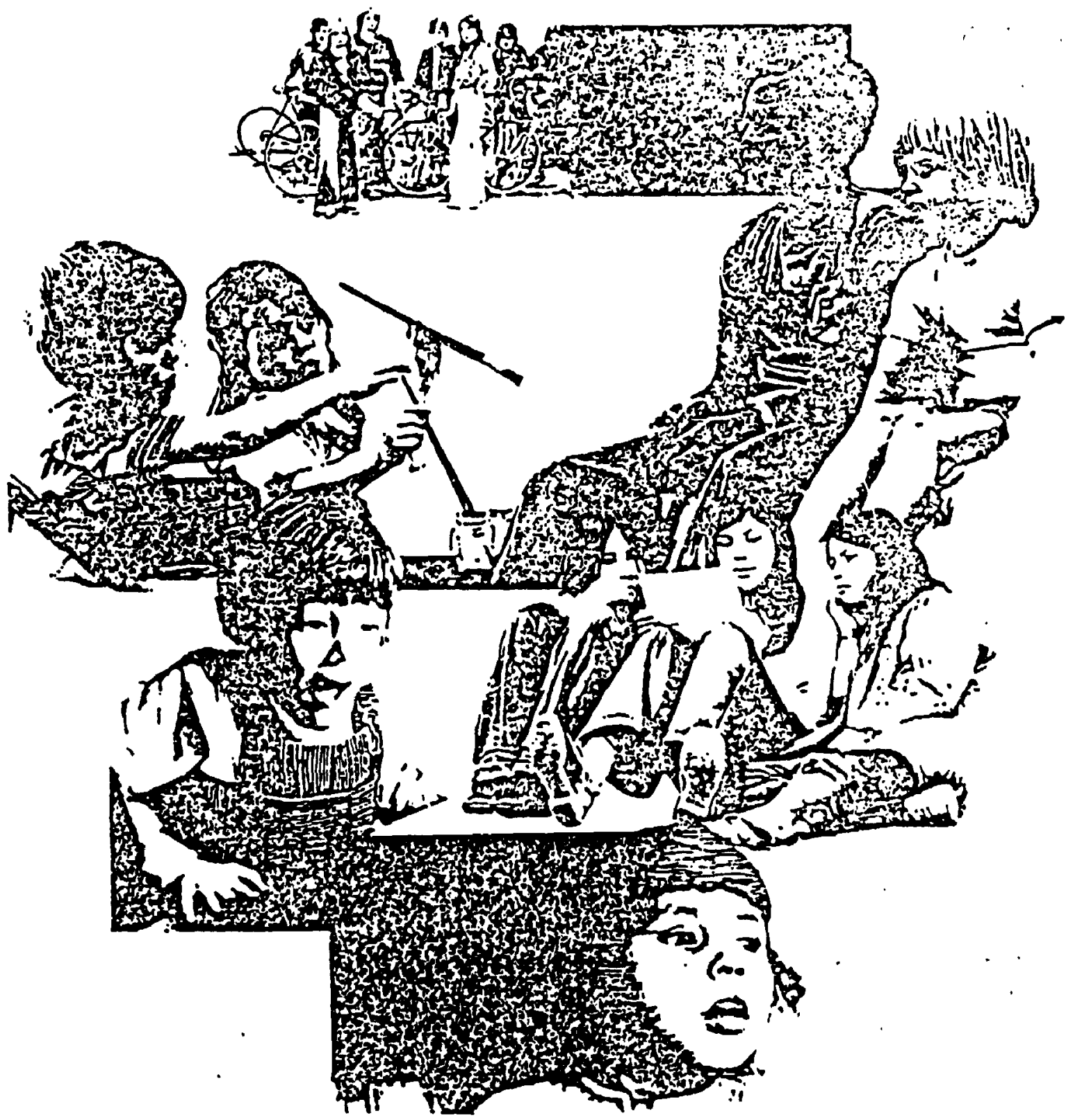
ART A: Answer each item as completely as possible, oven if you feel you lack complece information. Mark your answer in the appropriate ciele with a $\mathcal{X}$ or fill in the boxes provided. If you are unable to answer a question leave it blank.

1. Child's orede

(If ungreded or special dass, deseribe.)
04. How would rou describe this enild's current school performance in the lollowing calegories?

\begin{tabular}{|c|c|c|c|c|}
\hline & $\begin{array}{c}\text { Rezding } \\
\text { English }\end{array}$ & Spelling & $\begin{array}{l}\text { Arithmetic } \\
\text { of Math }\end{array}$ & Overall \\
\hline Far below grade & & & & \\
\hline Somewhas below g & & 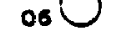 & & \\
\hline Af groog lavel. & & 10 & 11 & 12 \\
\hline Somewnat sbove g & & & 15 & 10 \\
\hline Far soove grade & & 8 & 19 & 20 \\
\hline
\end{tabular}

05, Has inis chidd over repested or (jiled a grade?

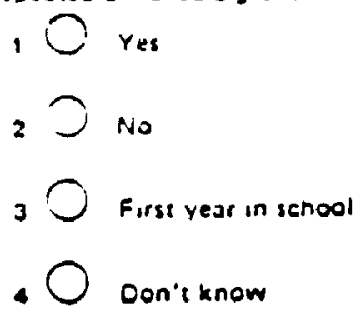

3. How wall do you know this child?
$1 O$ very wall
$2 \bigcirc$ Moderataly well
$\pm \bigcirc$ Not noll

ART B: Below is a list of statements that describe some of the feelings and behaviour of children. For each statement, please mark the circle that best describes this child now or within the past 6 months. Please mark only one of the three circles for each statement.

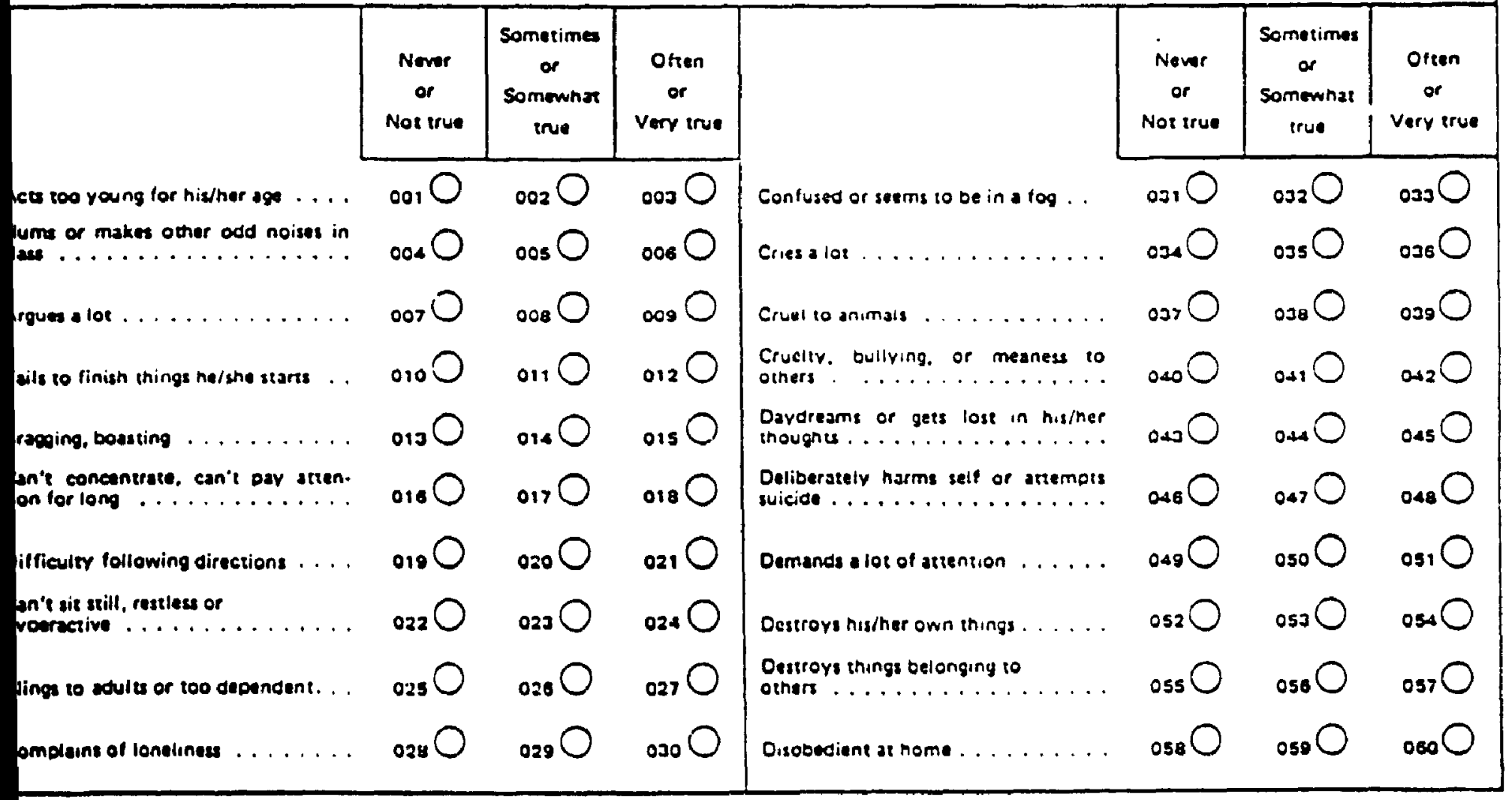


PART A:

Below is a list of statements that describe some of the feelings and behaviour of children. For each statement, please mark the circle that best describes now or within the past

6 months. Please mark only one of the three circles for each sta'ement. Mark your answers like this 8.

\begin{tabular}{|c|c|c|c|c|c|c|c|}
\hline & $\begin{array}{l}\text { Nover } \\
\text { or } \\
\text { Not true }\end{array}$ & $\begin{array}{c}\text { Somotimas } \\
\text { or } \\
\text { Somowhat } \\
\text { true }\end{array}$ & $\begin{array}{l}\text { Orten } \\
\text { or } \\
\text { Very true }\end{array}$ & & $\begin{array}{l}\text { Nover } \\
\text { or } \\
\text { Not irue }\end{array}$ & $\begin{array}{c}\text { Somotimes } \\
\text { or } \\
\text { Somewhat } \\
\text { true }\end{array}$ & $\begin{array}{l}\text { Otten } \\
\text { or } \\
\text { Very true }\end{array}$ \\
\hline Acts tos young for his/her age . ... & $\infty 10$ & $\infty 02 \bigcirc$ & $\cos O$ & $\begin{array}{l}\text { Eats of drinks things that are not } \\
\text { lood (eg: crayons. dint. etc.). }\end{array}$ & 0760 & or $\bigcirc$ & $078 \bigcirc$ \\
\hline $\begin{array}{l}\text { Allergy } \ldots \ldots \ldots \ldots \ldots \ldots \ldots \ldots \\
\text { Arguas a lol } \ldots \ldots \ldots \ldots \ldots \ldots\end{array}$ & $\infty$ & $\cos C$ & $\begin{array}{l}\cos 0 \\
\cos O\end{array}$ & $\begin{array}{l}\text { Fears corrain animals. situa. } \\
\text { tons, or placos other inan school }\end{array}$ & 079 & $080 \bigcirc$ & $\infty 81$ \\
\hline Asthma .. & 010 & $011 C$ & $012 \bigcirc$ & Foars going to school ....... & & $003 \mathrm{O}$ & 084 \\
\hline Bragging, boasting............. & 0130 & 0.140 & $0,5 \bigcirc$ & $\begin{array}{l}\text { Fears ho/she mignt think or }=0 \\
\text { something bad } \ldots \ldots \ldots \ldots \ldots\end{array}$ & & & \\
\hline $\begin{array}{l}\text { Can't concontrato. can't pay atren. } \\
\text { tion for long ....................... }\end{array}$ & 0180 & 0.70 & 0.180 & Foels he/she has 10 bo porfocl & 088 & $\cos O$ & 090 \\
\hline $\begin{array}{l}\text { Can't got his/hor mind off cortan } \\
\text { thoughts. obsossions ............. } \\
\text { Can't sit still }\end{array}$ & $010 \bigcirc$ & $020 \bigcirc$ & 021 & $\begin{array}{l}\text { Feels or complains that no one loves } \\
\text { himnthet.................... }\end{array}$ & & & \\
\hline $\begin{array}{l}\text { Can't sit still, restloss or } \\
\text { hyporactuve } \ldots \ldots \ldots \ldots \ldots \ldots\end{array}$ & $022 \bigcirc$ & 023 & 024 & Foels others aro out to gel him/her & & & \\
\hline rlings to adults or too dependent & $025 \mathrm{C}$ & $028 \bigcirc$ & 027 & Fegls worthless or inlerior.... & & & \\
\hline - umplains of longliness $\ldots \ldots \ldots$ & $028 \bigcirc$ & $029 \bigcirc$ & 030 & Gets hun a lot, accicent-prone & & & \\
\hline $\begin{array}{l}\text { Conlused or seems to oo in a log. } \\
\text { Cries a lot . . . . . . . . . . . . }\end{array}$ & $\begin{array}{l}0310 \\
0340\end{array}$ & $\begin{array}{l}0320 \\
0.350\end{array}$ & $\begin{array}{l}0.33 C \\
0360\end{array}$ & Gets in many tights. & & 10 & \\
\hline Cruel to animais....... & $037 \bigcirc$ & are 0 & $\infty$ & Gets toased a lot ........... & & & \\
\hline $\begin{array}{l}\text { Crualty, bullyning, or meaness to } \\
\text { others } \ldots \ldots \ldots \ldots \ldots \ldots \ldots\end{array}$ & 020 & $0 \times 1 \bigcirc$ & $0 \times 2 O$ & $\begin{array}{l}\text { Hangs around with children who get } \\
\text { in trouble .............. }\end{array}$ & & & 111 \\
\hline $\begin{array}{l}\text { Dayereams or gets lost in his/her } \\
\text { inoughis } \ldots \ldots \ldots \ldots \ldots \ldots\end{array}$ & $\infty$ & $0+40$ & ass 0 & Hoars things that aron't inere & & 113 & 1140 \\
\hline $\begin{array}{l}\text { Doliberately harms solt of attempls } \\
\text { suicide ............................ }\end{array}$ & $0 \times 60$ & 0.47 & 048 & $\begin{array}{l}\text { Impulsive or acts without thinking } \\
\text { Likes to de alone ................ }\end{array}$ & $\begin{array}{l}115 \\
118\end{array}$ & ${ }_{119}^{119} \mathrm{C}$ & $\begin{array}{l}1170 \\
1200\end{array}$ \\
\hline Demands a bot of anention ..... & $\operatorname{sos} 0$ & $050 \bigcirc$ & osi 0 & Lying or cheating............. & 121 & 122 & ${ }_{123} \bigcirc$ \\
\hline Destroys his/her own things...... & $052 \bigcirc$ & 050 & $054 C$ & $\begin{array}{l}\text { Bites fingornails ............... } \\
\text { Nervous, highstrung, or tense ... }\end{array}$ & ${ }_{127}^{124}$ & ${ }_{128} \mathrm{C}$ & ${ }_{128}{ }_{128} \mathrm{C}$ \\
\hline $\begin{array}{l}\text { Destroys things belonging to } \\
\text { his/hor tamily or other children }\end{array}$ & oss $\bigcirc$ & 058 & 057 & Nervous movel tents or twitehing & 130 & 131 & 1320 \\
\hline Oisobadiont at nome $\ldots \ldots \ldots \ldots$ & ${ }_{050} C$ & $050 \mathrm{C}$ & 060 & Nighimares .............. & 133 & 134 & 125 \\
\hline $\begin{array}{l}\text { Disobodient at schood } \ldots \ldots \ldots \ldots \\
\text { Donsn't eal woll ............... }\end{array}$ & $\begin{array}{l}\cos O \\
\cos O\end{array}$ & $\begin{array}{l}062 \bigcirc \\
065 \bigcirc\end{array}$ & $\begin{array}{l}\infty 60 \\
\infty 060\end{array}$ & Not liked by other chileren. & 136 & 137 & 138 \\
\hline 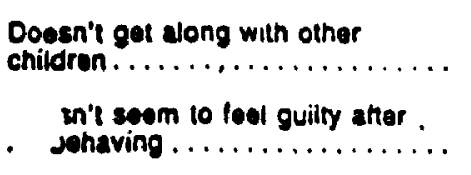 & $\begin{array}{l}067 \bigcirc \\
070 \bigcirc\end{array}$ & $\cos \bigcirc$ & 069 & $\begin{array}{l}\text { Constipstod, doosn't move bowels. } \\
\text { Too teartut or anxious .......... } \\
\text { Foels dizzy ................. }\end{array}$ & $\begin{array}{l}139 \bigcirc \\
142 \bigcirc \\
145 \bigcirc\end{array}$ & ${ }_{103}{ }_{10} C$ & ${ }_{141}^{14}($ \\
\hline Easily joalous . . . . . . . . . . ... & ors $\mathrm{O}$ & 0740 & $075 \bigcirc$ & Fools too guilty................ & ${ }_{140} O$ & 1490 & $150 \bigcirc$ \\
\hline
\end{tabular}




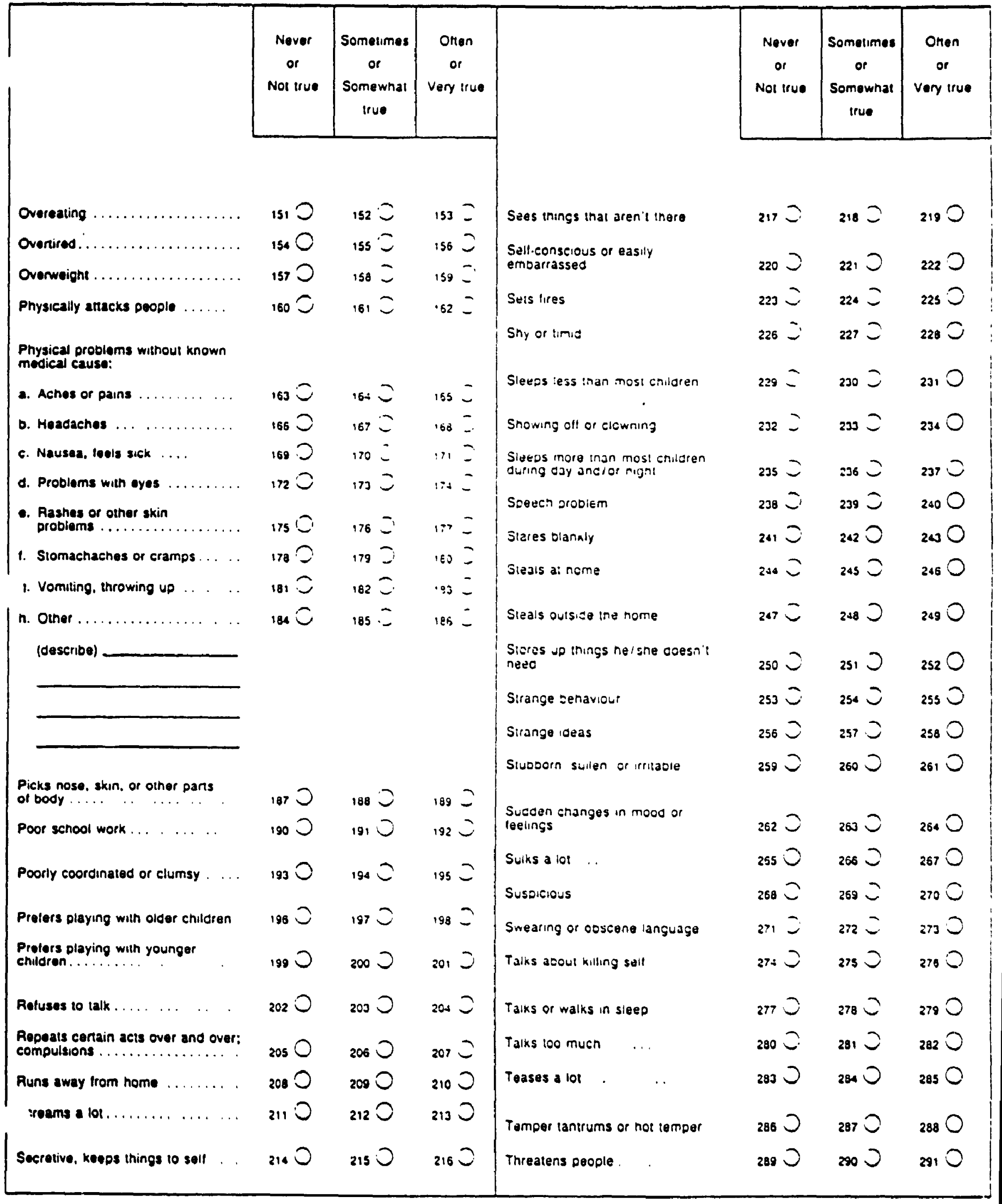




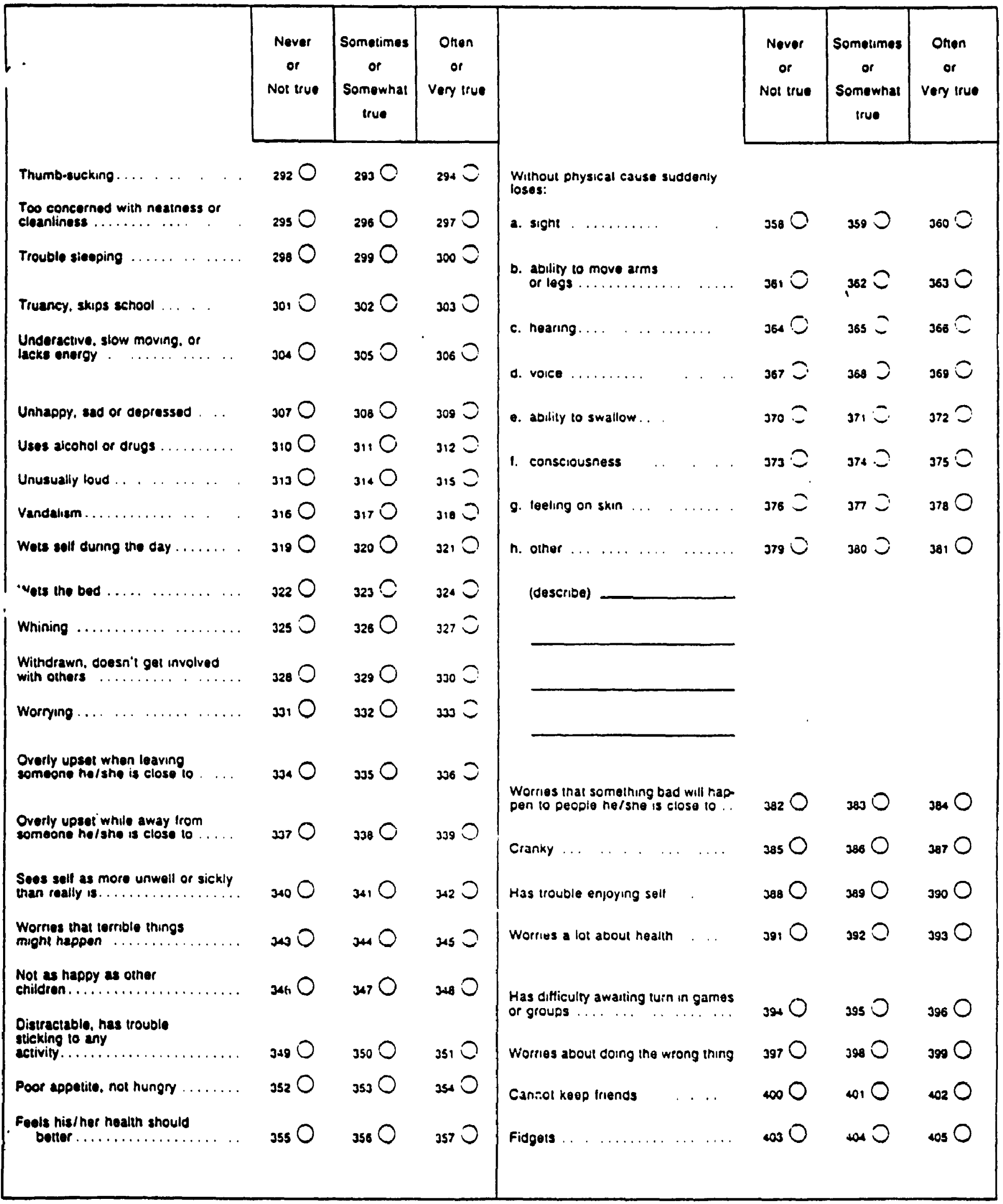




\section{PART B:}

The following questions ask about your child's friendships and social activities. For each question, please mark the answer you think comes closest. Mark your answers like this

01. About how many days a weok does he/she do things with friends?
10 Nover
20 i day a wook
3 O 23 days a wook
4 C 45 days a weak
$5 \bigcirc$ \&7 days a wook

02. About how many close Iriends does he/she have?
1 Nono
$2 \bigcirc 1$
302 or 3
4. or 5
56 or more

06. How well does helsne do in spons compared to orher kids his/ner age?
10 way below average
$2 \bigcirc$ Below averago
$3 \bigcirc$ Average
4 abovo average
$5 \bigcirc$ Way above averago

07. Ouiside of regular pnysical ecucation slasses, did ho/ she lake pan in any spons during the past yeat wnich involved acull coaching or insiruction?

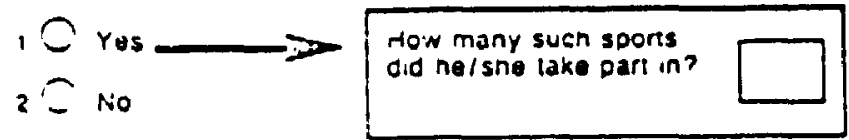

08. For acivities such as music. dance, an and individual hobores. how rell coes neisno do compared to olher kids misinor ace?

iC Way below avorage

$2 \bigcirc$ Below average

3 Average

- above average

$s \bigcirc$ Way above average

09. Outside of reguiar classes in school. did he/ she lake any lessons or instruction during the past year in music, dance, an. or other non-spon acivities?

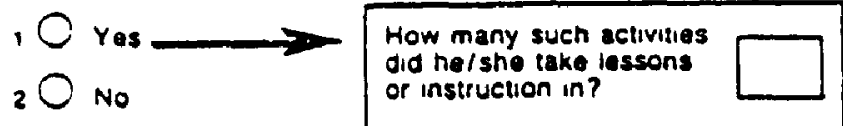

10. Dunng the past year has ho/ she bolonged to any clubs or groups with aduli leadersnip such as cubs, scouls. brownies, a church group of community programs?
1 Yes How many such clubs
or groups did he/she

$2 \bigcirc$ No

belong 10 ?

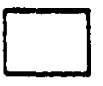

THANK YOU FOR ANSWEAING THESE OUESTIONS. IF YOU WISH. YOU MAY PUT THE COMPLETED FORM IN THE ENVE. LOPE PROVIDED BEFORE HANOING IT BACK TO YOUR INTER. VIEWER. 
Appendix 10: CBC Criteria

Ontario Child Health Study Parent Child Behaviour Form (Offord et al., 1986)

Note: A scoring manual is available from the authors.

Conduct disorder - requires one or both of criteria A \& B.

A: Physical violence against persons or property as part of a persistent pattern.

Cruel to animals

Cruelty, bullying or meanness to others

Physically attacks people

Gets in many fights

Destroys his/her own things

Destroys things belonging to his/her family or other children

Vandalism

Sets fires

B: Severe violation of social norms

Disobedient at school

Truancy, skips school

Threatens people

Lying or cheating

Steals at home

Steals outside the home

Runs away from home

Hyperactivity - requires all of criteria A, B \& C.

A. Inattention:

can't concentrate, can't pay attention for long;

distractible, has trouble sticking to any activity.

B. Impulsivity:

impulsive or acts without thinking;

has difficulty awaiting turn in games or groups.

C. Hyperactivity:

can't sit still, restless or hyperactive;

fidgets.

Emotional disorder - requires any of criteria A, B or C.

A: Dysphoric mood

Has trouble enjoying his/herself

Not as happy as other children

Unhappy, sad or depressed

Cries a lot

Talks about killing self

Deliberately harms self or attempts suicide

B: Compulsive, obsessive behaviour

Can't get his/her mind off certain thoughts, obsessions 
Feels he/she has to be perfect

Repeats certain acts over and over, compulsions

Too concerned with neatness or cleanliness

C: Strong feelings of tension

Nervous, high strung or tense

Too fearful or anxious

Worrying

\section{Somatization}

A. Distressing recurrent symptoms without evident physical cause constipated, doesn't move bowels

$$
\begin{aligned}
& \text { fuels dizzy } \\
& \text { aches or pains } \\
& \text { headaches } \\
& \text { nausea, feels sick } \\
& \text { problems with eyes } \\
& \text { rashes or other skin problems } \\
& \text { stomachaches or cramps } \\
& \text { vomiting, throwing up }
\end{aligned}
$$

B. Perception of self as generally sick, usually unwell sees self as more unwell or sickly than really is worries a lot about health

feels his/her health should be better 


\section{Residential Treatment Followup Study}

HOME BEHAVIOUR REPORT

1992 January

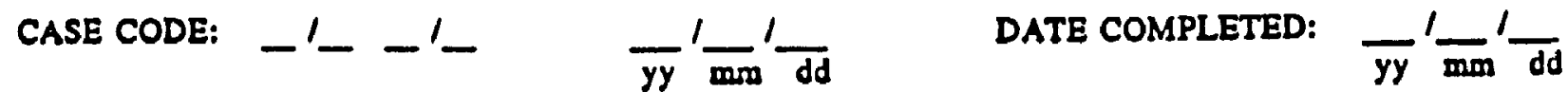

First \& last letters of family name, first \& last letters of given name and date of birth.

AGENCY:

RESIDENCE:

Have you ever filled out this questionnaire before?<smiles>[N+]=[N+]1CCCC1</smiles>

Yes<smiles>C1CCC1</smiles>

II 'yes' was this:

YES

before this child was treated at this centre?

While this child was treated at this centre?

at the end of treatment at this centre?

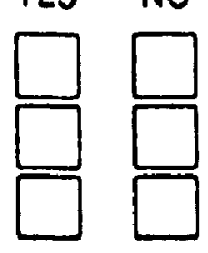

\section{PARENTS FORM}

(For children 4 to 18 )

CONFIDENTIAL (when completed)

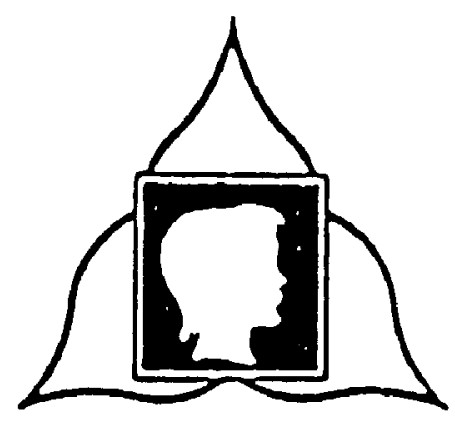

- Olford \& Boyle 1990 


\section{PART A:}

These questions ask aboul background and general health. For each question please mark the answer you think comes closest. Mark your answers like inis: $x$ Any additional explainations and comments may be added on the last page.

\section{ORIGIN}

01. What is your relationship to this child?

\section{Birth Parent}

Adoptive ParenI

Common Law Parent

Step Parent

Foster Parent

Grandparent

Aunt/Uncle

Brother/Sister

Othor Relative

Guardian but not related

Other (please specily):
05. Is this child's ancestry Status Indian, Non-Status Indian, Metis, or Invit?

$$
\begin{aligned}
& { }_{1} \square \text { Yes } \\
& { }_{2} \square \text { No }
\end{aligned}
$$

06. Belore this child was born, were you, (was this child's birth molher). ever admitted to hospital for complication ol that pregnancy?
, $\square$ Yes
2ם No
ग Don't know

07. Diy this chuld weigh less than 2,500 grams, (or the equivalent of less than 5 1/2 lbs.) when he/she was born?
$1 \square$ Yes
2 $\square$ No
ग Don'l know

Oldest child

One of middle shildren

Youngest

04. In what country was this child born?

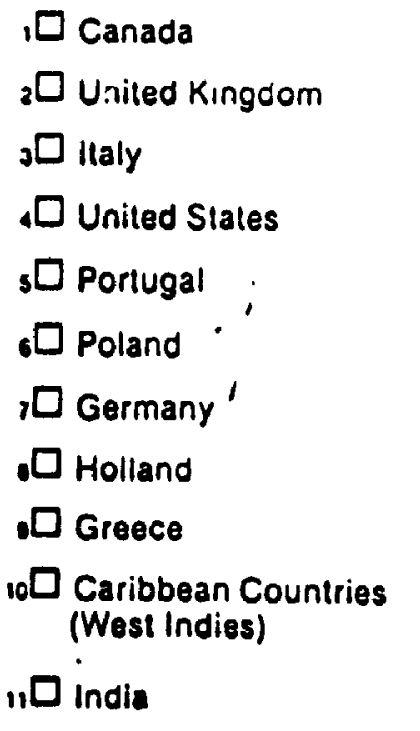

${ }_{12} \square$ Sri Lanka

is 0 Hong Kong

$14 \square$ Vietnam

1s $\square$ Phillipines

16 $\square$ Hungary

${ }_{13} \square$ Yugoslavia

10[ El Salvador

${ }_{10} \square$ Other (ploase spocily):

(a) In what year did he/she come to Canada

\begin{tabular}{|l|l|l|l|}
\hline 1 & 9 & & \\
\hline
\end{tabular}

08. Was this child kept in the hospital aller you, (this child's birth mother), went horne?
, $\mathrm{Y}$ Yes
${ }_{2} \square$ No
د Don't know

09. Belore the age of 3 did this child ever live away from you or was he/she out of your care for 3 consecutive monihs or longer? (II you are not the birth mother/father, any pre-adoption time of 3 months or longer should count as a separation).

$\square$ Yes

${ }_{2} \square$ No

د Don't know 
PART C:

Below is a list of statomonts that describe some of the teolings and behaviour of children. For each statement, please mark the box that best describes this child now or within the past six months. Please mark only one of the three boxes lor each statement. Mark your answors like inis: $x$

\begin{tabular}{|c|c|c|}
\hline $\begin{array}{c}\text { Never } \\
\text { or } \\
\text { Nol live } \\
\text { (0) }\end{array}$ & $\begin{array}{c}\text { Somelimes } \\
\text { of } \\
\text { Somewhat } \\
\text { lyut } \\
\text { (I) }\end{array}$ & $\begin{array}{c}\text { Olien } \\
\text { of } \\
\text { Very live }\end{array}$ \\
\hline
\end{tabular}

39. Cruelty, bullying or meanness 10 others

40. Avoids being alone

41. Overeating

42. Can't concentrate. can't pay attention for Icng

43. Jumps from one activity to another

44. Needs to be told over ana over that things are OK.

45. Worries about doing better al things.

46. Steals at home

47. Unhappy, sad or defressed

48. Interrupts or buits in on others

$2 \square$
$2 \square$
$2 \square$
${ }_{2} \square$
${ }_{2} \square$

49. Not as happy as olher children .................. 0 , $\square \quad$, $\square$

50. Argues a lol with adulis........, $0 \quad 0 \quad, \square \quad 2 \square$

51. Feeis $\operatorname{dizzy} \ldots \ldots \ldots \ldots \ldots \ldots \ldots \ldots, 0,0,0 \quad{ }_{2} \square$

52. Cruel to animals

53. Blames oiners for own mislinkes.

54. Feels his/her hea'in should be better ............. o $\square \quad$, $\square \quad$, $\square$

55. Does dangerous things without thinking ..................

56. Doesn't seem to listen .......... 0

57. Fidgets ...................

58. Has gained a lot of weight without trying 10

59. Worries that something bao will happen to people he/she is close to ........

60. Cries a lot .................. o $\square$

61. Repeats certain acts over and over, compulsions

62. Deliberately harms self or attempts suicide

63. Destroys things belonging to his/her family or other children

Newer
of
Not true
$(0)$

\begin{tabular}{|c|c|}
\hline $\begin{array}{l}\text { Somminus } \\
\text { Sompunat } \\
\text { (II) }\end{array}$ & $\begin{array}{l}\text { Olien } \\
\text { ory } \\
\text { very bue } \\
\text { (2) }\end{array}$ \\
\hline
\end{tabular}

64. Talks about killing self

65. Gels no pleasure from usual aclivities

66. Too concerned with neatness or cleanliness

67. Feels 100 gut...y

68. Gets into trouble when with other kids

69. Can'l stay sealed when required to do so.

70. Worries about being separated from loved ones .................

71. Sees sell as more unwell or sickly than really is

72. Disobedient at school ......... o $\square$

73. Cranky .................... cr

74. Feels hopeless ................. 0 o $\square \quad$ i $\quad{ }_{2} \square$

75. Can't get his/her mind olf certain thoughts. obsessions ................ o $\square \quad, \quad \square \quad{ }_{2} \square$

76. Feels he,'she has to be perlect

77. Poor appelite, nol hungry....... o $\square$

78. Has nightmares about being abandoned 


\begin{tabular}{|c|c|c|}
\hline $\begin{array}{c}\text { Nover } \\
\text { of } \\
\text { Nol tive } \\
\text { (0) }\end{array}$ & $\begin{array}{c}\text { Sometimns } \\
\text { or } \\
\text { Somewhal } \\
\text { tive } \\
\text { (1) }\end{array}$ & $\begin{array}{c}\text { Otien } \\
\text { of } \\
\text { Very tive } \\
\text { (2) }\end{array}$ \\
\hline
\end{tabular}

79. Scared to go to sleep without parents being near ...... 0 o $\square \quad, \quad \square \quad 2 \square$

80. Has no interest in usual activities................... o $\square \quad, \square \quad 2 \square$

81. Truancy, skips school ......... o $\square \quad$ i $\square \quad{ }_{2} \square$

62. Has broken into someone else's house, buitding or car ..... 0 , $\left[\begin{array}{llll} & , \square\end{array}\right.$

83. Has difficulty playing quielly..... 0 o $\square \quad, \quad \square \quad{ }_{2} \square$

84. Worries about doing the wrong thing

85. Impulsive, acts wilhoul thinking

86. Has lost a lot of weight without trying to

87. Can't sil still, restless or hyperactive

88. Easily annoyed by others

89. Has difficulty awaiting turn in games or groups............ $\square$

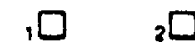

$\square$

${ }_{2} \square$

$\therefore \quad 2 \square$

,$\square \quad 2 \square$

,$\square \quad 20$

104. Disobedient at home

Nover
of
Noitrue
(0)

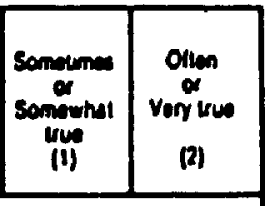

105. Too fearful or anxious

106. Avoids school to stay home.

107. Sleeps more than most children during day and/or night

108. Overlired

109. Overly upset while away from someone he/she is close to ..................

110. Threatens people

111. Runs away from home

112. Troutle sleeping

113. Does things that annuy others

114. Loses things ............... o $\square$

115. Sels lires .................

116. Gcts back at people

117. Hangs around with children who get into trouole.

118. Destroys his/her own Inings.

119. Fals to finish things he/she starts

120. Vandalism

121. Swearing or obscene language

122. Worries about past behaviour

123. Thinks about death

99. Overly upset when leaving someorie he/she is close to

100. Uses weapons when fighling.

Interrupts, blurts out answers to questions too soon .......... 0 , $\quad, \square \quad 2 \square$

101. Nervous. highstrung oi tense.................... o $\square$

102. Lying or cheating

103. Worries a lot about health

124. Worries about things in the luture

125. Gets in many fights

126. Worrying

127. Complains of feeling sick betore separating from those he/she is close to.
$2 \square$

${ }_{2} \square$

$2 \square$

$2 \square$

$2 \square$

$\square$
$2 \square$
$2 \square$
$2 \square$

$2 \square$ 


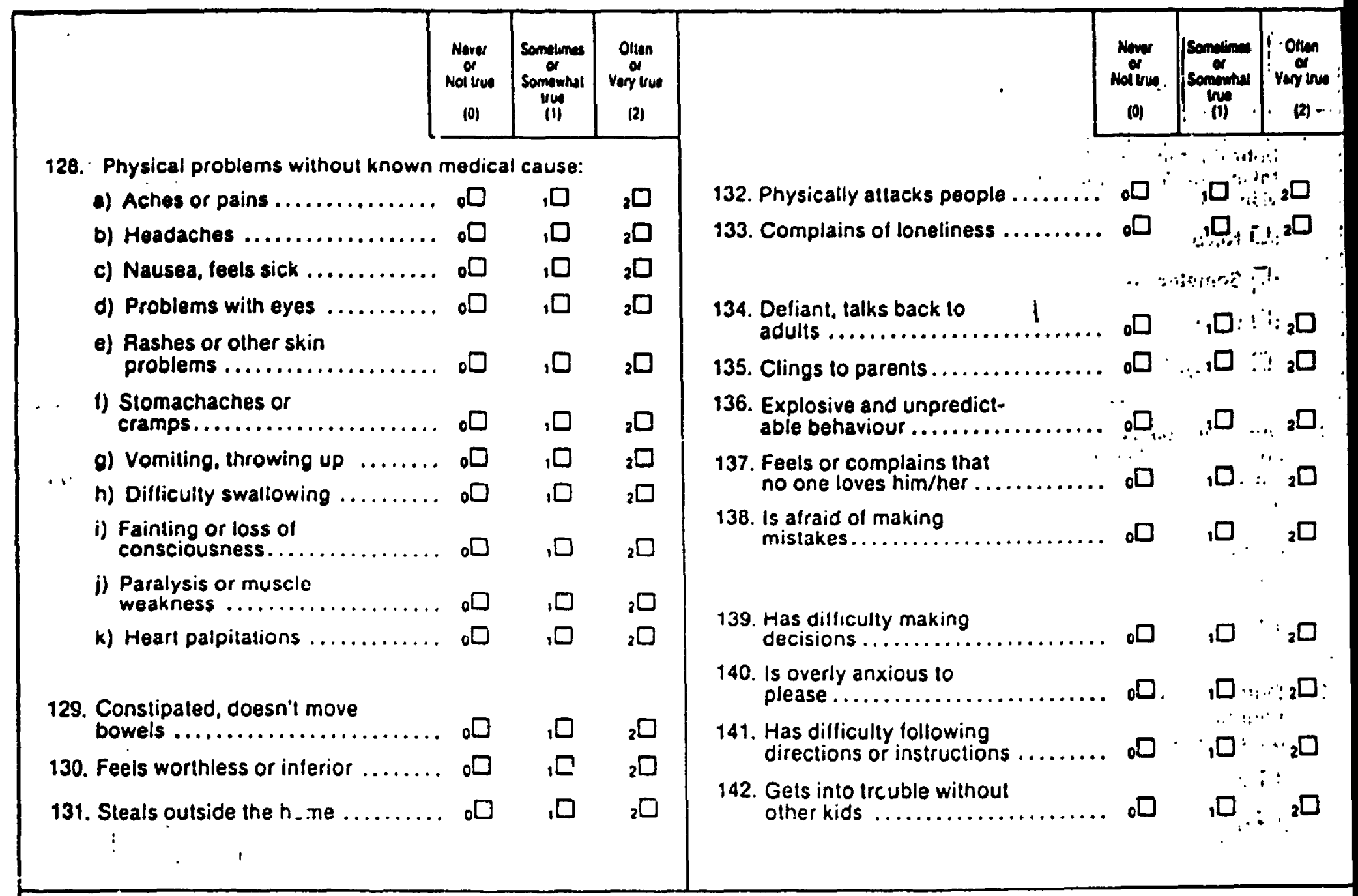

\section{PART D:}

The following questions ask about the possible ellects on this child of any of the problems you've identified in the previous section: For each question, please mark the answer you :hink come closest. Mark your answers like this $\mathbf{x}$

$\because \because \cdots !$

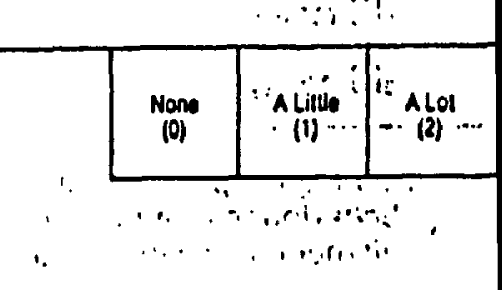

As a result of these problems how much trouble has this child had:

143. Gotting along with his/her teachers.

144. Gelting along with you or your spouse?

145. Being irrilable or fighting with friends? . .

146. Being withdrawn or isolating him/herself?

147. Doing things less with other kids?

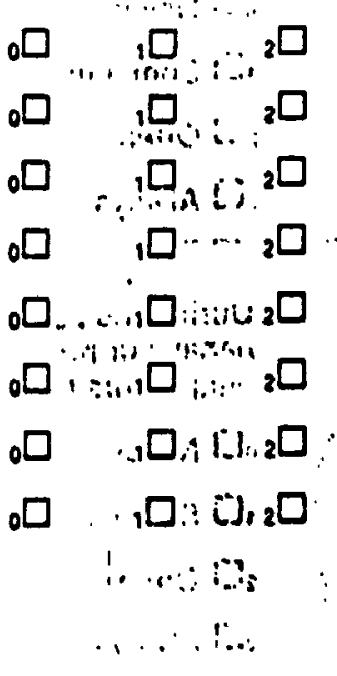

148. Mișsing school? .

149. With his/her grades going down?

150. Enjoying lite? 
Appendix 12: CBC-R Criteria

Child Behaviour Checklist - Revised (Offord et al., 1993)

Note: A scoring manual is available from the authors.

DSM-III-R Disorder Items

Conduct Disorder

. steals

. steals at home

. steals outside the home

. runs away from home

. lying or cheating

. sets fires

. truancy, skips school

. has broken into some else's house, building or car

. vandalism

. cruel to animals

. uses weapons when fighting

- physically attacks people

c cruelty, bullying or meanness to others

Oppositional disorder

- temper tantrums or hot temper

- argues a lot with adults

- defiant, talks back to adults (staff)

. does things that annoy others

. blames others for own mistakes

. easily annoyed by others

. angry and resentful

- gets back at people

. swearing or obscene language

Attention-deficit hyperactivity disorder

. fidgets

- can't stay seated when required to do so

- distractible, has trouble sticking to any activity

. has difficulty awaiting tum in games or groups

- interrupts, blurts out alswers to questions too soon

- difficulty following directions

- can't concentrate, can't pay attention for long

- jumps from one activity to another

. has difficulty playing quietly

. talks excessively

. interrupts or butts in on others

- doesn't seem to listen

- loses things

- does dangerous things without thinking 


\section{Overanxious disorder}

. worries about things in the future

- worries about past behaviour

. worries about doing better at things

- physical problems without known medical cause

(a) aches or pains

(b) headaches

(c) nausea, feels sick

(d) stomachaches or cramps

- self-conscious or easily embarrassed

- needs to be told over and over that things are okay

- nervous, highstrung or tense

\section{Separation anxiety}

- worries that something bad will happen to people he/she is close to

- worries about being separated from loved ones

- avoids school to stay home

- scared to go to sleep without parents being near

- avoids being alone

. has nightmares about being abandoned

. complains of feeling sick before separating from those he/she is close to

- overly upset when leaving someone he/she is close to

. overly upset while away from someone he/she is close to

Depression

- depressed mood

(a) unhappy, sad or depressed

(b) cranky

- markedly diminished interest or pleasure in all or almost all activities

(a) has no interest in usual activities

(b) gets no pleasure from usual activities

. significant weight loss or weight gain when not dieting

(a) has lost a lot of weight without trying to

(b) has gained a lot of weight without trying to

. insomnia or hypersomnia

(a) trouble sleeping

(b) sleeps more than most children during day and/or night

(c) sleeps in class

- psychomotor agitation or retardation

(a) can't sit still, restless or hyperactive

(b) underactive, slow moving or lacks energy

. overtired

- feelings of worthlessness or excessive in inappropriate guilt

(a) feels worthless or inferior

(b) feels too guilty

- diminished ability to think or concentrate, or indecisiveness

(a) can't concentrate, can't pay attention for long

(b) has difficulty making decisions

. suicidal ideation or behaviour

(a) talks about killing self

(b) deliberately harms self or attempts suicide 

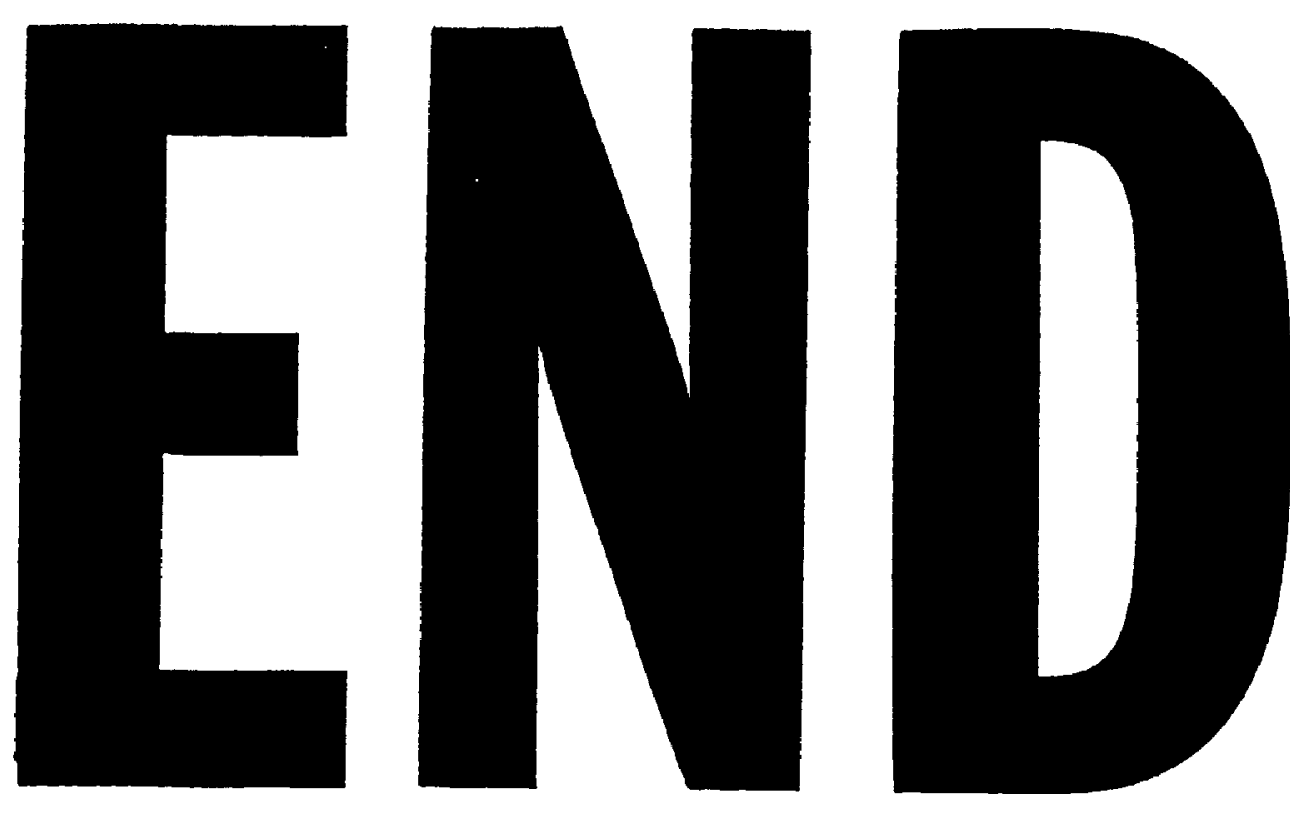

$08-11-94$
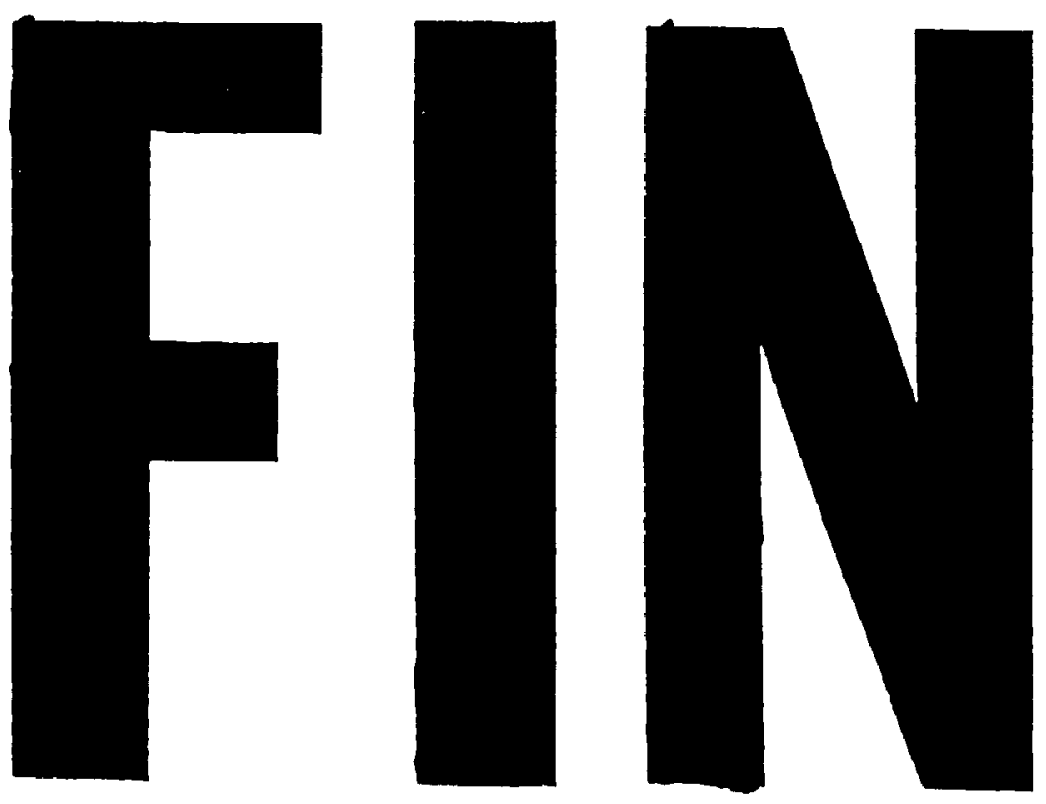